\title{
Impact of Collateral Enlargement on Smooth Muscle Phenotype
}

\author{
A Thesis \\ presented to \\ the Faculty of California Polytechnic State University \\ San Luis Obispo
}

\author{
In Partial Fulfillment \\ of the Requirements for the Degree \\ Master of Science in General Engineering \\ with a Specialization in Biomedical Engineering
}

by

Alexander Jerome Bynum

December 2011 
(C) 2011

Alexander Jerome Bynum

ALL RIGHTS RESERVED 
COMMITTEE MEMBERSHIP

TITLE:

Impact of Collateral Enlargement on Smooth Muscle Phenotype

AUTHOR: $\quad$ Alexander Jerome Bynum

DATE SUBMITTED: December 2011

COMMITTEE CHAIR: $\quad$ Dr. Trevor Cardinal

COMMITTEE MEMBER: Dr. Kristen O’Halloran Cardinal

COMMITTEE MEMBER: Dr. Lily Laiho 


\begin{abstract}
Impact of Collateral Enlargement on Smooth Muscle Phenotype
\end{abstract}

Alexander Bynum

Peripheral Artery Disease is a very serious disease characterized by an arterial occlusion due to atherosclerotic plaques. In response to an arterial occlusion, arteriogenesis occurs, causing smooth muscle cells to transition from a contractile to synthetic state. Also following an arterial occlusion, functional impairment was seen in the collateral circuit. An immunofluorescence protocol was developed in order to assess the impact of collateral enlargement (arteriogenesis) on smooth muscle phenotype at various time points. Smooth muscle $\alpha$-actin was used to mark all smooth muscle cells, Ki-67 was used to label proliferating smooth muscle cells, and a fluorescent nuclear stain was used to quantify the number of cells present. Samples of the profunda femoris and gracilis were dissected from each mouse hind limb (one ligated, one sham) at three different time points: 3 days, 7 days, and 14 days after a femoral artery ligation surgery. Smooth muscle cell phenotype and luminal cross-sectional area were assessed in the profunda femoris and the midzone of the gracilis collaterals. Smooth muscle cells were proliferating at 3 and 7 days following the occlusion in the gracilis collaterals and significant collateral vessel growth was observed over the two week period. No proliferation was observed in the profunda femoris and although there was an increasing trend in vessel size over the two week period, the averages were not significantly different. The phenotypic transition of the smooth muscle cells was not the cause of vascular impairment in the collateral circuit. This shows that further research is needed to characterize impairment in the collateral circuit. 
Keywords: Vascular Smooth Muscle Cells, Arteriogenesis, Immunofluorescence, Mouse, Collateral Circuit, Peripheral Artery Disease 


\section{ACKNOWLEDGEMENTS}

I would like to acknowledge Trevor Cardinal for teaching me to always maintain a positive attitude, regardless of how challenging the journey may seem. I would also like to thank my parents (Roosevelt and Susan Bynum), my sister (Mandy Bynum), and my brother (Teddy Bynum) for their unconditional love and life-long support and the past and present members of the Microcirculation and Tissue Repair Lab for their help in making this research possible.

All labor that uplifts humanity has dignity and importance and should be undertaken with painstaking excellence.

-Martin Luther King 


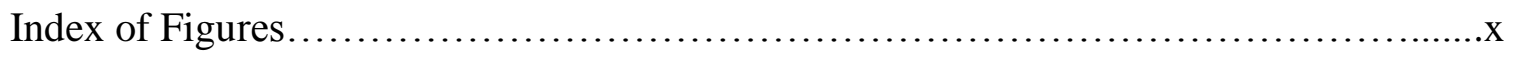

\section{Chapter}

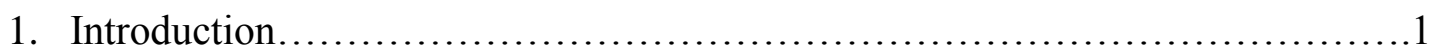

a. Normal Vascular Anatomy and Function............................

i. The Circulatory System...................................1

ii. Smooth Muscle Cell Function in the Arterial Network.............4

b. Vascular Adaptations..............................................

i. Angiogenesis............................................ 8

ii. Arteriogenesis......................................... 9

c. Peripheral Artery Disease and Atherogenesis.........................12

i. Mechanisms Involved in the Development of Atherosclerotic

Plaques...............................................13

ii. Diagnosis and Management of PAD ......................... 15

iii. Current Treatments for PAD .............................16

d. Impact of Ischemia on Vasculature............................... 19

i. Impaired Vasodilation....................................19

ii. Vascular Smooth Muscle Phenotypes.......................20

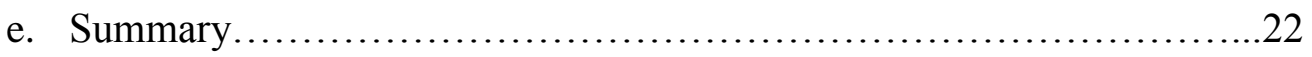

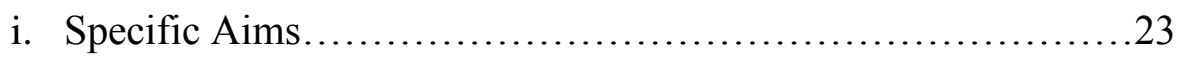


2. Methods.

a. Surgical Model...............................................24

i. Femoral Artery Ligation................................24

ii. Ventricular Catheterization and Perfusion Fixation............25

b. Histology................................................27

i. Sample Preparation....................................27

ii. Tissue Content Assessment.................................28

iii. Immunohistochemistry.................................29

iv. Immunofluorescence...................................30

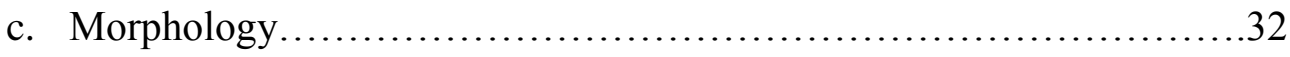

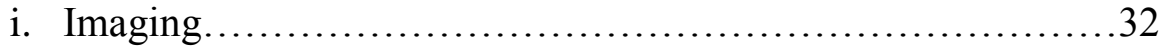

ii. Vessel Cross-Sectional Area..............................32

iii. Cell Nuclei Counting...................................33

iv. Data Analysis..........................................34

3. Results.......................................................... 35

a. Vessel Cross-Sectional Area....................................35

b. Vascular Smooth Muscle Cell Quantification..........................39

i. Total Smooth Muscle Cell Count.............................39

ii. Smooth Muscle Cell Phenotype............................41

4. Discussion

a. Time Dependence of Smooth Muscle Cell Phenotype.................44

b. Impact of Location on the Collateral Circuit........................46

c. Conclusions..................................................... 52 


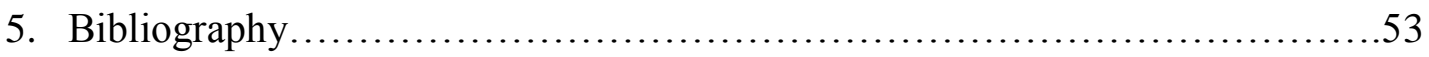

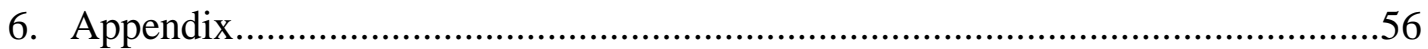

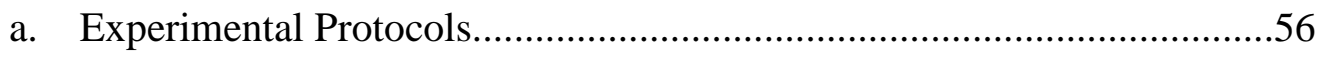

b. Vessel Morphology and Phenotype Raw Data......................................64

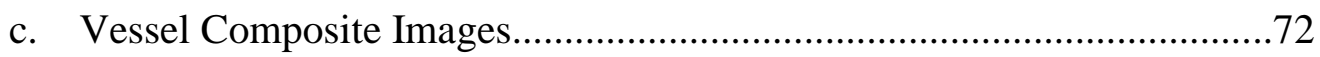


Index of Figures

Figure

Page

1. Schematic Diagram of the Circulatory System..................................

2. Laser Doppler Image of Collateral Blood Flow Following an Occlusion..........9

3. Immune and Inflammatory Cells in Atherosclerosis..........................14

4. Proximal Ligation Site and Surgery Setup ..................................24

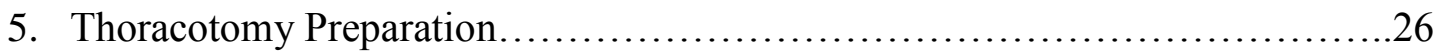

6. Catheter Placement for Vascular Perfusion...................................27

7. Hematoxylin and Eosin Stain of Profunda Femoris...........................28

8. Gracilis Collateral Artery Stained with Ki-67 ...............................30

9. Immunofluorescence Multiplex Stain of a Gracilis Collateral Artery..............31

10. Vessel Cross-sectional Area Measurement Example.............................33

11. Phenotyping of Vascular Smooth Muscle Cells...............................34

12. Progression of Gracilis Collateral Enlargement Over a Two Week Period.......35

13. Average Gracilis Collateral Cross-Sectional Areas.............................36

14. Progression of Profunda Femoris Artery Following a Femoral Ligation..........36

15. Average Profunda Femoris Cross-Sectional Areas................................37

16. Progression of Gracilis Collateral artery vs. Profunda Femoris Artery ...........38

17. The Average Gracilis Collateral vs. Profunda Femoris Cross-Sectional Areas...38

18. Average number of Smooth Muscle Cells in Gracilis Collaterals................39

19. Average Number of Vascular Smooth Muscle Cells in the Profunda Femoris....40

20. Average number of VSMCs in the Gracilis Collaterals and Profunda Femoris...41 
21. Overall Progression of the Gracilis Collaterals Over a Two Week Post Ligation

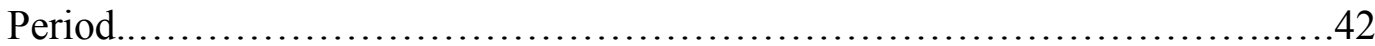

22. Average Number of Proliferating Smooth Muscle Cells in Ischemic Gracilis

Collateral Arteries........................................................ 43 
Introduction

\section{Introduction}

\section{Normal Vascular Anatomy and Function}

\section{The Circulatory System}

The circulatory system supplies the body's tissue with oxygen and nutrients while simultaneously removing carbon dioxide and other waste products for excretion by the lungs and kidneys. This exchange of gases, water, and solutes between the vascular and interstitial fluid compartments occurs mainly in the capillaries, in which the vessel wall consists of a single endothelial cell and associated perivascular cells. While distributing essential substances to the tissues and removing the by-products of metabolism, the circulatory system also maintains homeostasis through evaporative cooling, delivering endocrine products, and adjusting oxygen and nutrient supply for different physiological states [1].

The heart that supplies this circulatory system is comprised of two pumps, or ventricles, in series. The right ventricle works to propel blood through the lungs for exchange of oxygen and carbon dioxide; this is referred to as the pulmonary circulation. The left ventricle works to propel blood to all other tissues of the body, the systemic circulation. From the heart, the blood is pumped into the aorta, the largest of the arteries. After the blood moves from the aorta into the large network of arteries, it flows into small arteries and arterioles, which are the resistance vessels of the circulation. The diameter, or vascular tone, of these vessels, coupled with the output of the left ventricle, determine the distribution of the circulation. Once blood leaves these arterioles, it moves into the capillaries for nutrient and waste exchange. Once blood leaves the capillaries it enters the 
network of venules followed by the larger veins, and finally the largest vein, the vena cavae. From the vena cavae, the blood flows back into the heart to be pumped into the lungs. This unidirectional flow through the heart is achieved by the appropriate arrangement of valves. Although the cardiac output is intermittent, continuous flow to the periphery occurs by distension of the aorta and its branches during ventricular contraction (systole) and elastic recoil of the walls of the large arteries with forward propulsion of the blood during ventricular relaxation (diastole). After the blood flows from the heart into the aorta, a predominantly elastic structure, the peripheral arteries become more muscular until the muscular layer predominates at the arterioles [1].

In a normal intact circulation, the total volume of blood is constant, and an increase in the volume of blood in one area must be accompanied by a decrease in another. This distribution of the circulating blood to the various regions of the body is determined by the vascular tone of the resistance vessels (small arteries and arterioles) in these regions. The circulatory system is composed of these various conduits arranged in series and in parallel as displayed in Figure 1 [1]. 


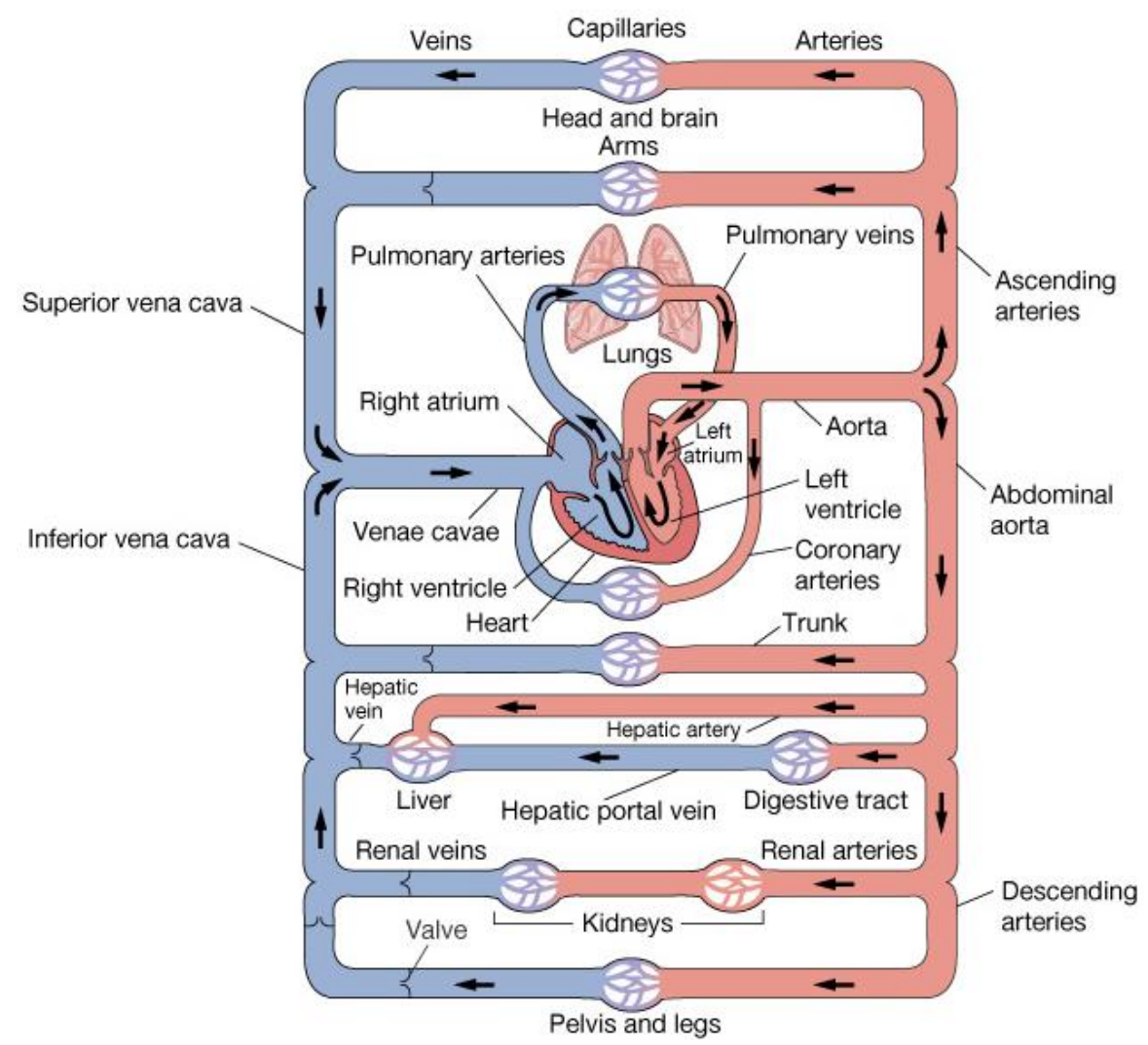

Figure 1 Schematic diagram of the parallel and series arrangement of the vessels composing the circulatory system[1].

Between the aorta and the capillaries, the number of vessels increases up to 3 billion-fold, and the total cross-sectional area increases about 500-fold. The volume of blood in the systemic vascular system is greatest in the veins and venules, which contain about $67 \%$ of the body's blood during rest. Only $5 \%$ of the total blood volume is located in the capillaries and only $11 \%$ of the blood is contained in the aorta, arteries, and arterioles collectively. In contrast, blood volume in the pulmonary vascular bed is about equally divided among the arterial, capillary, and venous vessels [1]. 
Introduction

\section{$\underline{\text { Smooth Muscle Cell Function in the Arterial Network }}$}

Smooth muscle cells (SMCs), are inherently important to the circulation because of their role in the regulation of vascular tone (i.e. blood pressure and blood flow control). Although SMCs are located in all vessel walls, vascular tone and the distribution of blood are determined by the contractile state of SMCs within the arteriole and small/muscular artery wall.

While smooth muscle cells are different than cardiac or skeletal muscle cells, they do have many individual similarities to striated muscle. For instance, smooth muscle cells contain many of the same types of organelles and contractile proteins that can be found in skeletal muscle. Unlike skeletal muscle, embryonic smooth muscle cells do not fuse, and each differentiated cell has a single, centrally located nucleus. SMCs are typically 40 to $600 \mu \mathrm{m}$ long and are 2 to $10 \mu \mathrm{m}$ in diameter in the region of the nucleus, with most cells exhibiting a spindle shape [4].

There are various types of smooth muscle cells that can be categorized based on their method of stimulation, their level of connection with other SMCs, or their activity patterns. Vascular smooth muscle cells (VSMCs), in particular, are considered multiunit SMCs because most are not electrically coupled. This means that the stimulation of one cell does not necessarily result in activation of adjacent cells. This is in contrast to single unit SMCs, in which all cells are electrically coupled, resulting in consecutive stimulation of adjacent cells (e.g. SMCs in the gut during peristalsis). VSMCs can also be classified as tonic smooth muscle cells because they are, at times, continuously active [4]. During tonic contraction, myoplasmic $\mathrm{Ca}^{++}$and cross-bridge phosphorylation decline after an 
initial spike followed by a slow increase in force, eventually tapering off at a high level. Referred to as the "latch state," this sustained force is maintained with only $20 \%$ to $30 \%$ of the cross-bridges phosphorylated, and thus ATP utilization is reduced. Smooth muscle cells use 300 -fold less ATP than would be required by skeletal muscle to generate the same force with fatigue only occurring if the cells are deprived of oxygen [4].

The contractile state of vascular smooth muscle cells within the arteriole and small/muscular artery wall is regulated by intercellular calcium concentration [5]. A rise in intercellular calcium is usually due to an action potential or the presence of a hormone/agonist. This rise in intracellular $\left[\mathrm{Ca}^{2+}\right]$ results in the binding of $\left[\mathrm{Ca}^{2+}\right]$ ions to calmodulin, creating a complex that activates myosin light-chain kinase (MLCK), which phosphorylates the regulatory light chain of myosin [4]. This phosphorylation, along with an ATP molecule to energize each myosin cross-bridge, is critical for the interaction of smooth muscle myosin and actin in the development of force [4]. When myoplasmic $\left[\mathrm{Ca}^{2+}\right]$ falls, MLCK becomes inactive, and the cross-bridges are dephosphorylated (i.e. cross-bridge cycling stops) [4]. This myosin cross-bridge cycling is similar to that of striated muscle in that it involves a ratcheting action of the myosin head that pulls the thin filament toward the center of the thick filament, causing a generation of force. However, the kinetics of cross-bridge cycling is slower for smooth muscle cells, and unlike striated muscle, cannot occur if the regulatory light chain of myosin is not phosphorylated [4]. Also, in contrast to striated muscle, the sensitivity of contraction to $\left[\mathrm{Ca}^{2+}\right]$ is variable in smooth muscle, in that different agonists can increase the force of contraction at submaximal levels of intracellular $\left[\mathrm{Ca}^{2+}\right][4]$. 
A variety of drugs and hormones relax smooth muscle by increasing the cellular concentrations of cyclic nucleotides, such as cGMP. Soluble guanylyl cyclase (sGC), a receptor for nitric oxide (NO), produces cGMP. Increases in cGMP promote the activation of protein kinase $\mathrm{G}$, which inactivates myosin light chain kinase, causing the actin-myosin cross-bridge cycling to cease [4]. So, by increasing cGMP, NO, produced by nerves and vascular endothelial cells, relaxes smooth muscle [4]. A reduction in intracellular $\left[\mathrm{Ca}^{2+}\right]$, associated with the relaxation of smooth muscle, is usually via stimulation of $\left[\mathrm{Ca}^{2+}\right]$ pumps in the sarcolemma, the sarcoplasmic reticulum (SR) or both [4]. Acetylcholine released from parasympathetic fibers also causes vasodilation in some vascular beds as a result of the production of NO by vascular endothelial cells [4]. Vasoconstrictors and vasodilators use two methods, often simultaneously, to stimulate contraction and dilation, respectively. They can adjust sensitivity to $\left[\mathrm{Ca}^{2+}\right]$ or change the levels of intracellular $\left[\mathrm{Ca}^{2+}\right]$ in VSMCs. In contrast, an elevation in endothelial $\left[\mathrm{Ca}^{2+}\right]$ induces relaxation of the adjacent VSMCs. Therefore, fine tuning of $\left[\mathrm{Ca}^{2+}\right]$ in both cell types is imperative for precise regulation of organ and tissue perfusion [5].

The contractile activity of SMCs are systemically controlled by the autonomic nervous system, specifically, vascular smooth muscle cells are primarily innervated by sympathetic fibers [4]. Sympathetic fibers, using norepinephrine (NE) as a neurotransmitter, stimulate $\alpha_{1}$-adrenergic receptors on VSMCs. Binding of NE causes the G protein dependent activation of phospholipase C (PLC), which results in the production of inositol 1,4,5-triphosphate $\left(\mathrm{IP}_{3}\right)$. Elevated levels of $\mathrm{IP}_{3}$ activates the $\mathrm{IP}_{3}$-gated $\left[\mathrm{Ca}^{2+}\right]$ channel in the SR, which results in an increase of myoplasmic $\left[\mathrm{Ca}^{2+}\right]$ and leads to vasoconstriction [4]. Although VSMCs are primarily controlled by adrenergic 
stimulation, their contractility is still susceptible to muscarinic stimulation via acetylcholine, as mentioned above [4]. The tone of the SMCs, as discussed above, is subject to local influence from circulating hormones and neighboring endothelial and skeletal muscle cells via diffusable substances such as NO and adenosine [4]. VSMC tone can also be stimulated by physical stretch, a phenomenon called the myogenic response. VSMCs will contract in response to an increase in transumural pressure stretch and relax in response to a decrease in transmural pressure [1]. An initial flow increment produced by an abrupt increase in perfusion pressure that passively distends the blood vessels would be followed by a return of flow to the previous control by contraction of the VSMCs in the resistance vessels [1].

Smooth muscle function can be controlled systemically or locally, via the nervous system, endocrine system, or physical stretch. These alterations in smooth muscle contractility and vascular tone facilitate adjustments in blood flow in order meet the oxygen demands of various parts of the body on an acute basis [4].

\section{Vasculature Adaptations}

Acute changes in blood flow are brought on by vascular responses such as a change in smooth muscle contractility and vascular tone. However, if blood flow is consistently altered, the vessel will experience chronic changes (i.e. vascular adaptations). Arterial occlusion is a common stimulus for chronic changes in blood flow. An arterial occlusion induces both angiogenesis, the sprouting of the capillaries, as well as arteriogenesis, the growth/remodeling of pre-existent arterioles into conduit arteries [6]. 
Interarterial connections associated with arteriogenesis are called collateral vessels or anastomoses [6]. These vessels are present in almost all organs. During arteriogenesis, the vessels can enlarge to an astonishing degree and can function under favorable conditions as efficient blood conductors preventing or limiting tissue necrosis [6]. Physical factors such as fluid shear stress are well established as the initiating events of arteriogenesis. Although angiogenesis plays an important role in the adaptation to arterial occlusion due to hypoxia in the downstream tissue, arteriogenesis is more efficient at restoring blood flow [6]. It has been shown that arteriogenesis can also prevent angiogenesis by restoring blood flow to the ischemic tissue and that ischemia is not the direct driving force in arteriogenesis [6].

\section{$\underline{\text { Angiogenesis }}$}

Although angiogenesis is a normal vascular adaptation, it also occurs in many diseases, including cancer, diabetic retinopathy, and atherosclerosis. Anti-angiogenic agents have entered clinical use for cancer and eye disease and angiogenesis has been proposed as a treatment for of ischemic diseases [7].

Angiogenesis occurs through multiple, complementary roles in normal or pathological angiogenesis [7]. Pathological angiogenesis often occurs in response to hypoxia which causes endothelial cells and parenchymal cells to increase the transcription of hypoxiainducible factor-1 (HIF-1), which upregulates vascular endothelial growth factor (VEGF) [8]. As a result of an increase in VEGF, proteolytic degradation of the extracellular martrix occurs, followed by chemotactic migration and proliferation of endothelial cells, 
the formation of a lumen, and the functional maturation of the endothelium [8]. The result of this sprouting angiogenesis is a newly formed capillary loop in the once hypoxic tissue.

\section{$\underline{\text { Arteriogenesis }}$}

Arteriogenesis is the process whereby a preexisting arteriole outwardly remodels into a conductance artery. An example would be in the case of an occlusion of the femoral artery in the mouse hindlimb. Collateral vessels enlarge in the upper leg between proximal and distal side branches, relatively close to the site of occlusion (due to the large changes in hemodynamics) [3]. In contrast, ischemia induces hypoxia in the lower leg and the foot, which causes angiogenesis to occur [3].

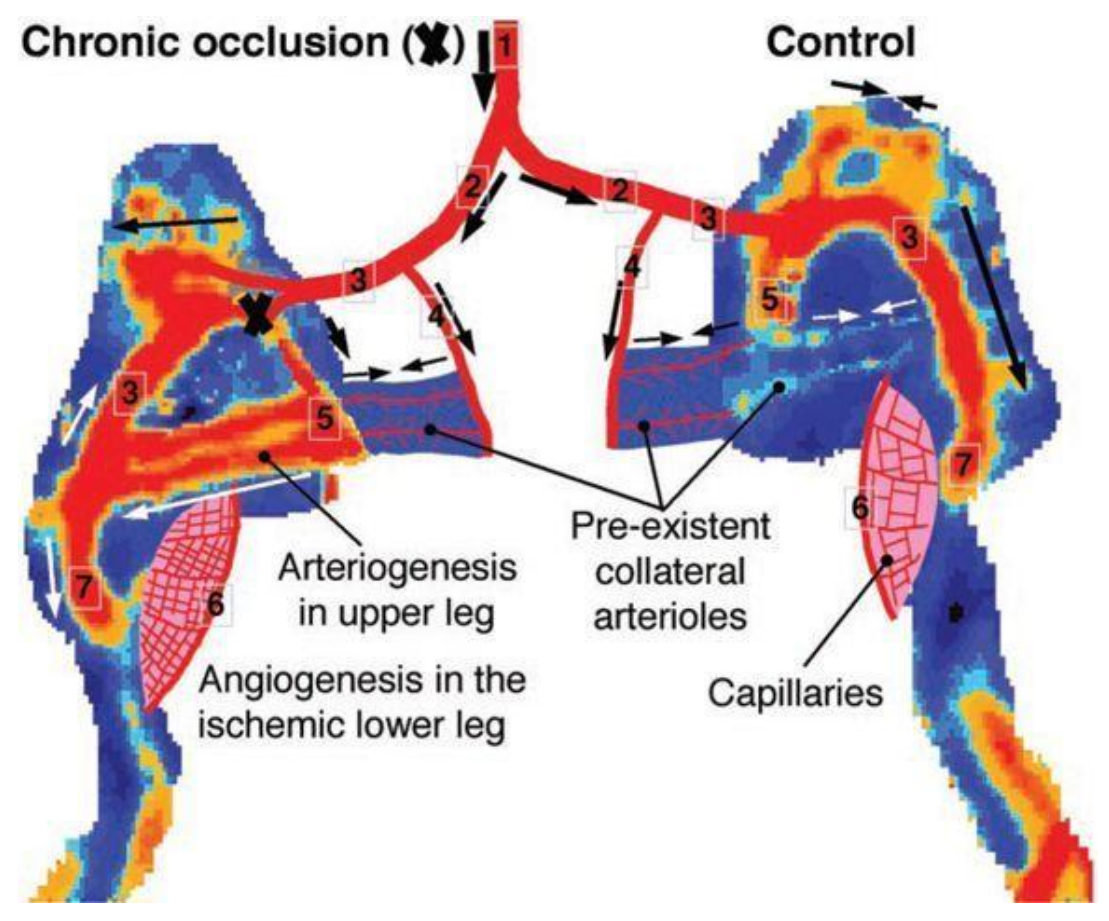

Figure 2 Laser Doppler image of collateral blood flow in an anesthetized mouse with exposed upper thigh skeletal muscles with chronic occlusion (7days) of the left femoral artery [3]. 
As we can see from Figure 2, the superficial adductor muscles in the murine upper leg have a dual arterial blood supply. Different side branches enter the muscle from both medial and lateral ends and taper down; the primary arterioles from both side branches meet and connect in the middle of the muscle, forming an anastomosis [3].

The collateral vessel is associated with three different zones: the stem, mid-zone and reentry. The stem is characterized by the feed vessel to the collateral (the profunda femoris in Figure 2). The mid-zone is characterized by the middle of the collateral, where the greatest degree of arteriogenesis usually occurs post occlusion (the gracilis collaterals in Figure 2). Reentry is the area where the collateral supplies blood flow downstream of the occluded vessel (where the gracilis collateral meets the saphenous artery in Figure 2).

As a result of an arterial occlusion, the rerouting of blood in the collateral circuit causes an increase in shear stress on the vessel wall. These changes in wall stress and shear stress are sensed by the endothelium, which up-regulates growth factors and secrete nitric oxide (NO) and prostacyclin [3]. Eventually the chronic increased shear stress causes the activated endothelium to lose volume control and swell [3]. When this mechanical force is transmitted from the deformed cell it will activate transcription factors, such as egr-1, which will up-regulate chemokines like MCP-1 and adhesion molecules like intracellular adhesion molecule-1 (ICAM-1), which are necessary monocyte docking [3]. Monocytes are crucial to facilitating arteriogenesis and suppression of them significantly delaya arteriogenesis [3]. 
The midzone of growing collaterals is surrounded by a perivascular inflammatory infiltrate, consisting mainly of monocytes and T-lymphocytes. These cells have migrated partially from the arterial lumen. The media of these vessels is thus surrounded from both sides by inflammatory cells that secrete growth factors and proteases that are necessary to remodel the old media. T-lymphocytes are also necessary to destroy cells in the close vicinity of the collateral artery to create the space to be occupied by the greatly expanded vessel [3].

Remodeling begins after the acute phase of arteriogenesis, which is dominated by the inflammatory events (i.e. endothelium activation and extravasation of monocytes and Tlymphocytes). The process begins with the upregulation of matrixmetalloproteinases (MMPs), a type of protease that digests the extracellular matrix of the vessel wall and provides space for new cells and enables SMCs to migrate away from the intima to create a new, larger conductance vessel [3]. A new elastic lamina is synthesized by the smooth muscle cells (SMCs), and the rebuilding of the media and the formation of an intima begins with the upregulation of the tissue inhibitor of MMPs [3]. The role of SMCs in arteriogenesis will be discussed later in more detail, as they are a key component in this study. 


\section{Perpherial Artery Disease and Atherogenesis}

Perpherial Artery Disease (PAD), the most common cause of peripheral arterial occlusion in patients, is characterized by fatty deposits in the inner linings of the artery walls. These fatty deposits can restrict blood circulation to the periphery, causing the downstream tissue to become ischemic, often leading to serious health problems in the individual.

PAD affects a large segment of the adult population, with an age-adjusted prevalence of $4 \%$ to $15 \%$, affecting more than 5 million adults in the United States and increasing up to $30 \%$ with age and the presence of cardiovascular risk factors. Twenty percent of patients with PAD have typical symptoms of intermittent leg-muscle discomfort on exertion, ulceration or gangrene. Another third of patients have atypical exertional leg symptoms [9].

Age and gender-adjusted risk factors associated with the development of PAD are similar to the traditional risk factors for atherosclerosis, which include: cigarette smoking, diabetes, hyperlipidemia, hypertension, hyperhomocystinemia and chronic renal insufficiency [10]. Smoking and diabetes are the strongest risk factors and are associated with more aggressive disease progression [9]. The relative risk of claudication is 3.7 times the normal risk in current smokers and 3 times in ex-smokers [11]. Also, the presence of diabetes increases the risk of PAD by 2- to 4-fold with 5- to 10-times higher need for major amputation in diabetics compared to non-diabetics [12].

Studies of the natural history of PAD indicate that the risk of ischemic limb events for non-diabetic patients is relatively low, with less than $2 \%$ requiring major or minor amputation. Although intermittent claudication can lead to less exercise, causing obesity, 
osteoporosis, etc., cardiovascular disease and manifestations of atherosclerosis in other vascular beds are the major determinants of prognosis in these patients [9]. There is approximately a 2- to 4-fold increase in coronary and cerebrovascular disease in patients with PAD, with an annual rate of 5-7\% for cardiovascular events (myocardial infarction, stroke, or death from cardiovascular causes) [10]. Notably, the risk of cardiovascular morbidity and mortality is similar in all patients with PAD, regardless of the presence of symptoms [13]. Therefore, managements of the disease are directed not only at improving symptoms of claudication and the lower limb ischemia, but more importantly at reducing the overall cardiovascular risk [9].

\section{Mechanisms Involved in the Development of Atherosclerotic Plaques}

This build up of fatty deposits, or atherosclerosis, is characterized by lipid deposition and inflammation in the artery wall. Cholesterol is the major lipid species in artherosclerotic lesions and accumulates in both unesterfied and esterfied forms [14].

Atherosclerosis is also characterized by plaques consisting of necrotic cores, calcified regions, accumulated modified lipids, inflamed smooth muscle and endothelial cells, leukocytes, and foam cells. As described, atherosclerosis is a disease that involves components of the vascular, metabolic, and immune systems [2].

The occurrence of inflammatory cells in atherosclerotic lesions depends on the rate of their recruitment and egress and the balance of proliferation, survival, and apoptosis within the arterial wall [2]. The following figure diagrams the mechanisms involved in the development of atherosclerosis. 


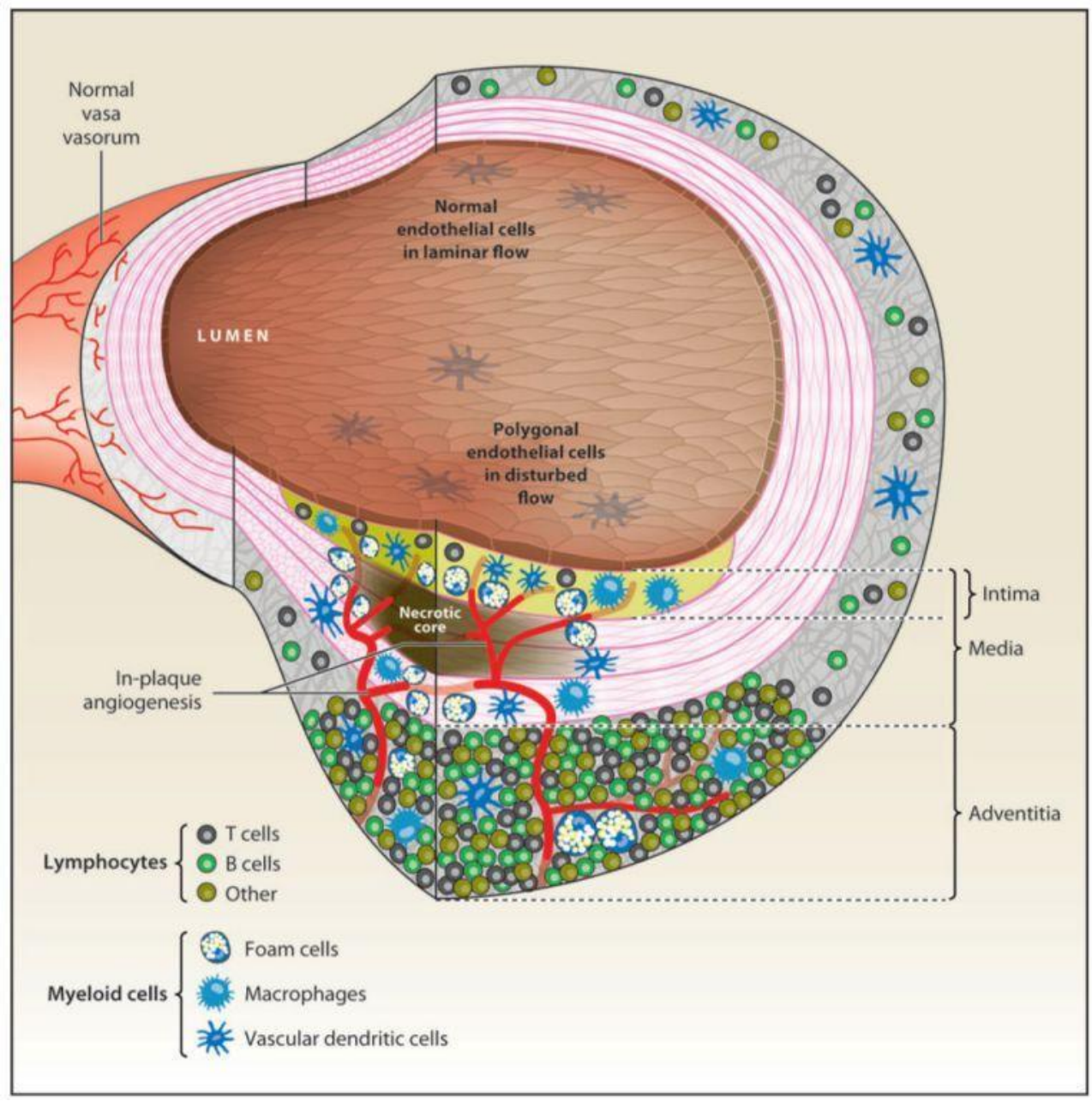

Figure 3 Immune and inflammatory cells in atherosclerosis[2].

The endothelial cells above the lesion are polygonal in shape, whereas the normal endothelial cells are aligned with the direction of flow [2]. Also, the normal intima is usually very thin, and would be almost invisible except at the highest resolutions, but the neointima is greatly expanded in the lesion area [2]. In this area, there are vascular dendritic cells, macrophages, foam cells, and T lymphocytes [2]. The foam cells surround the necrotic core, which is composed of foam cells that have undergone necrosis [2]. The normal media is populated by smooth muscle cells that are organized between an internal and external elastic laminae. Myeloid cells invade the media in the lesion area, while the 
Introduction

normal adventitia is populated by sparse T cells, B cells, lymphocytes, and dendritic cells. In the lesion area, lymphocytes induce an angiogenesis in the vasovasorum that is thought to destabilize plaque and precipitate rupture events [2].

\section{Diagnosis and Management of PAD}

Atherosclerosis eventually leads to a reduced blood flow distal to the injury, causing ischemia in the downstream tissue. Although there are no cures for this disease, there are ways to diagnose and manage the symptoms. Initial evaluations include a careful history and physical examination with shoes and socks removed to assess for signs of acute or chronic peripheral ischemia, with attention to peripheral pulses, hair loss, skin color, and trophic skin changes [9]. The abdomen is also examined for evidence of an aortic aneurysm and blood pressure is measured in both arms[9]. Also, a stethoscope is used to check for sounds of turbulent flow at the neck, and over the clavicles, as well as pulses in the abdomen and femoral region [9]. Upon clinical suspicion for PAD, referral to a vascular laboratory is the initial step for noninvasive diagnostic assessment of the location and severity of the arterial disease. These noninvasive tests can also be repeated over time to follow the disease progression and response to medical treatment or revascularization[9]. Some of these tests include ankle-brachial pressure measurement or noninvasive imaging techniques [9].

In attempts to manage PAD, patients will undergo risk factor modification, an exercise program, pharmacologic treatment, and endovascular or surgical revascularization. In most cases, revascularization is reserved for patients experiencing significant disability. Patient-specific managements may include smoking cessation programs, aggressive 
Introduction

control of hyperglycemia, and lipid-lowering to reduce the risk of cardiovascular events due to atherosclerosis [9].

\section{$\underline{\text { Current treatments for PAD }}$}

Once PAD has been diagnosed, there are various treatments available. The extensiveness of the treatment often depends on the progression of the disease in the patient. The most efficacious treatment is exercise, which significantly improves walking time and overall walking ability in patients with intermittent claudication [10]. Notably, exercise may be more effective than antiplatelet therapy in improving maximal walking time and have equivalent efficacy to surgery [10]. Furthermore, physical activity both prevents and helps treat many established atherosclerotic risk factors, such as elevated blood pressure, insulin resistance and glucose intolerance, elevated triglyceride concentrations and low high-density lipoproteins [9]. Habitual physical activity also helps to reduce inflammation, which is associated with the pathogenesis of atherosclerosis [9].

If there is a serious hindrance on a patient's quality of life, or they have a reduced exercise capacity, antiplatelet therapy may be suggested. Antiplatelets are a class of drugs that decrease platelet aggregation and inhibit thrombus formation. In patients at high risk of arterial occlusive disease, antiplatelet therapy with aspirin reduces the risk of myocardial infarction, stroke and cardiovascular death by $25 \%$ [15]. Although aspirin has not been shown to improve claudication, it delays the progression of PAD, reduces the need for intervention, and reduces graft failure in patients who have undergone surgery [9]. Clopidogrel is another anti-platelet therapy that has been shown to reduce the risk of myocardial infarction, stroke or cardiovascular death. Because aspirin is cheaper and 
easier to obtain, clopidogrel is currently only recommended as an effective alternative for those who may be allergic to aspirin or other NSAIDs. There are also many other antiplatelet therapies available, but these are less beneficial than aspirin in patients with PAD because of the associated increased risk of major bleeding in the patient [9].

If antiplatelet therapies are not sufficient, there are other pharmacological agents that specifically treat claudication. Cilostazol is a proficient treatment for claudication because it is a vasodilator with mild anti-platelet properties. Treatment with cilostazol significantly increases maximal and pain-free walking distance and may improve the quality of life in patients with PAD. Although there are other options to cilostazol, they have been shown to be less effective at treating claudication [16].

Since there is often an inadequate response to exercise or the previously discussed pharmacological therapies, researchers continue to search for new therapies. The use of angiogenic growth factors, such as vascular endothelial growth factor (VEGF), recombinant fibroblast growth factor 2 ( $\mathrm{rFGF}-2)$ and hypoxia-inducible factor-1, have generated considerable enthusiasm as potential treatments of PAD because of their role in the stimulation of new vessel growth [9]. Clinical studies on delivering single growth factors intramuscularly were not successful. Recent applications have effectively integrated the use of gene transfer strategies of angiogenic proteins, but these applications still prove ineffective [17]. More studies and trials need to be conducted to assess the overall efficacy and safety of these growth factors [17].

Although exercise and pharmalogical treatments have proven to be somewhat effective at combating the symptoms and slowing the progression of PAD, some patients may have 
Introduction

more severe cases in which these methods prove ineffective [9]. With these patients, endovascular treatments are often suggested. Endovascular techniques to treat PAD include percutaneous transluminal angioplasty (PTA) with balloon dilation, endografts, atherectomy, cutting balloons, drug-coated balloon angioplasty, cryoplasty, percutanoues thrombectomy and brachytherapy [9]. From all of the therapies listed above, PTA is the recommended initial endovascular treatment for PAD [10].

Endovascular stenting is also another form of treatment for PAD because it avoids the problems of early elastic recoil, residual stenosis and flow-limiting dissection after balloon angioplasty and thus can be used to treat long and calcified lesions. Although stent designs continue to improve over the years, more data is required to improve patency while reducing the chance of fracture [18].

Initial attempts have been made using newer technologies, such as drug-eluting stents and balloons that have proved beneficial as percutaneous coronary intervention (PCI) techniques. However, this technology has not yet been successful when used in the peripheral arteries [19]. Aside from the previously described endovascular therapies, there are still many emerging endovascular technologies. While these methods are currently being investigated, their role in the treatment of PAD still remains controversial [9].

As the population ages, it is anticipated that the prevalence of PAD will increase[9]. Although there has been a rapid evolution of technology for treatments, there are still vital improvements that need to be made in the future. All non-interventional techniques either treat symptoms or slow the disease and interventional techniques are often 
dangerous and complicated. While these treatments can slow the dangers associated with the disease, there is still a need to better understand the progression of atherosclerosis. By studying the development of atherosclerosis and its side-effects (e.g. impaired vasodilation), we can develop new approaches that work towards either reversing the progression atherosclerosis or restoring proper blood flow to ischemic tissues.

\section{Impact of Ischemia on Vasculature}

\section{Impaired Vasodilation}

While PAD is becoming more prevalent throughout our population, the root of the problem is atherosclerosis and its co-morbidities (e.g. hypercholesterolemia) which are known to impair the vasculature. Atherosclerosis is a systemic disease, therefore patients with a clinical manifestation of a specific atherosclerotic disease (e.g. CAD) are likely to have pathologically similar lesions in other vascular beds. As eluded to earlier, patients who develop atherosclerotic occlusions experience impaired vasodilation in the collateral circuit [20]. This supports the hypothesis that atherosclerosis systemically affects the functional and morphological characteristics of several parts of the circulatory system.

Although ischemic disease is associated with impaired vasodilation, an arterial occlusion alone also causes impairment [21]. This is supported by studies showing that vasomotor responses of relatively large collateral vessels to vasodilators are impaired in ischemic limbs of animal models in vivo[22]. 
Introduction

\section{$\underline{\text { Vascular Smooth Muscle Phenotypes }}$}

There is speculation that impaired vasodilation following arterial occlusion is due to arteriogenesis occurring in the collateral circuit. The transition of vascular smooth muscle cells from a differentiated (contractile) to a dedifferentiated (synthetic, migratory) phenotype plays a crucial role in the process of arteriogenesis. This phenotypic switch of SMCs also plays a critical role in many other physiological and pathological processes, including atherosclerosis, angiogenesis, smooth muscle hypertrophy, and hyperplasia [23]. Smooth muscle cells display a plastic diversity, meaning they dynamically exhibit distinct contractile and synthetic phenotypes with unique morphological, biochemical, functional, and gene expression characteristics [24]. The contractile smooth muscles are largely filled with contractile proteins and contain few subcellular organelles, while the synthetic smooth muscles have more subcellular organelles (e.g. free ribosomes and endoplasmic reticulum) involved in protein synthesis [25].

As mentioned above, a marked difference is found in the expression of cytoskeletal and contractile proteins in these two phenotypes. Rabbit VSMCs can express at least three types of myosin heavy chain isoforms: SM1, SM2, and SMemb [25]. SM1 and SM2 are alternative RNA splicing products of a single gene and both are specifically expressed in SMCs. SM1 is constitutively expressed from early development, but SM2 only appears after birth. On the other hand, SMemb is predominantly expressed in embryonal and neonatal aortas but is down-regulated in adults [25]. In addition to its abundance in the brain vasculature, SMemb is expressed together with SM1 in SMCs undergoing growth and/or cell division, such as embryonic SMCs of fetal aorta and proliferating SMCs in 
Introduction

atherosclerotic neointima [26]. Based on these developmental characteristics, the myosin heavy chain profiles are most useful in defining smooth muscle cell differentiation as well as identifying abnormally proliferating smooth muscle cells in injured arteries [25].

VSMCs and their phenotypic transition are an integral step in the outward remodeling of collateral vessels. Prior to the synthesis of a new elastic lamina by VSMCs, MMPs digest the matrix and provide space for new cells and enable VSMCs to migrate toward the intima. Many non-proliferative VSMCs of the old media apoptose and are replaced by daughter cells of proliferative VSMCs [3]. Those that proliferate change their phenotype and degrade most of their contractile proteins, which are replaced by expanded endoplasmic reticulum and free ribosomes, an indication of their synthetic activity. The loss of the contractile phenotype is ascribed to the combined activities of protein kinase G, activin, and RGs-5 [3]. In addition to actin and myosin, desmin and calponin are downregulated and fibronectin is upregulated [3]. The thickening of the vessel wall occurs under markedly increased tangential wall stress causing the intercellular connections and the communication between cells to change. This is paralleled by the strongly induced expression of connexin 37 in VSMCs, which is an early marker for arteriogenesis that is normally not expressed in VSMCs and only weakly in endothelium [3].

It is hypothesized that smooth muscle cell proliferation and migration, and the inability for the cells to relax and contract could be the reason for vascular impairment during a post-occlusion arteriogenic event. 
Introduction

\section{Summary}

It is proficiently documented that patients with PAD or other ischemic diseases experience reduced blood flow to tissues distal of an atherosclerotic occlusion [10]. In addition to this, ischemic disease is typically coupled with an impaired vasculature characterized by reduced vascular reactivity [21]. In order to eventually understand the underlying mechanisms of dysfunction in patients with PAD, we must start by assessing vascular adaptations in simple animal models. This will help us determine the effects of the different responses to an arterial occlusion. We have chosen to study arteriogenesis first because it is thought to be critical for limb salvage and groups are currently trying to develop new therapies to stimulate this process. We hypothesize that smooth muscle cells, in their transition from a contractile to a synthetic state in response to vascular injury, are the cause of impaired vasoactivity observed in animal models. These studies will be a precursor for tailoring therapies to either stimulate vascular reactivity or to work around the area of impaired vasculature (i.e. arteriogenesis) in order to supply the ischemic tissue with adequate blood flow in patients with PAD. 
Introduction

\section{$\underline{\text { Specific Aims }}$}

In response to an arterial occlusion, arteriogenesis occurs, causing smooth muscle cells to transition from a contractile to synthetic state. Also following an arterial occlusion, functional impairment was seen in the collateral circuit. During this transition, smooth muscles cells proliferate and migrate, and in the process it is thought that they lose their ability to contract and relax efficiently. We hypothesize that this phenotypic transition of smooth muscle cells is the cause of impaired vasoactivity following arterial occlusion. We will assess the vasculature following an occlusion to understand the impact of arteriogenesis on smooth muscle proliferation.

- Specific Aim 1 - Develop immunohistochemistry and immunofluorescence protocols to assess smooth muscle cell proliferation and determine vessel crosssectional area.

- Specific Aim 2 - Determine the impact of an arterial occlusion on smooth muscle proliferation in the midzone and stem regions of the collateral circuit.

- Specific Aim 3 - Determine the time dependence of smooth muscle proliferation and changes in vessel cross-sectional area in the collateral circuit. 


\section{Methods}

Surgical Model

\section{Femoral Artery Ligation}

A femoral artery ligation surgery was performed to stimulate arteriogenesis in the superficial adductor collaterals of the house hind limb. To obtain an aseptic environment, surgical instruments and materials were autoclaved and the surgical field was disinfected with Novalsan. Refer to the appendix for specific instruments and sterile pack contents.

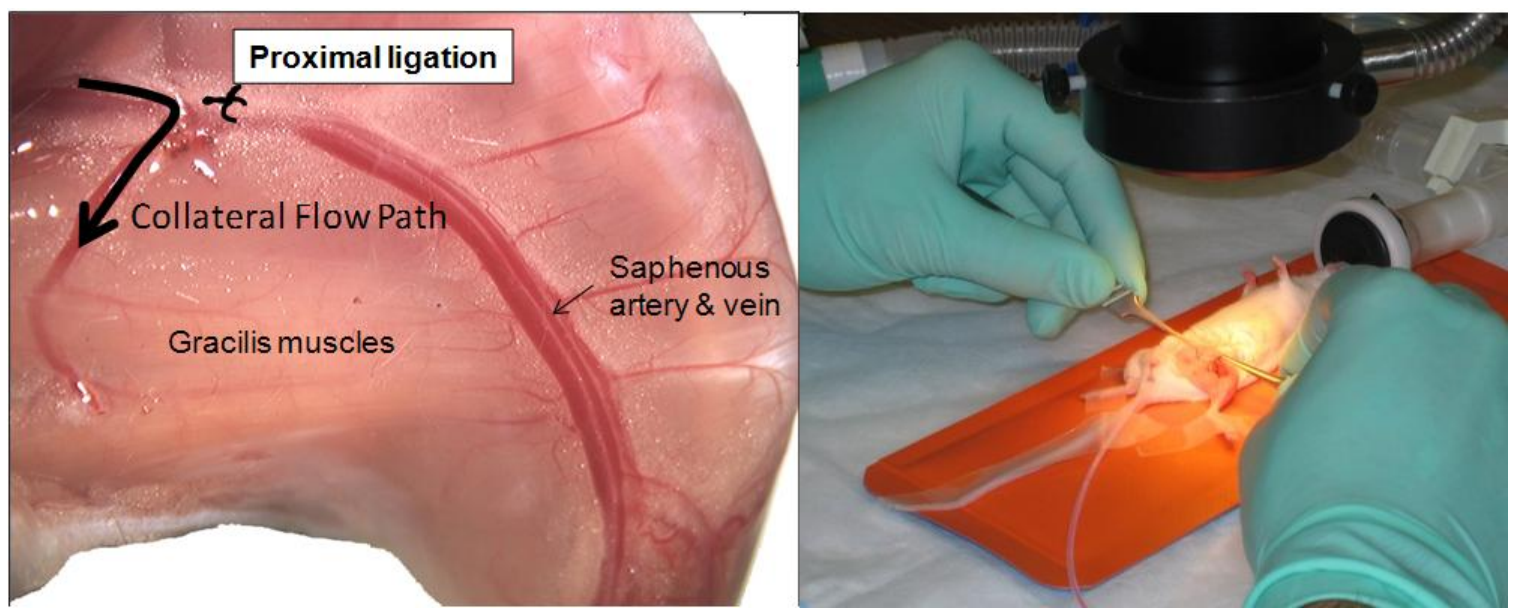

Figure 4 On the left is a diagram of the proximal ligation site, on the right is the surgery setup for a proximal ligation.

The mouse was then weighed and placed into an anesthesia induction chamber where it was anesthetized with $5 \%$ isoflurane mixed with oxygen flowing at $\sim 31 / \mathrm{min}$. Once anesthetized, anesthesia was maintained with 1-3\% isoflurane mixed with oxygen flowing at $0.5-1.0 \mathrm{l} / \mathrm{min}$. An ear-hole punch was used for identification purposes (left ear, right ear, both ears, no ears). The hair on the left hind limb was removed with clippers and depilatory cream. The hind limb was then disinfected with Nolvasan and the animal was then given a subcutaneous injection of buprenorphine $(0.075 \mathrm{mg} / \mathrm{kg})$ for analgesia. 
Once the animal was moved to the heat pad, a surgical anesthetic plane was maintained via a non-rebreathing nose-cone. Body temperature was maintained via rectal probe at $37^{\circ} \mathrm{C}$ and veterinary ointment was applied to the eyes to avoid desiccation.

A small incision was made in the middle medial aspect of the left thigh and extended up to the abdominal wall. Once surgical exposure was maximized, a heat cautery was used to resect the fat pad and the epigastric atrioventricular (a-v) pair. The femoral artery was blunt dissected from the neurovascular bundle, in between the profunda femoris and popliteal branches (See Figure 4). The femoral artery was tied off with a 6.0 silk suture and the incision was closed using a 7.0 polypropylene suture. A contra-lateral sham control was prepared by making a similar incision in the middle, medial aspect of the right thigh and blunt dissecting the connective tissue. The incision on the sham limb was also closed with a 7.0 polypropylene suture.

A second subcutaneous injection of buprenorphine $(0.075 \mathrm{mg} / \mathrm{kg})$ was given for analgesia post surgery. Once ambulatory, the animal was placed in a new cage with surgery indicated on the cage card.

\section{Ventricular Catheterization and Perfusion Fixation}

Before the dissection, a vasodilator cocktail was prepared using heparin, adenosine, and sodium nitroprusside, and heated to $37^{\circ} \mathrm{C}$.

The mouse was then weighed and placed into an anesthesia induction chamber where it was anesthetized and prepared as described above. The animal's limbs where then taped down to a heated bench cover and small incisions were made in the middle medial aspect of both hind limbs to visualize the femoral a-v pair and ensure proper vascular profusion. 
The skin was removed from the abdomen up to the top of the thoracic cavity. A $20 \mathrm{~mL}$ syringe of the vasodilator cocktail was attached to a catheter and placed in the syringe pump. An incision was made in the abdomen over the xiphoid process and hemostats were clamped on the xiphoid process for handling of the thoracic wall prior to performing a thoracotomy (see Figure 5).

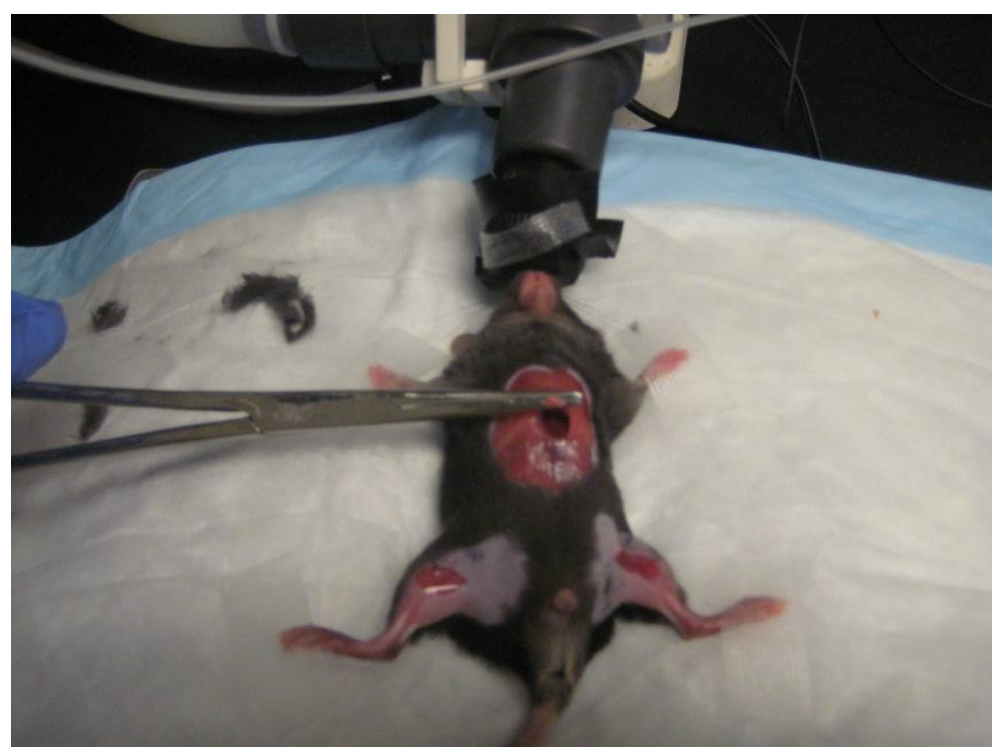

Figure 5 Hemastats clamped on to exposed xiphoid process in preparation for entering the thoracic cavity.

A small incision was made in the apex of the heart and a catheter was inserted into the left ventricle and clamped in place with a vascular clamp. The right atrium was also cut to allow drainage. Once catheterized, the vasculature was perfused with the vasodilator cocktail at $4 \mathrm{~mL} /$ minute. Next, $15 \mathrm{~mL}$ of histochoice was perfused to fix the vasculature in a dilated state (see Figure 6). 


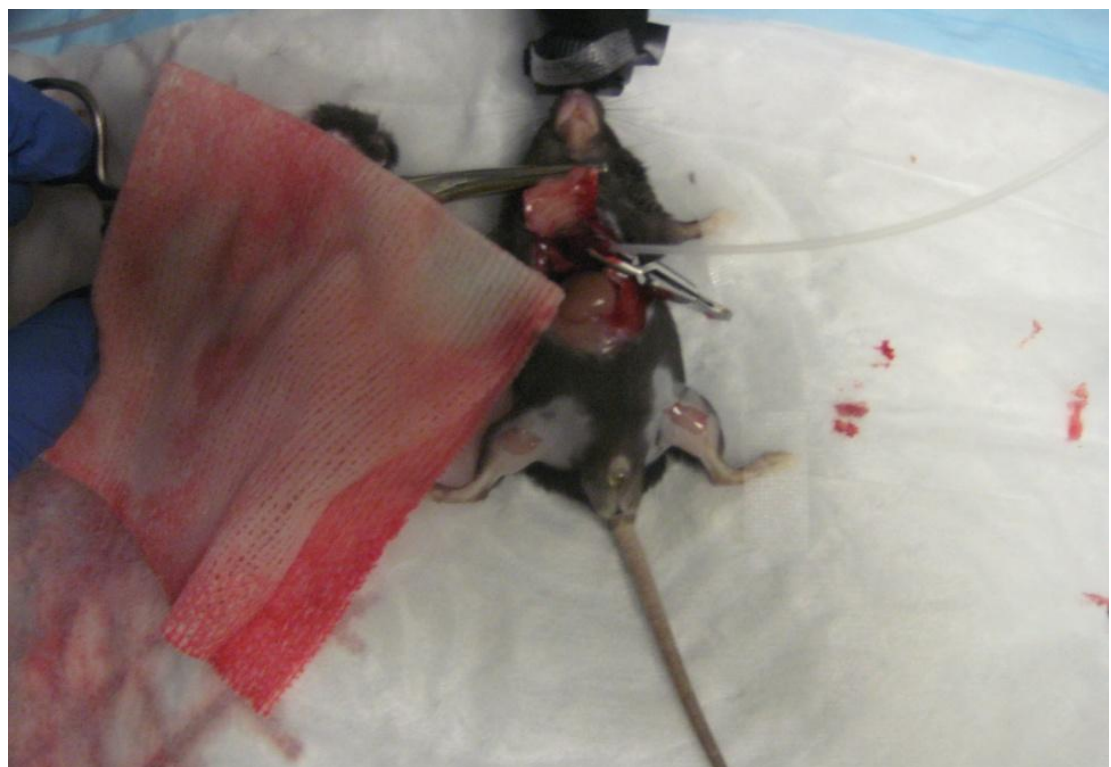

Figure 6 Correct catheter placement in the left ventricle for vascular perfusion.

The gracilis muscle and the profunda femoris artery were dissected from each hind limb and fixed in histochoice overnight. After post fixation, the tissue was stored in PBS at $4^{\circ} \mathrm{C}$.

\section{Histology}

\section{$\underline{\text { Sample Preparation }}$}

The tissue samples were dehydrated and impregnated with paraffin wax with a Shandon Excelsior ES tissue processor. Once processed, tissues were embedded in paraffin wax. The gracilis muscles were cut perpendicular to the muscle striations (exposing a crosssection of the collaterals) and the profunda femoris artery was cut perpendicular to the longitudinal axis to obtain a vascular cross-section. The tissues were placed with the medial aspect of the sample facing down in the cassette (so that the middle of the arteries would appear in the earlier sections). Once embedded, the tissue blocks were sectioned 
into $6 \mu \mathrm{m}$ sections using a Leica RM 2255 microtome. Tissue blocks were capped with hot wax and left to dry until the next use to minimize protein oxidation.

\section{$\underline{\text { Tissue Content Assessment }}$}

Before immunostaining, tissue morphology was assessed using a standard hematoxylin and eosin stain (provided by Fisher Science). Once imaged, one can determine whether the tissue cross section is the correct orientation, whether the tissue contains vessels (in particular, gracilis collaterals or profunda femoris arteries), and whether these vessels were properly perfused, dilated and fixed. Once tissue morphology was assessed, the tissue blocks that contained pertinent vessels were marked for use in subsequent immunostains.

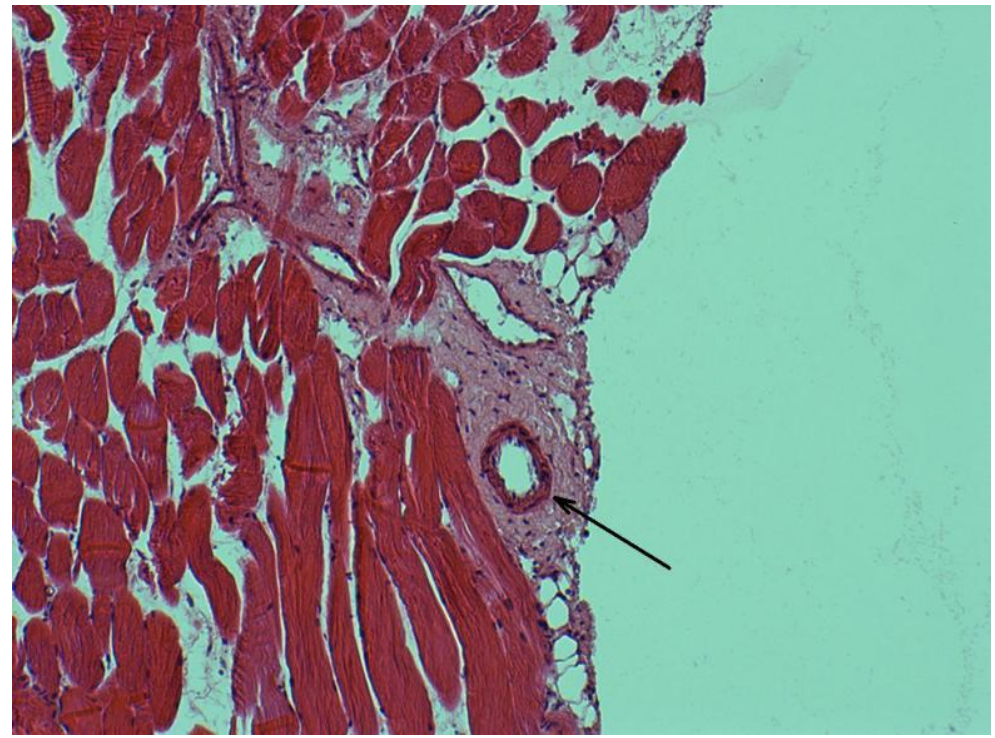

Figure 7 Profunda femoris artery in the left hind limb 7 days after femoral artery ligation (designated by black arrow). 


\section{$\underline{\text { Immunohistochemistry }}$}

Immunohistochemistry was used to detect proliferating smooth muscle cells, with peroxidase as the primary detection method. Tissues that contained pertinent vessels were sectioned with at least two samples on each slide (allowing for a negative control). The slides were placed into slide racks, and the paraffin was melted in an oven/incubator.

The samples were then rehydrated in xylene, dehydrant, and distilled water and placed in an incubation chamber. Enzymatic antigen retrieval was performed with Promega Proteinase K and permeablization with $0.1 \%$ Triton X-100. After blocking non-specific protein binding with $1.5 \%$ donkey serum, proliferating smooth muscle cell nuclei were labeled with a Ki-67 primary antibody. A donkey anti-rabbit biotinylated antibody was used as the secondary detection method followed by the application of an avidin-biotin complex. A DAB-peroxidase substrate was used to give the positive tissues a brown precipitate. After dehydrating in dehydrant and xylene, samples were mounted and imaged using a bright-field microscope (See appendix for specific reagents, dilutions and incubation times). 


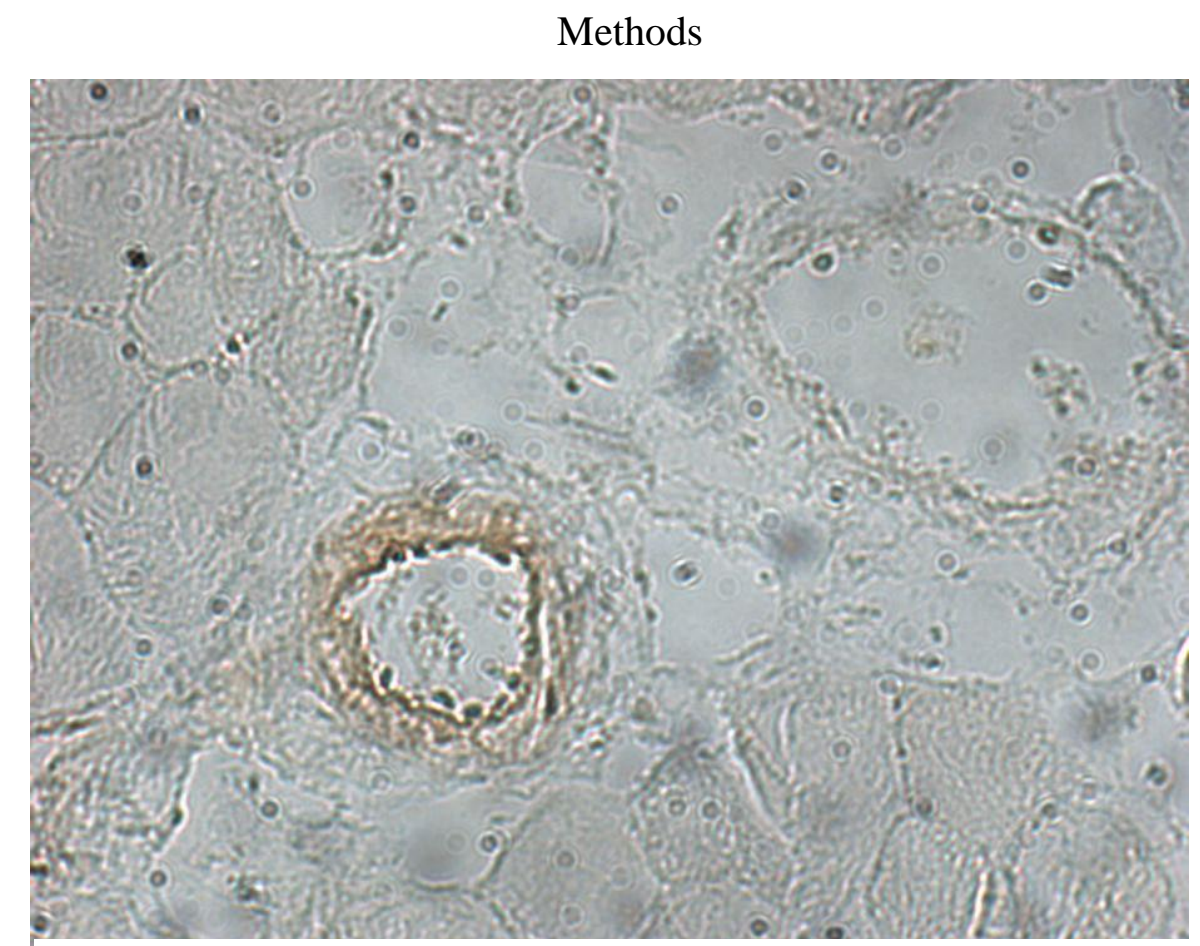

Figure $8 \mathrm{~A}$ gracilis collateral artery 7 days after femoral artery ligation stained with Ki-67. Proliferating smooth muscle cells show a brown precipitate.

\section{Immunofluorescence}

Immunofluorescence was used to assess proliferating vs. non-proliferating smooth muscle cells, as well as vessel lumen areas in the gracilis collaterals and profunda femoris arteries. Tissues that contained pertinent vessels were sectioned, placed in slide racks, and then in an oven/incubator to melt the paraffin. The samples were then rehydrated in xylene, and dehydrant, and distilled water.

The slides were then taken out of the slide racks and placed into an incubator. Enzymatic antigen retrieval was performed with Promega Proteinase K and permeablization with $0.1 \%$ Triton $\mathrm{X}-100$. After blocking non-specific protein binding with $1.5 \%$ donkey serum, proliferating smooth muscle cell nuclei were labeled by a Ki-67 primary antibody. An Invitrogen Alexa Fluor® 594 donkey anti-rabbit IgG was used as a secondary fluorescent detection method for the Ki-67. The sample was then stained with smooth muscle $\alpha$-actin that was labeled with a Invitrogen Zenon® Tricolor Mouse $\operatorname{IgG}_{2 a}$ 
Labeling Kit, allowing for the conjugation of a fluorescent complex to the $\alpha$-actin primary antibody. Once the samples were post-fixed in $10 \%$ formalin, a nuclear counterstain was performed with BBI. The slides were then mounted and examined under the appropriate fluorescent light for imaging (see appendix for specific reagents, dilutions and incubation times).

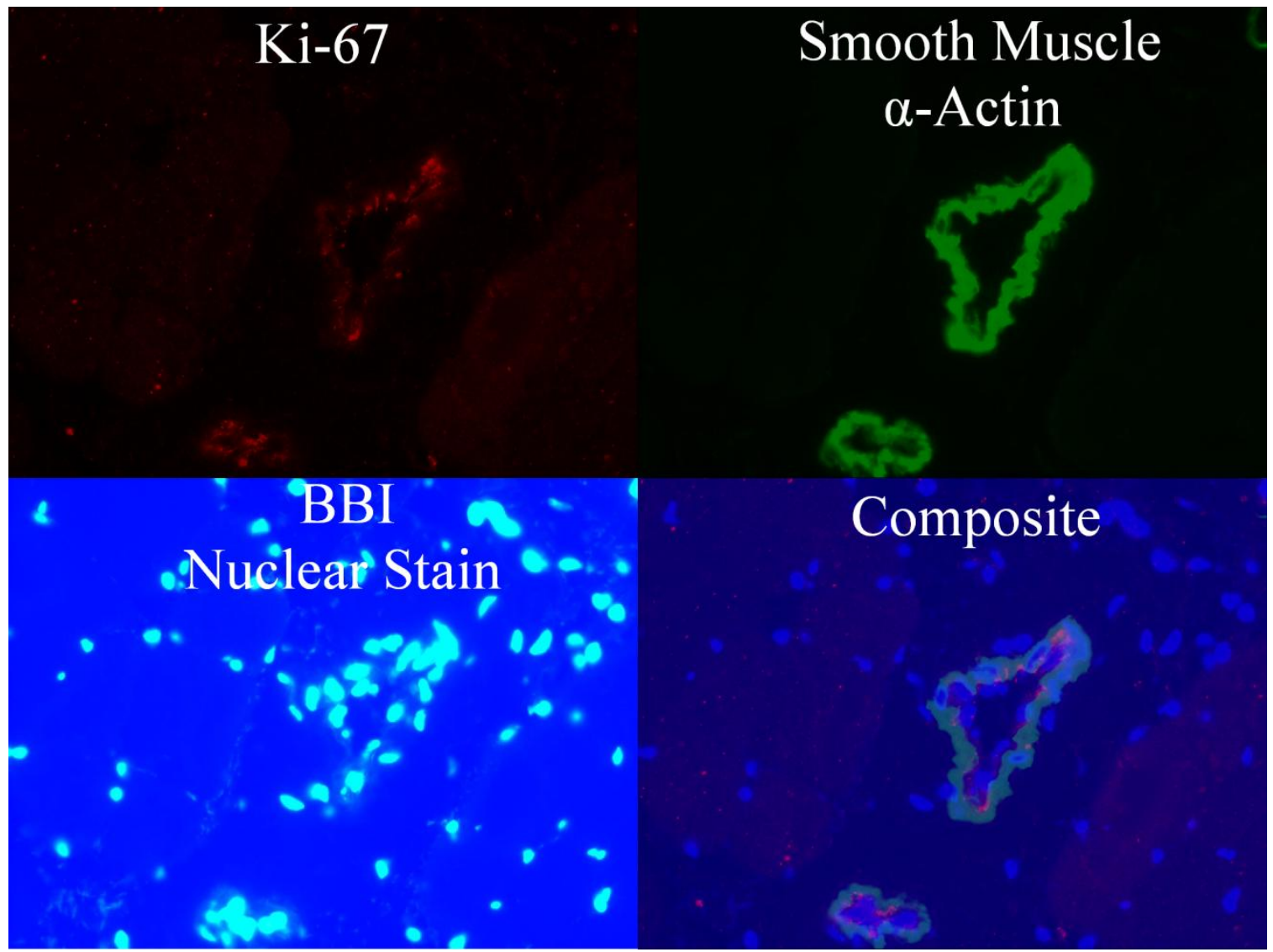

Figure 9 A Gracilis Collateral Artery 7 Days after a Femoral Artery Ligation. The collateral artery was stained with Ki-67 (green), smooth muscle alpha actin (red), and BBI (blue). 
Methods

Morphology

\section{Imaging}

Three separate images were taken of each pertinent vessel in order to assess morphology. One image showing Ki-67 positive cells, another image showing smooth muscle $\alpha$-actin, and a third showing cell nuclei (BBI) were all digitally captured. Once all samples were imaged, morphological measurements were taken using ImageJ, a free scientific imaging analysis software from the National Institutes of Health. An image of a $1 \mathrm{~mm}$ micrometer was also taken at various magnifications in order to calibrate the measurement features in ImageJ.

\section{Vessel Cross-Sectional Area}

In order to make all measurements consistent, areas were taken from images of the vessels stained with smooth muscle alpha actin because these images gave the best contrast. This assumed that the endothelial cell layers of all the vessels were relatively the same thickness since the measurement starts deep to the intimal layer. Although this assumption may be inaccurate, measurements remained consistent among each other. Images were converted into a binary form in to allow for a semi-automated tabulation of luminal areas. 

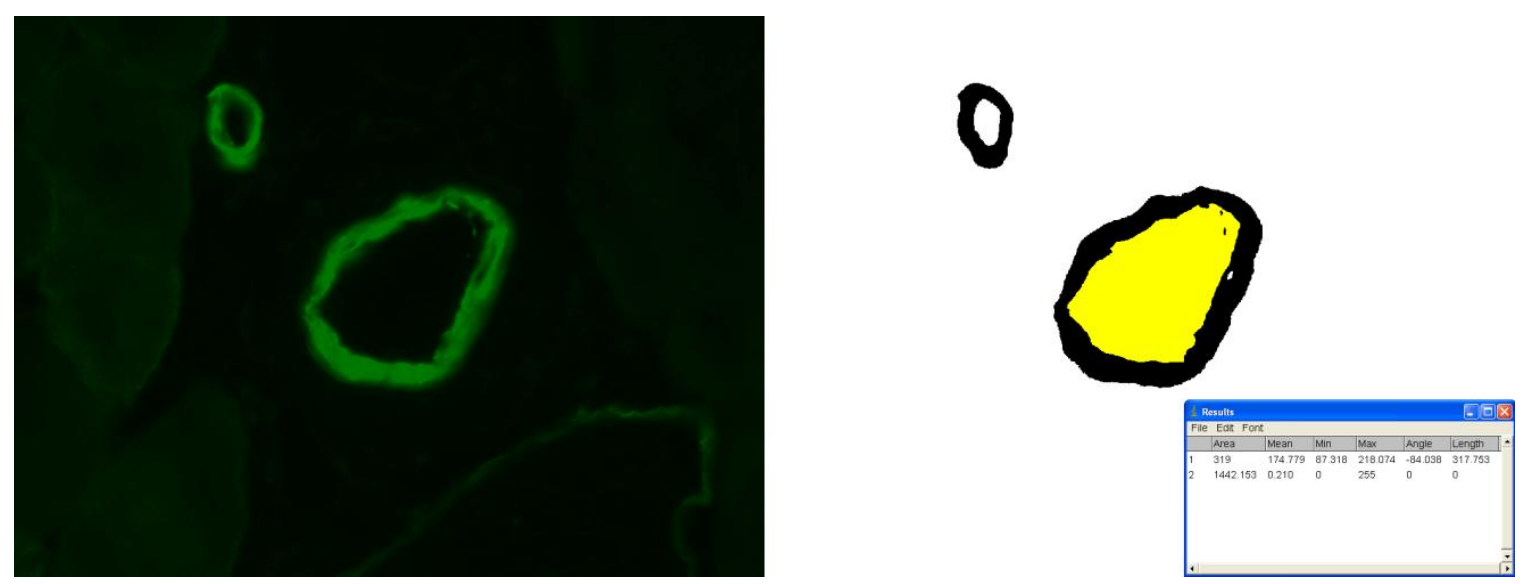

Figure 10 Images of normally stained SM alpha actin (green) and the binary form of the image used to take area measurements.

Once the areas were tabulated for each vessel, they were entered into a Microsoft Excel spreadsheet under their respective tissue type and time point for further analysis.

\section{Cell Nuclei Counting}

Images of vessels displaying smooth muscle $\alpha$-actin (green), Ki-67 (red) and BBI (blue) were merged to determine which cell nuclei were smooth muscle nuclei, and which of those smooth muscle cells were proliferating. Those nuclei immersed in green were deemed smooth muscle cell nuclei. If these smooth muscle nuclei had red staining around the edges or within the nuclei, it was deemed to be a proliferating nuclei cell. The amount of normal and proliferating smooth muscle cells were then counted for quantification. An example of smooth muscle phenotyping is shown in Figure 11. 


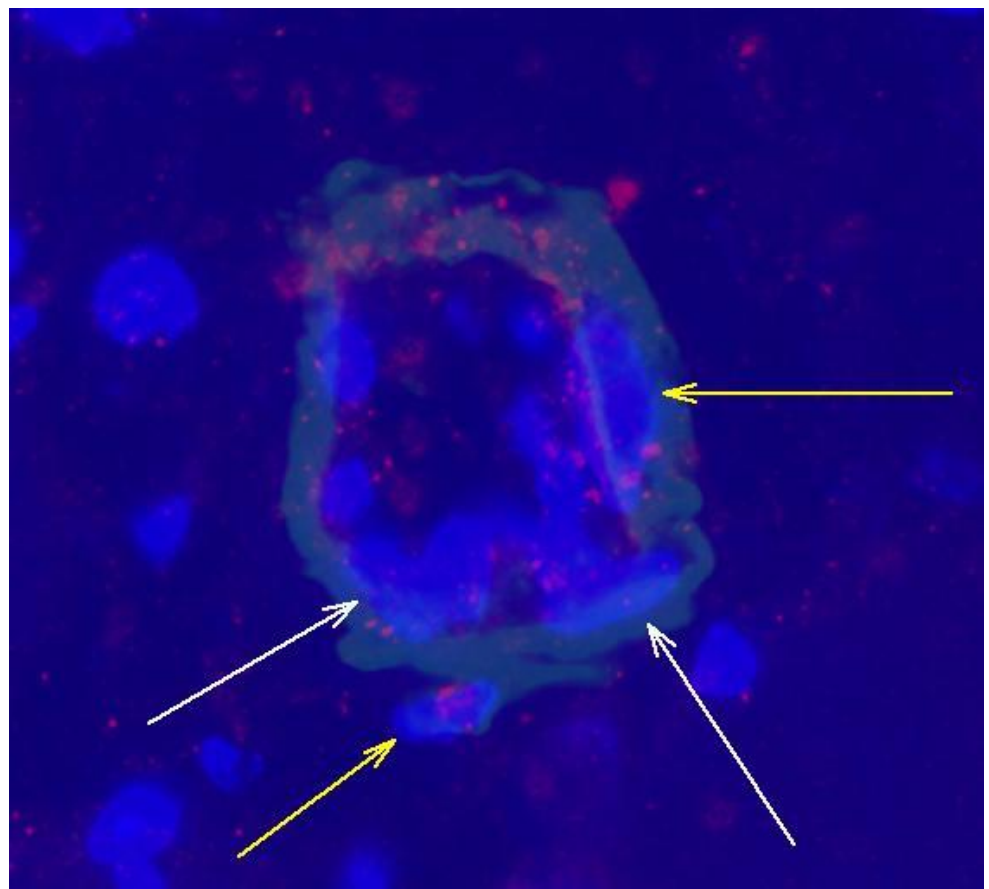

Figure 11 Phenotyping of vascular smooth muscle cells in a gracilis collateral artery 3 days after femoral artery ligation. Non-proliferating smooth muscle cells are designated by the white arrows. Proliferating smooth muscle cells are designated by yellow arrows.

\section{Data Analysis}

Once the experimental data (vessel cross-sectional areas and vascular smooth muscle cell quantity) was gathered from each sample, a statistical analysis was performed using Microsoft Excel. A two-sample t-test (assuming unequal variances) was done, comparing data from the non-ligated and ligated samples for each time point (e.g. non-ligated vs. ligated gracilis cross-sectional areas for day 3, 7, 14). Two-sample t-tests were also used to compare the data from each time point for the profunda femoris versus the gracilis collaterals. Regression analysis and analysis of variance (ANOVA) was used to compare individual sets of data to their counterparts at the different time points (e.g. day 3 vs. day 7 vs. day 14 ligated left gracilis cross-sectional areas). Statistical data was presented in mean \pm standard error of the mean and statistical significance was determined by $p<0.05$. 


\section{Results}

\section{Vessel Cross-Sectional Area}

Cross-sectional area measurements were taken of the medial luminal area (this assumes that the endothelial cell layers of all the vessels are relatively the same thickness since the measurement starts at the media layer) for each vessel. Although vessel size appears to markedly increase as the post ligation period increased, a significant difference between the ligated and non-ligated areas was only seen at the day 7 and day 14 time points. A one way ANOVA for independent samples shows that the cross-sectional areas of the ligated gracilis collaterals for day 14 are significantly different than that of day 3 and day 7 (see Figure 13).

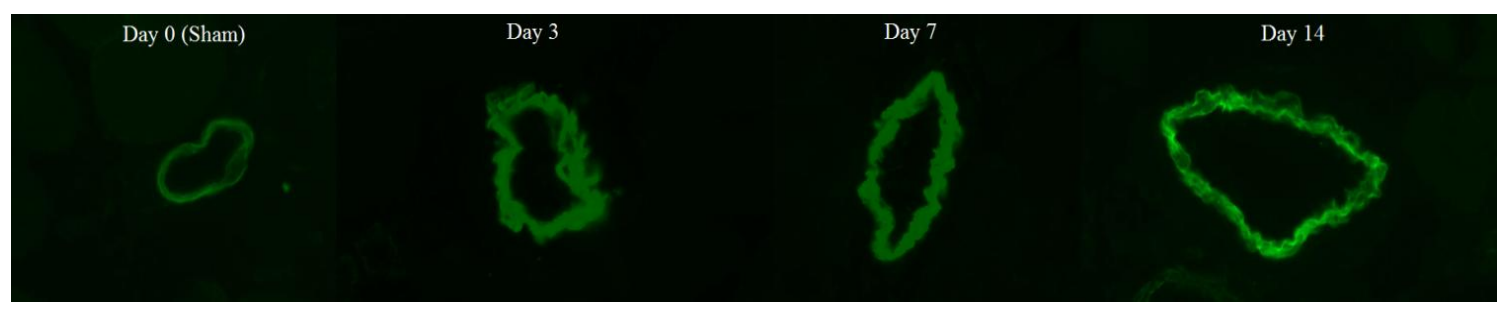

Figure 12 Progression of gracilis collateral enlargement over a two week period. Images chosen where those closest to the average in all groups. Vessel cross-sections were stained with smooth muscle $\alpha$-actin (green). 


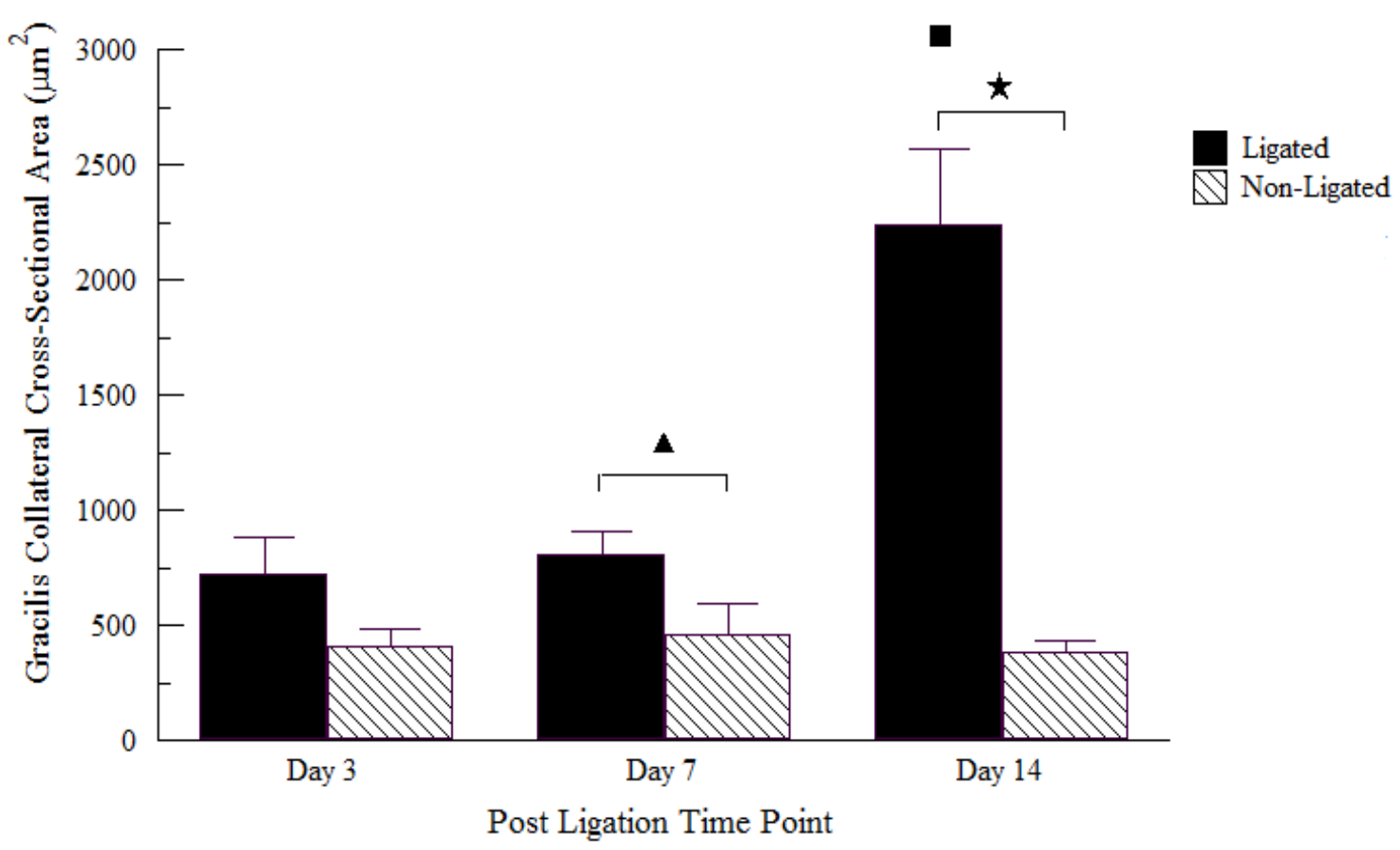

Figure 13 Average gracilis collateral cross-sectional areas in ligated and non-ligated c57 hind limbs areas at 3,7 , and 14 days after femoral artery ligation. At day 7 and day 14 the areas are significantly different with $\mathrm{p}$ values of 0.0352 (denoted by $\boldsymbol{\Lambda}$ ) and 0.0007 (denoted by $\star$ ) respectively. A one-way ANOVA shows that day 14 ligated CSA is significantly different from day 3 and day 7 (denoted by $\mathbf{m}$ ).

The profunda femoris (muscular branch artery) showed a trend of increased crosssectional area as the post ligation time increased. However, although there was a trend of growth throughout the examined time periods, the cross-sectional areas of the ligated versus the contra lateral control was not significantly different for any time points (see

\section{Figure 15).}

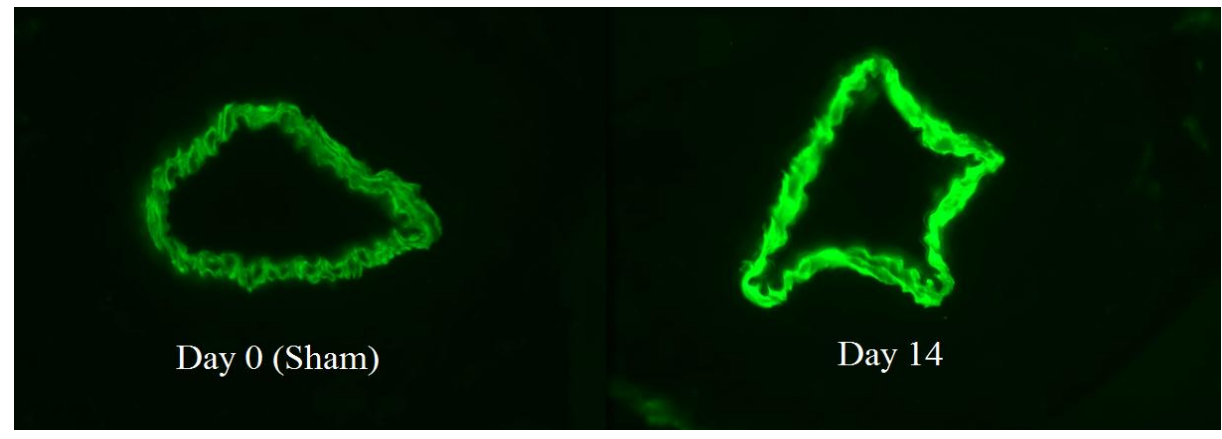

Figure 14 An average sham (day 0) profunda femoris artery (left) and a profunda femoris artery 14 days after a femoral artery ligation (right). Images chosen where those closest to the average in both groups. Vessel cross-sections were stained with smooth muscle $\alpha$-actin (green). 


\section{Results}

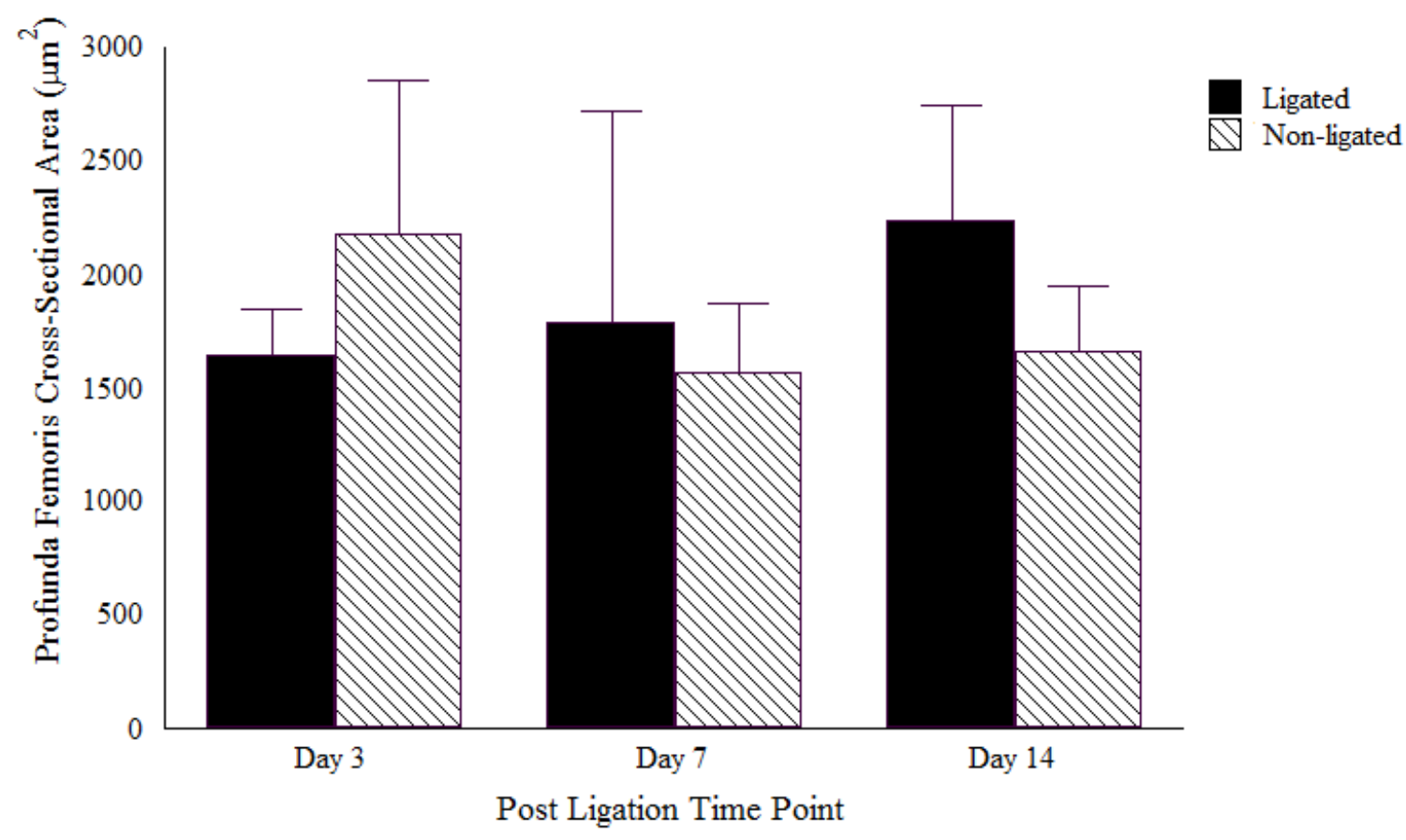

Figure 15 Average profunda femoris cross-sectional areas in ligated and non-ligated c57 hind limbs at 3, 7, and 14 days after femoral artery ligation. Although there was an increasing trend in the average area of the vessels in the ligated legs, no significant difference was seen between the ligated and contra lateral control.

When comparing the cross-sectional areas of the ligated gracilis collateral and profunda femoris arteries it appears that the gracilis collaterals generally approach the relative size of the profunda femoris arteries. A t-test shows that the profunda femoris and gracilis collateral cross-sectional areas are significantly different in day 3. Although the difference between the averages of the gracilis collateral and profunda femoris arteries is larger in day 7 than it is in day 3, a t-test showed that the day 7 averages were not significantly different. Figure 6 shows that the cross-sectional area of the gracilis collaterals approaches that of the profunda femoris over the two week period. 


\section{Results}

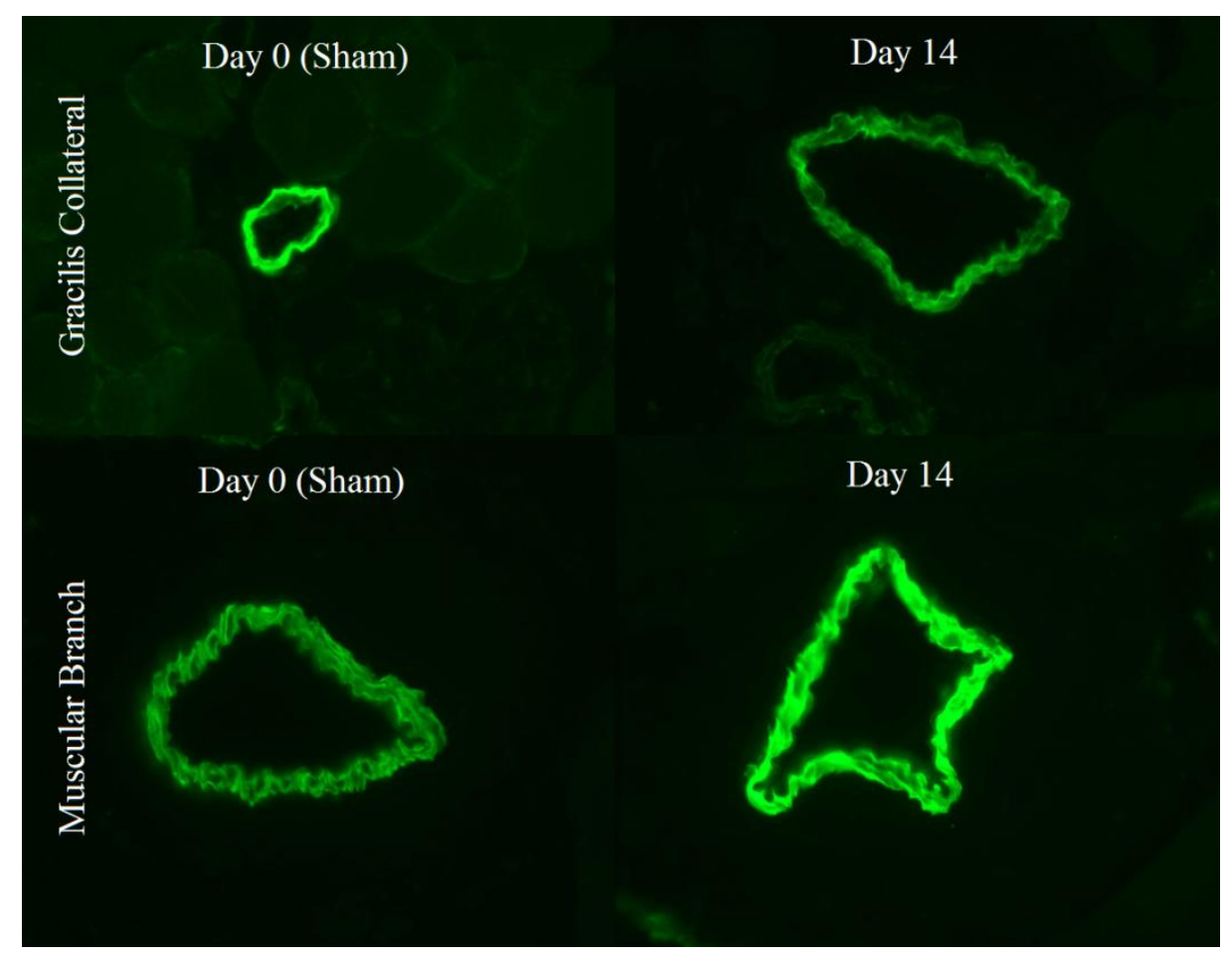

Figure 16 Progression of gracilis collaterals (top row) and profunda femoris arteries (bottom row) from day 0 (left column) to day 14 (right column). Images used were those with areas closest to the average. Vessel cross-sections were stained with smooth muscle $\alpha$-actin (green).

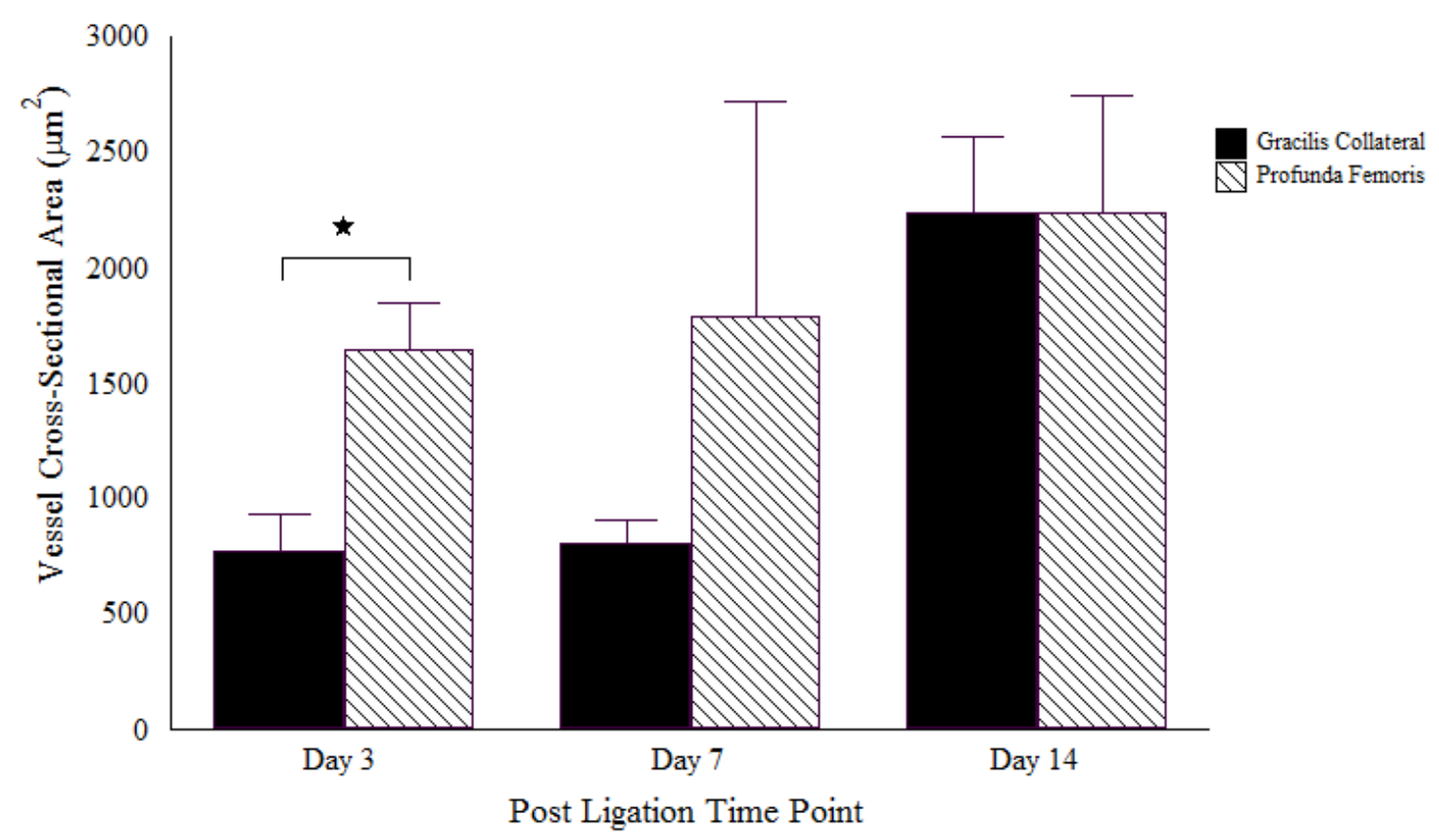

Figure 17 The average gracilis collateral vs. profunda femoris cross-sectional areas in ischemic c57 hind limbs at 3, 7, and 14 days after femoral artery ligation. A t-test with a p-value of 0.002 (denoted by $\star$ ) shows that the areas of the two arteries are significantly different at day 3 . 


\section{Results}

\section{Vascular Smooth Muscle Cell Quantification}

\section{$\underline{\text { Total Smooth Muscle Cell Count }}$}

The total number of vascular smooth muscle cells (VSMCs) present in each vessel was tabulated. In the gracilis collaterals, there was an increasing trend in the average number of VSMCs in the ligated samples. However, only days 3 and day 14 showed a significant difference between the ligated and contra lateral control. Although a one-way ANOVA gave a p-value of 0.0411 , the difference between the averages in the ligated gracilis collaterals at day 3 , day 7 , and day 14 were deemed non-significant.

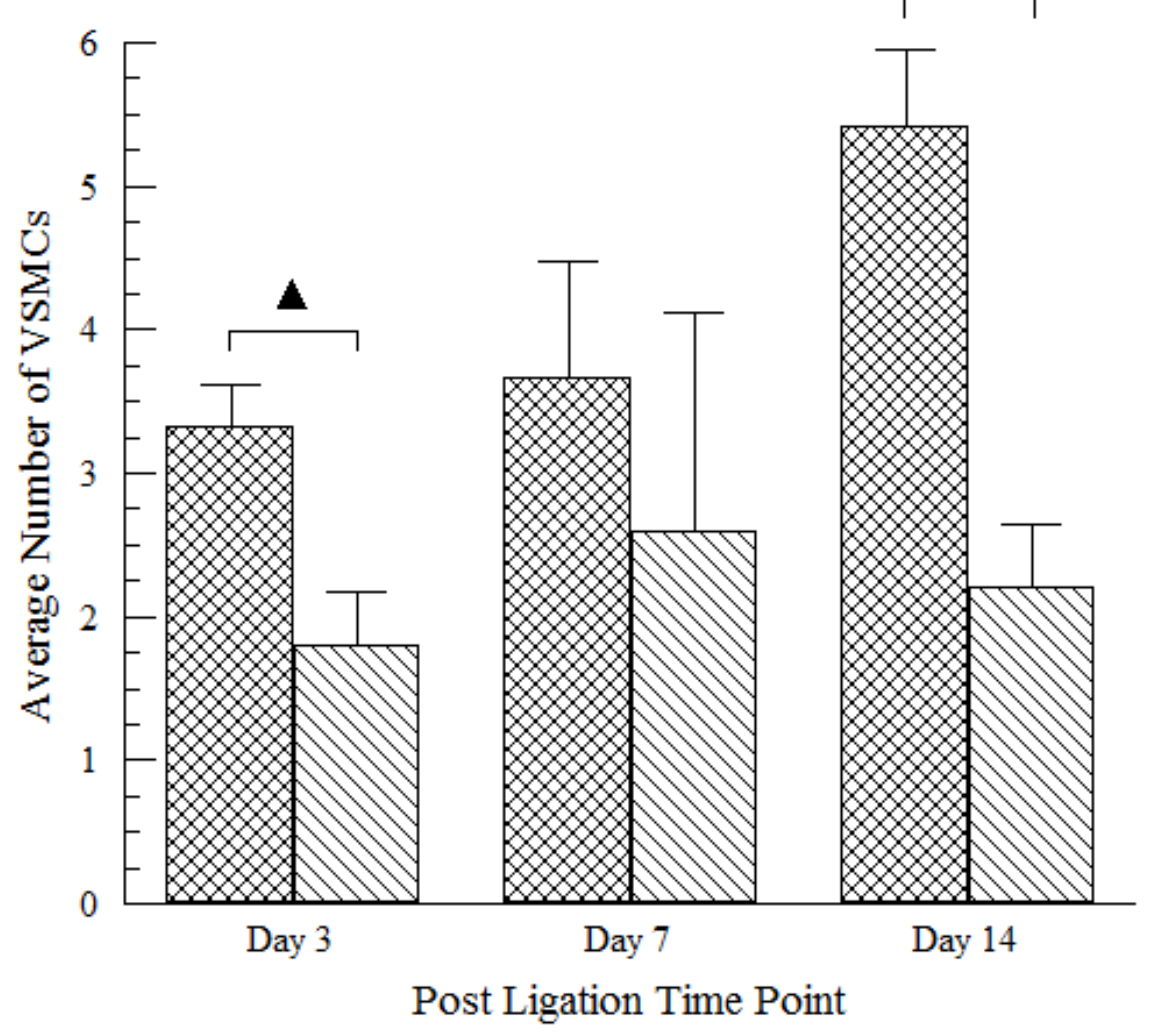

Figure 18 The average number of vascular smooth muscle cells in the gracilis collaterals in ligated and non-ligated hind limbs. The average number of smooth muscle cells was significantly different at day 3 and day 14 , with p-values of 0.0128 (denoted by $\mathbf{\Delta}$ ) and 0.0002 (denoted by $\star$ ), respectively. 


\section{Results}

As for the profunda femoris arteries, there was little variation between the ligated and non-ligated groups. None of the time points showed a significant difference when comparing the ligated with the non-ligated hind limb (see Figure 19).

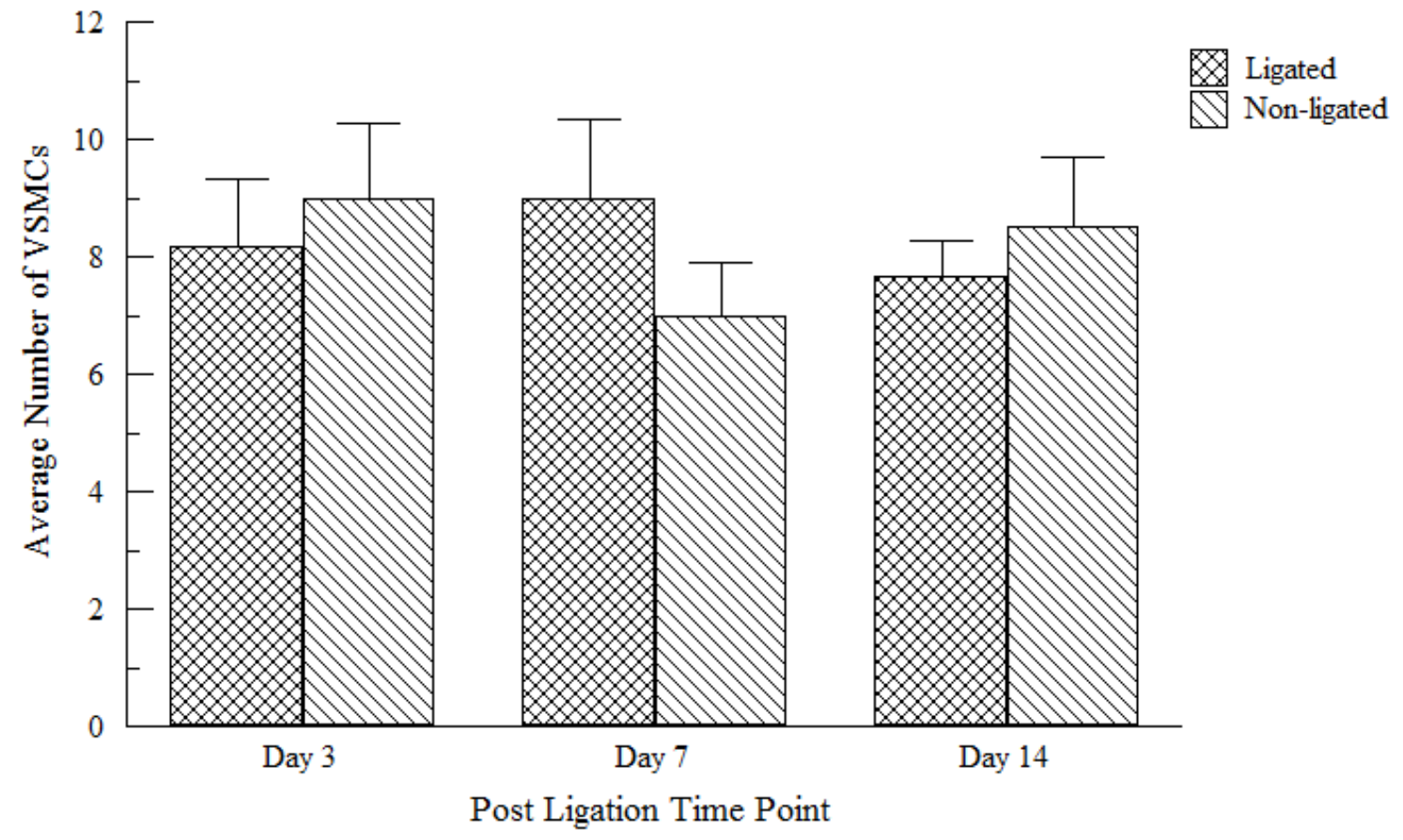

Figure 19 The average number of vascular smooth muscle cells in the profunda femoris arteries in ligated and non-ligated hind limbs. None of the time points showed a significant difference when comparing the ligated and non-ligated data.

When comparing the quantity of VSMCs in gracilis collaterals and profunda femoris arteries, all time points showed a significant difference. Although all p-values were under 0.05 , the day 3 and day 7 time points were more significantly different than that of day 14 (see Figure 20). 


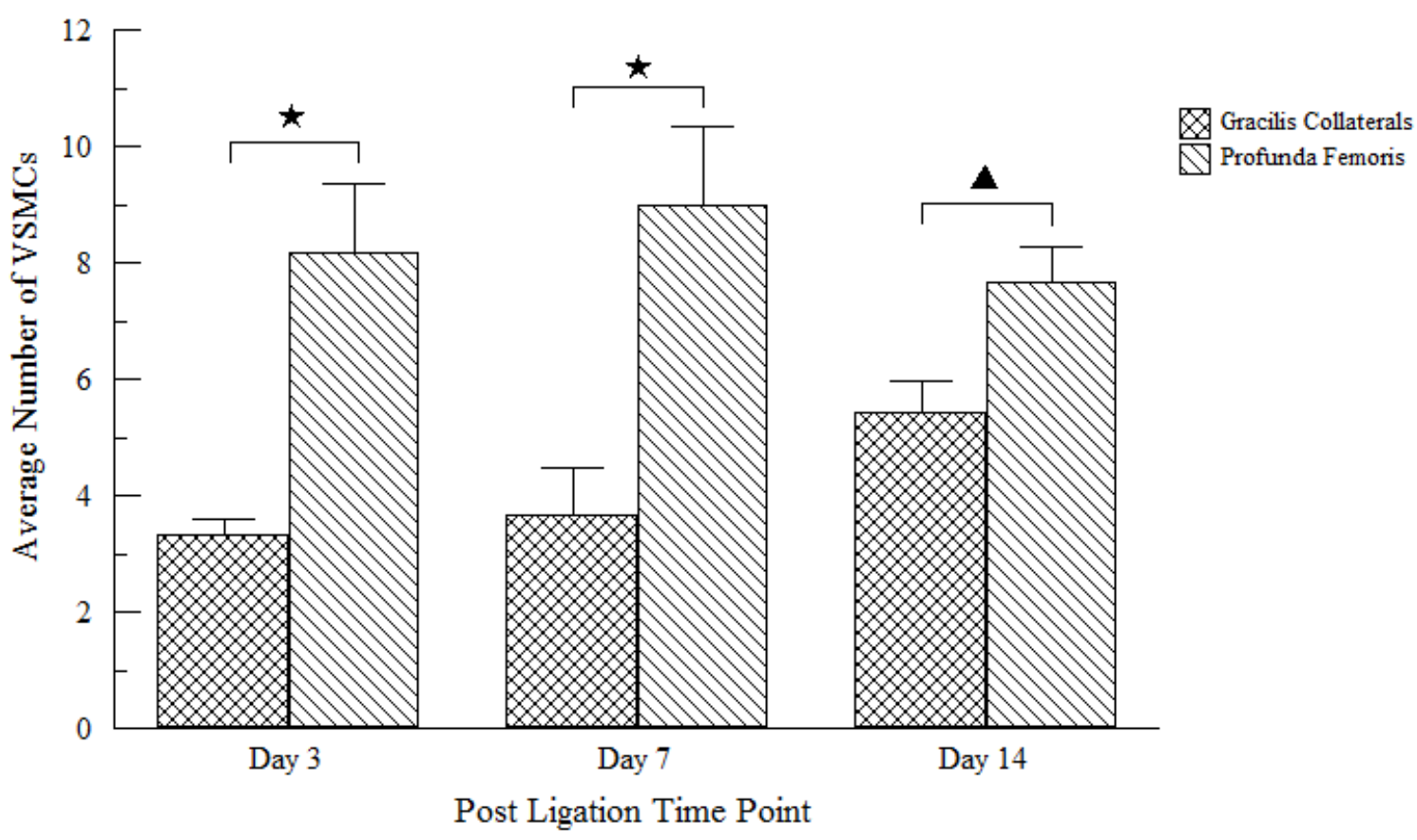

Figure 20 The average number of VSMCs in the gracilis collaterals and profunda femoris arteries in the ligated c57 hind limbs. Days 3 and 7 gave p-values less than 0.01 ( 0.0032 and 0.0098 respectively, denoted by $\star$ ) and day 14 gave a p-value less than 0.05 ( $\mathrm{p}=0.01$, denoted by $\mathbf{\Lambda})$.

\section{$\underline{\text { Smooth Muscle Cell Phenotype }}$}

The only samples that stained positive for Ki-67 were the gracilis collaterals at day 3 and day 7 following a femoral artery ligation. This signifies that smooth muscle cells were proliferating at day 3 and day 7, but not day 14. There was an average of 1.6 and 2.5 proliferating VSMCs at day 3 and day 7 respectively. A t-test showed that the amount of proliferating VSMCs present at day 3 and day 7 are significantly different than those found at day 0 (sham) and day 14. The line graph shown in Figure 22, shows the progression of the proliferating VSMCs over the two week period. 


\section{Results}

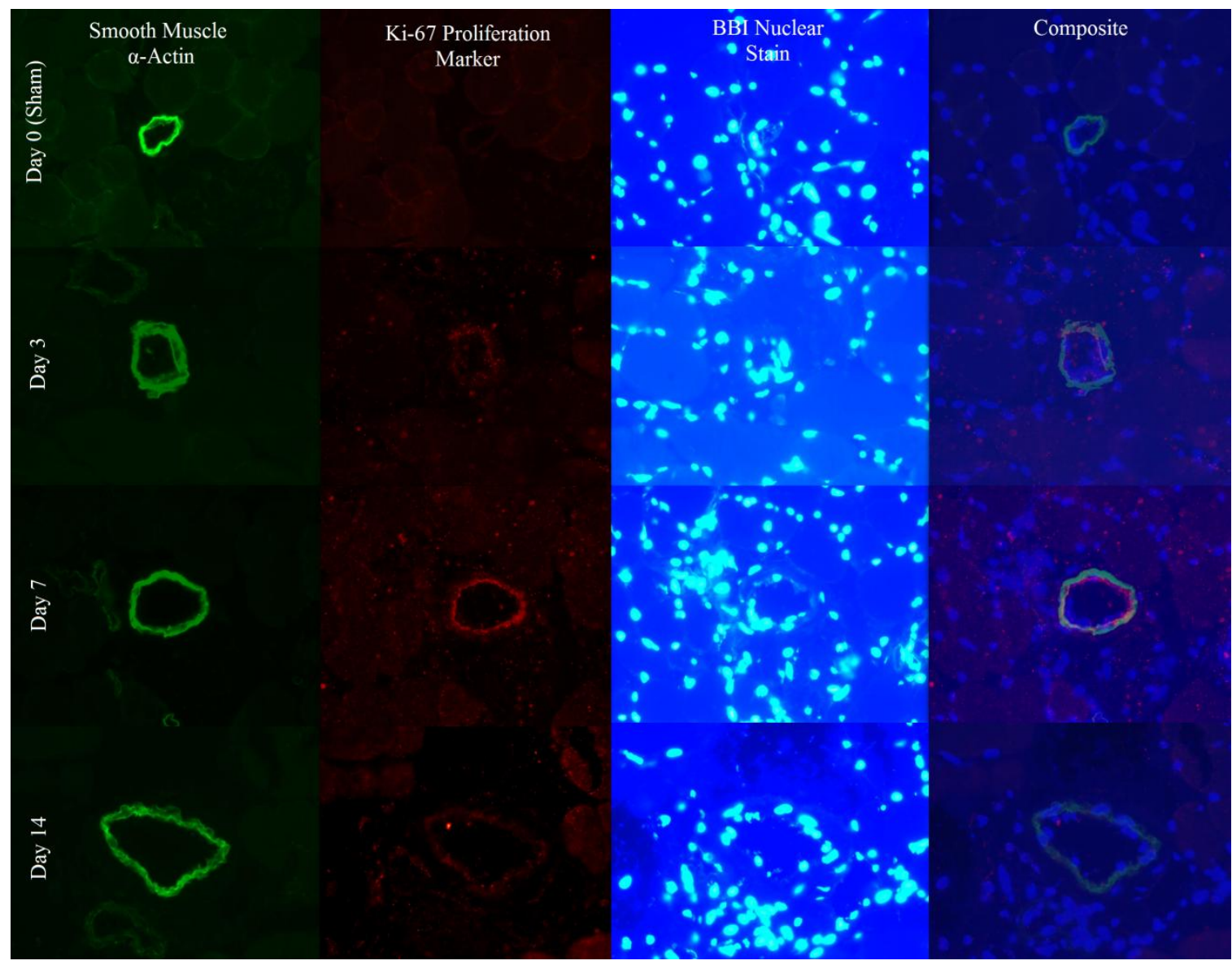

Figure 21 Progression of the gracilis collaterals over the two week post-ligation period. Vessels chosen were those that had the closest areas and amount of VSMCs to the averages in each group. Each vessel was stained with smooth muscle $\alpha$-actin (green), the Ki-67 proliferation marker (red), and BBI for the nuclei (blue). 


\section{Results}

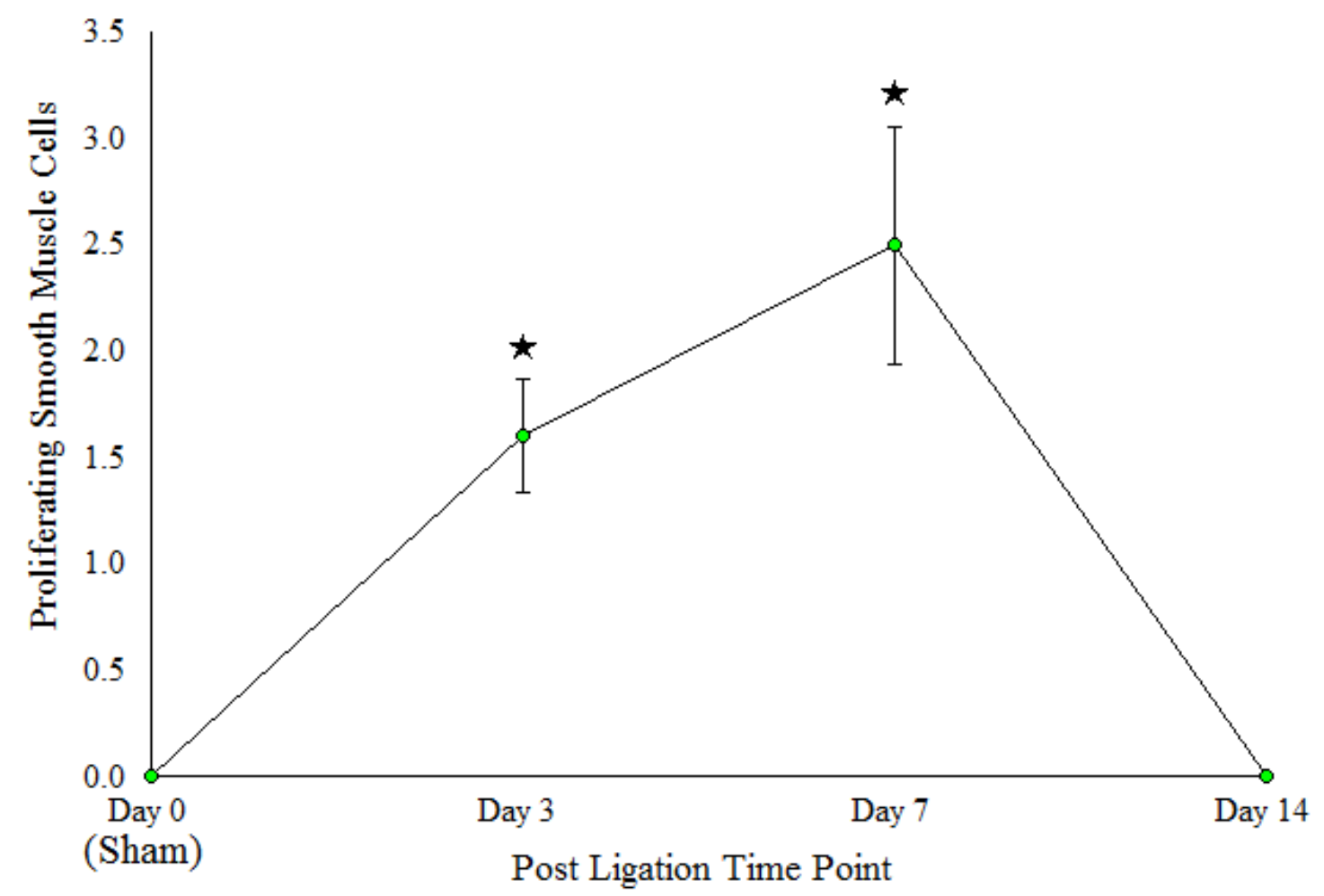

Figure 22 Average number of proliferating smooth muscle cells in ligated gracilis collateral arteries. A ttest showed that days 3 and 7 were significantly different from day 0 and day 14 with a p-value less than 0.005 ( $\mathrm{p}=0.0003,0.0033$ for day 3 and day 7 respectively). 


\section{Discussion \\ Time Dependence of Smooth Muscle Cell Phenotype}

The gracilis collaterals experienced arteriogenesis following a femoral artery ligation in the C57 mouse hind limb, Figure 21. Evidence of this was supported by the fact that the smooth muscle cells that were positive for Ki-67 at 3 and 7 days and collaterals significantly enlarge over the two week period following the ligation. Although smooth muscle cells were quantified, we mainly wanted to show that proliferation was observed at day 3 and day 7 , but not at day 0 and day 14. To obtain a more accurate quantification in the future, imaging exposure times, incubations periods, and procedural conditions must remain consistent in order to use implications, such as fluorescent intensity, as an indication of quantity.

Since the Ki-67 protein is expressed during all active phases of the cell cycle and the rapid disappearance of the Ki-67 antigen is associated with a non-proliferative (inactive) state of any part of the cell cycle [27], we can also postulate that SMCs positive for Ki-67 are proliferating, or in a synthetic state. Although there was a trend of more proliferation at day 7, a one-way ANOVA shows that the average amounts of proliferating VSMCs present at days 3 and 7 are not significantly different.

These findings were somewhat consistent with previous work. The first positive Ki-67 reaction (i.e. proliferating cells) in the vessel wall of the growing collaterals in New Zealand white rabbits was found 24 hours after the occlusion in the mid-zone of the collaterals of the quadriceps [28]. The Ki-67 reaction increased up to day 3, however proliferation diminished in the collaterals at days 7 and 21 [28]. 


\section{Discussion}

Previous work in mice was also used to distinguish the different phases of remodeling during arteriogenesis. The first, proliferative phase of arteriogenesis occurs 1-3 days after occlusion, and is characterized by a maximal mitotic activity in the endothelial cells, SMCs, and fibroblasts [28]. The next stage is the synthetic/growth phase (3-14 days) that is characterized by reduced mitosis and initiation of synthetic and proteolytic activity in SMCs [28]. During this time the internal elastic lamina is digested and fragmented by the elastolytic enzymes to facilitate positive remodeling by the SMCs [28]. Although the previous work was done in New Zealand white rabbits, the time course is similar to that of our study.

Previous work also characterized the proliferation phase as 1-3 days after occlusion [29]. Three days after femoral occlusion in the mouse hind limb, remodeling is characterized by swollen endothelium, disrupted elastic lamina, mitotic phenotypes in both smooth muscle and endothelial cells (evidenced by endothelial and smooth muscle cells taking up BrdU and Ki-67 labeling) [6]. The period from 3 days to 2 weeks is defined as the synthetic phase and is characterized by high proliferation activity at the beginning of the phase, followed by the first recovery of blood flow to the ischemic limb after 7 days [29]. The vessel's ultrastructure returned to normal 7 to 14 days after occlusion, and the BrdU and Ki-67 labeling decreased [6]. Then, after 10 to 14 days proliferation activity diminishes and SMCs gradually return to the contractile phenotype [29].

Although my results were similar to previous work, this study only measured proliferation in the SMCs, so another cogitation to be considered about this study is the distinction between a proliferating and a synthetic smooth muscle cell. Since only proliferating smooth muscle cells were assessed, we want to know what allotment of 


\section{Discussion}

those cells were in a "synthetic" state as well. Smooth muscle cells dynamically exhibit distinct contractile and synthetic phenotypes with unique morphological, biochemical, functional, and gene expression characteristics [24]. The plasticity of the length-tension properties and the organization of contractile filaments in smooth muscle further extends the functional diversity of SMCs [24]. These observations tell us that there is a full spectrum of SMC function, dictated by phenotypic and mechanical plasticity, that is controlled by molecular mechanisms [24].

Although SMCs are on a plastic continuum, cells in the contractile state are deemed nonproliferative, evidenced by the fact that this phenotype is that of a differentiated cell. This is not to say that contractile smooth muscle cells have zero proliferation, but that there is a minimal rate of proliferating and a balance in the production and degradation of proteins [30]. According to Scholz et al., although proliferation appears to peak at day 3, it is present for up to three weeks, which encompasses the synthetic activity period in the SMC (3 to 14 days) [28]. From this, we can postulate that Ki-67 positive smooth muscle cells from day 3 to day 14 is of a synthetic nature.

\section{Impact of Location on the Collateral Circuit}

Although we saw proliferation in the gracilis collaterals, the mid-zone of the collateral circuit, there was no proliferation seen in the profunda femoris (muscular branch) arteries, the stem region of the collateral circuit, at any of the time points. However, following the femoral artery ligation, the average cross-sectional area of the profunda femoris experienced an increasing trend over the two week period. While an increasing trend was seen, a t-test on all three time points showed that none of the average areas 


\section{Discussion}

were significantly larger than the non-ligated samples. A one-way ANOVA also demonstrated that the average areas at the post ligation time points were not significantly different, nor were the non-ligated time points. Although no significant difference was seen in this study, previous work does show a significant difference at certain time points.

Despite observing no proliferation or a significant increase in profunda femoris crosssectional area, it has been well documented that an arterial occlusion can lead to impaired vasoactivity in the stem region of the collateral circuit. Proliferating smooth muscle cells seen after an occlusion could explain abnormal functional dilation in the gracilis collaterals. However, we found no proliferating SMCs in the profunda at any time after the occlusion, leading us to believe that the impaired vasodilation may be caused by other changes in smooth muscle phenotype or may not be smooth muscle dependent.

Two previous studies on the impact of vascular occlusion on vascular reactivity through femoral artery ligation showed cross-sectional area measurements that were inconsistent with those of this study. The vessel diameter measurements for the previous studies were taken via in vivo intravital microscopy and because the vessel measurements for this study were taken via histological analysis, there are expected discrepancies between the two sets of data.

Our group measured cross-sectional areas (assuming a perfectly cylindrical vessel) 3 days after the same proximal femoral artery ligation and saw no significant difference between vessel diameters of the ligated and non-ligated profunda femoris arteries. Although the areas tabulated from this study (ligated profunda CSA $\approx 2,551 \mu \mathrm{m}^{2}$, non-ligated profunda $\left.\mathrm{CSA} \approx 1654 \mu \mathrm{m}^{2}\right)$ and my own $\left(\mathrm{L}=1643 \mu \mathrm{m}^{2}, \mathrm{NL}=2176 \mu \mathrm{m}^{2}\right)$ are slightly different, 


\section{Discussion}

the overall data for this time point was consistent between the two. Our group also measured two sets of day 7 cross-sectional areas, which yielded different results from the measurements of this study. The first set of cross-sectional area measurements of the ligated profunda femoris $\left(\approx 3525 \mu \mathrm{m}^{2}\right)$ was significantly larger $(\mathrm{p}$-value $<0.05)$ than that of the non-ligated profunda femoris $\left(\approx 1978 \mu \mathrm{m}^{2}\right) 7$ days post occlusion. The second set of measurements also yielded a significant difference $(\mathrm{p}$-value $<0.01)$ in the crosssectional areas of the ligated $\left(\approx 7853 \mu \mathrm{m}^{2}\right)$ and non-ligated $\left(\approx 1963 \mu \mathrm{m}^{2}\right)$ profunda femoris arteries. Although the measurements are within reasonable range of my own $(\mathrm{L}=$ $1789 \mu \mathrm{m}^{2}, \mathrm{NL}=1568 \mu \mathrm{m}^{2}$ ), there was a statistical difference present that did not occur in this study. Previous measurements by our group also showed a significant difference (pvalue $<0.01)$ between the ligated $\left(\approx 6361 \mu \mathrm{m}^{2}\right)$ and the non-ligated $\left(\approx 2375 \mu \mathrm{m}^{2}\right)$ profunda femoris arteries 14 days after occlusion. Similar to the day 7 study, the nonligated profunda femoris $\left(=1664 \mu \mathrm{m}^{2}\right)$ from this study is within range, but the ligated profunda femoris $\left(=2239 \mu \mathrm{m}^{2}\right)$ was much smaller and there was no significant difference between the two.

There are many physiological and experimental factors that could have attributed to the substantial differences seen in the ligated profunda femoris measurements, especially in the day 7 and day 14 studies. The main source of inconsistencies was most likely the different methods of vessel measurement. Intravital microscopy measurements from the previous two studies were taken in vivo when the vasculature was in a resting state. In this study, the vasculature was perfused with a vasodilator and immediately perfused with a fixative to achieve a maximal resting diameter. However, ventricular catheterization is a delicate procedure. At times, only the arterial side would perfuse or the vasodilator would 


\section{Discussion}

barely perfuse the vasculature at all (due to improper catheter placement, puncture of the ventricular septum, clotting, etc.). Because of this, not all vessels were fixed in a fully dilated state. Also, to examine samples histologically, the tissues must be processed, a procedure that tends to substantially shrink the tissues.

Aside from the different methods of taking vessel measurements, another source of error could have originated from the ligation procedure. Although each surgeon followed the same procedure for the proximal femoral artery ligation, inconsistencies can still occur. For instance, if there were branch points proximal to the ligature and distal to the profunda, there would be a reduced shear on the profunda, which may have had an effect on the results obtained.

Although different results were obtained from this study and previous similar studies, the overall trend shows an enlargement of the profunda post occlusion. This is expected because of the increased blood flow in the profunda femoris when the femoral artery is occluded. Although the profunda increases in diameter, impaired functional vasodilation was only seen in one of the two studies on the effects of vascular occlusion. The other study showed that the ligated and non-ligated profundas dilated relatively the same percent when stimulated.

The next logical step would be to take the same intravital measurements at 3, 7 and 14 days post ligation to confirm the presence of a functional vasodilation impairment. If no impairment is observed, this would support the hypothesis that smooth muscle proliferation is necessary to induce impaired vasodilation. Since the vessel did not contain proliferative cells, if impaired dilation is observed, it is possible that the 


\section{Discussion}

impairment was due not to proliferation, but an acute mechanoadaptation, which may have occurred to cause the profunda to enlarge following the occlusion. In response to prolonged constriction, VSMCs undergo a mechanoadaptation process involving "length autoregulation" that would be energetically favorable for maintenance of a reduced vessel diameter [31]. This process involves cellular repositioning of the VSMCs in the presence of the maintained constriction[31]. Although this phenomenon has mostly been witnessed in vessels exposed to prolonged vasoconstriction, studies have shown that prolonged vasodilation can also cause acute outward remodeling [32]. Although there is no evidence that the SMCs in the profunda experienced this acute mechanoadaptation following the ligation, this could explain why the vessel enlarged over the two week period in all three studies, without proliferation, and may explain any confirmed impairment in functional vasodilation. While the smooth muscle cells do not change phenotypes during this mechanoadaptation, it is possible that a transient reduction in smooth muscle function could have occurred due to the reconstitution of the extracellular matrix and the repositioning of the smooth muscle cells.

To test this hypothesis we would measure vascular reactivity to endothelial and smooth muscle dependent agents using intravital microscopy. This would initially involve the same surgical procedure as the previous experiments in which a ligation surgery would be performed on at least six mice for each time point (day 3, day 7, day 14). At each time point the mice would undergo a superfusion procedure in which smooth muscle and endothelial dependent dilators (e.g. sodium nitroprusside and acetylcholine) would be placed over the profunda while diameter measurements are taken simultaneously via intravital microscopy. If the profunda does not respond to endothelial or smooth muscle 


\section{Discussion}

dependent dilators, then the aforementioned hypothesis of a transient reduction in smooth muscle function due to a mechanoadaption would be supported. If the profunda only responds to smooth muscle and not endothelial dependent dilators, then this would support the hypothesis that the impairment is endothelial dependent.

Although impaired vascular function is not likely a result of smooth muscle cell proliferation in the profunda, as mentioned above, it is possible that SMCs are the cause of vascular impairment in the gracilis collaterals. The gracilis collaterals enlarged over the two week period following a femoral artery ligation. A t-test shows that the average cross-sectional areas from day $7\left(=805 \mu \mathrm{m}^{2}\right)$ and day $14\left(=2237 \mu \mathrm{m}^{2}\right)$ are significantly different from that of day 0 averages $\left(=417 \mu \mathrm{m}^{2}\right)$, with $\mathrm{p}$-values of 0.0352 and 0.0007 respectively. Also, a one-way ANOVA showed that the average CSA at day 14 was significantly different from that at days 3 and 7. This data is consistent with many other studies in which we see significant collateral growth over a two week time period following an upstream arterial occlusion.

Since SMCs were proliferating at day 3 and day 7 following a ligation in the gracilis collaterals, the next logical experimental step would be to examine vascular function in this region of the collateral circuit following an occlusion. This experiment would require the use of a multiphoton fluorescence microscope, as the gracilis collaterals are too deep to examine via traditional intravital microscopy. At each time point following the ligation surgeries (day 3, day 7, day 14), fluoropores would be injected into the vasculature in order to make the collaterals visible via fluorescent microscopy. Once visible, functional 
measurements can be taken following the application of SNP and acetylcholine to determine the functionality of both endothelial and smooth muscle cells. If there is little functional response to SNP and these responses parallel the same time course as smooth muscle proliferation, this would strongly suggest that vascular impairment is smooth muscle dependent in the gracilis collaterals following a ligation.

\section{Conclusions}

At days 3 and 7 following a femoral artery ligation, we observed proliferating smooth muscle cells in the gracilis collaterals as well as significant collateral vessel growth over a two week period. This study correlated well with previous studies in that proliferation followed a similar time course, and significant vessel growth was observed. As mentioned above, the next logical step would be to determine if the time course of proliferation parallels with functional impairment in the gracilis collaterals. If there is a parallel, then this would strongly suggest that the impairment in the gracilis collaterals is due to smooth muscle dysfunction during their phenotypic transition.

Following the same ligation we did not observe any proliferation in the profunda femoris and although there was an increasing trend in vessel size over the two week period, none

of the averages were significantly different. These results differed from those of previous studies performed within the lab group. The previous studies also differed in that one study observed impairment and one did not. For this reason, the next step should be to make functional measurements again to determine if there is impairment in the profunda after a ligation. If there is no impairment then my results would make sense, since there is 


\section{Discussion}

no SMC proliferation. If there is impairment, then we know that smooth muscle cell proliferation is not the cause, and further tests need to be done to find the cause of this vascular dysfunction. 


\section{Bibliography}

1. Berne, R.M. and M.N. Levy, Cardiovascular physiology. 8th ed. The Mosby physiology monograph series. 2001, St. Louis, MO: Mosby. xiv, 312 p.

2. Galkina, E. and K. Ley, Immune and inflammatory mechanisms of atherosclerosis (*). Annu Rev Immunol, 2009. 27: p. 165-97.

3. Schaper, W. and D. Scholz, Factors regulating arteriogenesis. Arterioscler Thromb Vasc Biol, 2003. 23(7): p. 1143-51.

4. Berne, R.M., B.M. Koeppen, and B.A. Stanton, Berne \& Levy physiology. 6th ed. 2010, Philadelphia, PA: Mosby/Elsevier. xii, 836 p.

5. Nelson, M.T., et al., Calcium channels, potassium channels, and voltage dependence of arterial smooth muscle tone. Am J Physiol, 1990. 259(1 Pt 1): p. C3-18.

6. Scholz, D., et al., Contribution of arteriogenesis and angiogenesis to postocclusive hindlimb perfusion in mice. J Mol Cell Cardiol, 2002. 34(7): p. 77587.

7. Benest, A.V., et al., VEGF and angiopoietin-1 stimulate different angiogenic phenotypes that combine to enhance functional neovascularization in adult tissue. Microcirculation, 2006. 13(6): p. 423-37.

8. $\quad$ Risau, W., Mechanisms of angiogenesis. Nature, 1997. 386(6626): p. 671-4.

9. Kasapis, C. and H.S. Gurm, Current approach to the diagnosis and treatment of femoral-popliteal arterial disease. A systematic review. Curr Cardiol Rev, 2009. 5(4): p. 296-311.

10. Norgren, L., et al., Inter-Society Consensus for the Management of Peripheral Arterial Disease (TASC II). Eur J Vasc Endovasc Surg, 2007. 33 Suppl 1: p. S175.

11. Fowkes, F.G., et al., Edinburgh Artery Study: prevalence of asymptomatic and symptomatic peripheral arterial disease in the general population. Int $\mathbf{J}$ Epidemiol, 1991. 20(2): p. 384-92.

12. Peripheral arterial disease in people with diabetes. Diabetes Care, 2003. 26(12): p. 3333-41.

13. Hooi, J.D., et al., Asymptomatic peripheral arterial occlusive disease predicted cardiovascular morbidity and mortality in a 7-year follow-up study. J Clin Epidemiol, 2004. 57(3): p. 294-300.

14. Chen, Z., et al., Cholesterol in human atherosclerotic plaque is a marker for underlying disease state and plaque vulnerability. Lipids Health Dis, 2010. 9: p. 61.

15. Collaborative meta-analysis of randomised trials of antiplatelet therapy for prevention of death, myocardial infarction, and stroke in high risk patients. BMJ, 2002. 324(7329): p. 71-86. 
16. Thompson, P.D., et al., Meta-analysis of results from eight randomized, placebocontrolled trials on the effect of cilostazol on patients with intermittent claudication. Am J Cardiol, 2002. 90(12): p. 1314-9.

17. Pacilli, A., et al., An update on therapeutic angiogenesis for peripheral vascular disease. Ann Vasc Surg, 2010. 24(2): p. 258-68.

18. Schillinger, M., et al., Sustained benefit at 2 years of primary femoropopliteal stenting compared with balloon angioplasty with optional stenting. Circulation, 2007. 115(21): p. 2745-9.

19. Duda, S.H., et al., Drug-eluting and bare nitinol stents for the treatment of atherosclerotic lesions in the superficial femoral artery: long-term results from the SIROCCO trial. J Endovasc Ther, 2006. 13(6): p. 701-10.

20. Poredos, P., M. Golob, and M. Jensterle, Interrelationship between peripheral arterial occlusive disease, carotid atherosclerosis and flow mediated dilation of the brachial artery. Int Angiol, 2003. 22(1): p. 83-7.

21. Colleran, P.N., et al., Vasoresponsiveness of collateral vessels in the rat hindlimb: influence of training. J Physiol, 2010. 588(Pt 8): p. 1293-307.

22. Takeshita, S., et al., Endothelium-dependent relaxation of collateral microvessels after intramuscular gene transfer of vascular endothelial growth factor in a rat model of hindlimb ischemia. Circulation, 1998. 98(13): p. 1261-3.

23. Quintavalle, M., et al., MicroRNA control of podosome formation in vascular smooth muscle cells in vivo and in vitro. J Cell Biol, 2010. 189(1): p. 13-22.

24. Halayko, A.J. and J. Solway, Molecular mechanisms of phenotypic plasticity in smooth muscle cells. J Appl Physiol, 2001. 90(1): p. 358-68.

25. Okamoto, E., et al., Diversity of the synthetic-state smooth-muscle cells proliferating in mechanically and hemodynamically injured rabbit arteries. Lab Invest, 1996. 74(1): p. 120-8.

26. Sakurai, S., et al., Embryonic form of smooth muscle myosin heavy chain (SMemb/MHC-B) in gastrointestinal stromal tumor and interstitial cells of Cajal. Am J Pathol, 1999. 154(1): p. 23-8.

27. Scholzen, T. and J. Gerdes, The Ki-67 protein: from the known and the unknown. J Cell Physiol, 2000. 182(3): p. 311-22.

28. Scholz, D., et al., Ultrastructure and molecular histology of rabbit hind-limb collateral artery growth (arteriogenesis). Virchows Arch, 2000. 436(3): p. 25770.

29. Heilmann, C., F. Beyersdorf, and G. Lutter, Collateral growth: cells arrive at the construction site. Cardiovasc Surg, 2002. 10(6): p. 570-8.

30. Opitz, F., et al., Phenotypical plasticity of vascular smooth muscle cells-effect of in vitro and in vivo shear stress for tissue engineering of blood vessels. Tissue Eng, 2007. 13(10): p. 2505-14.

31. Martinez-Lemus, L.A., et al., Acute mechanoadaptation of vascular smooth muscle cells in response to continuous arteriolar vasoconstriction: implications for functional remodeling. FASEB J, 2004. 18(6): p. 708-10.

32. Martinez-Lemus, L.A., M.A. Hill, and G.A. Meininger, The plastic nature of the vascular wall: a continuum of remodeling events contributing to control of arteriolar diameter and structure. Physiology (Bethesda), 2009. 24: p. 45-57. 
Appendix

\title{
Appendix
}

\author{
Protocols
}

$\underline{\text { Femoral Artery Ligation Protocol }}$

Materials

Sterilize- autoclave or flash autoclave

1. forceps (2)

2. fine forceps (2)

3. ultrafine forceps (1)

4. fine scissors (1)

5. microscissors spring loaded (1)

Pre-sterilize in autoclave

6. cotton gauze (2)

7. cotton swabs (12)

8. $\quad 6.0$ silk suture $(2 \times 1$-inch)

9. needle holder (1)

Obtained in surgery suite

10. sterile Petri dish w/ sterile saline

11. sterile gloves

12. sterile 7.0 prolene suture

13. heat-cautery

14. FST heat pad w/ rectal probe

15. heat pad

16. recovery bin $\&$ weigh boat

17. depilatory cream

18. non-sterile cotton swabs

19. non-sterile cotton gauze

20. isolation mask \& cap

21. analgesic (Buprenorphine)

Surgery preparation

22. Spray surgery area with Nolvasan 
23. Weigh animal in weight boat

24. Place animal in anesthesia box

25. Open the oxygen cylinder and set anesthesia-machine flow meter to $\sim 31 \cdot \mathrm{min}^{-1}$

26. Anesthetize animal $\mathrm{w} / 5 \%$ isoflurane

27. Affix non-rebreathing circuit to bench-top with tape

28. Reduce flow rate to $0.5-1.01 \cdot \mathrm{min}^{-1}$ and the isoflurane to $1-3 \%$

29. Apply ear tag high on left ear

30. Lay animal supine with nose in nose-cone

31. Shave hair on the right hindlimb \& lower abdomen with clippers

32. Remove excess hair with depilatory cream

33. Spray right hindlimb with Nolvasan

34. Return animal to anesthesia box

35. Apply $4 x 4$ gauze sponge to heat pad to protect animal from excessive heat

36. Affix non-rebreathing circuit to surgery table w/ chemistry clamp

37. Lay animal supine on circulating heat pad $\mathrm{w} /$ nose in nose-cone

38. Insert rectal probe and set thermo-controller to $37^{\circ} \mathrm{C}$

39. Apply veterinary ointment to eyes to avoid drying during procedure

40. Apply veterinary ointment to anus and place rectal probe $\sim 1 \mathrm{~cm}$ into anus to monitor core-body temperature

Surgery

41. Make a small incision on the middle, medial aspect of the left thigh

42. Extend the incision up to the abdominal wall

43. Blunt dissect the subcutaneous connective tissue to maximize surgical exposure

44. Use cautery to remove fat pad overlying femoral a-v pair \& cauterize epigastric av-pair

45. Blunt dissect the femoral artery from the neurovascular bundle just downstream from the deep femoral branch

46. Tie off the femoral artery \& vein with 6.0 silk suture, just downstream to the deep femoral branch

47. Use 6.0 polypropylene suture to close the skin

48. Make a small incision on the middle, medial aspect of the right thing

49. Extend the incision up to the abdominal wall

50. Blunt dissect the subcutaneous connective tissue to maximize surgical exposure

51. Use 6.0 polypropylene suture to close the skin 
Post-Surgical

52. Give the animal an subcutaneous injection of buprenorphine $(0.075 \mathrm{mg} / \mathrm{kg})$

53. Place the animal in the recovery bin, on a blue bench cover, above a heat pad and allow to recover

54. Turn flow meter down to 0 , turn off isoflurane, and close the oxygen cylinder

55. Indicate surgery on cage card

\section{$\underline{\text { Perfusion Fixation Protocol }}$}

Materials

Non-Sterilize Dissection Instruments

56. forceps (2)

57. fine forceps (2)

58. Bone Scissors(1)

59. Skin Scissors (1)

60. Dissection Scissors (1)

61. Hemostats(1)

62. Vascular clamp (1)

Obtained in surgery suite

63. Tape

64. $10 \mathrm{~mL}$ Syringes (2)

65. Bench cover

66. Heating pad

67. Catheter

68. Avertin Anesthetic

69. Non-sterile saline

70. Cotton swab

Vasodilator Cocktail Preparation

71. Turn on water bath to $37^{\circ} \mathrm{C}$

72. $400 \mu \mathrm{L}$ heparin

73. $1 \mathrm{~mL} \mathrm{SNP(orange)}$

74. $600 \mu \mathrm{L}$ Adenosine(clear)

75. 38mL PBS solution

76. Thaw SNP and Adenosine

77. Add heparin, SNP, Adenosine, and PBS solution together in a 50mL conical

78. Place vasodilator cocktail in water bath 
Appendix

79. Prepare $15 \mathrm{~mL}$ of histochoice in a $50 \mathrm{~mL}$ conical and place in water bath

Procedure Preparation

80. Weigh animal and draw up appropriate dose of Avertin anesthetic $(.15 \mathrm{~mL} / 10 \mathrm{~g})$

81. Obtain saline filled beaker, cotton swab, and instruments

Fixation

82. Anesthize mouse with Avertin

83. Heat up heat pad in microwave and wrap with bench cover when warm

84. Remove hindlimb hair on both legs by shaving

85. Tape animal down to heated bench cover

86. Separate skin from muscle from the abdomen to the top of the thoracic cavity

87. Fill $10 \mathrm{~mL}$ syringe with warm Vaso D

88. Cut through abomen close to diaphragm

89. Quickly cut through the ribs and diaphragm to open chest cavity and clamp back with hemostats

90. Cut away excess tissue around the heart

91. Make a small incision in the apex of the heart

92. Insert catheter and clamp with vascular clamp and cut right ventricle

93. Inject Vaso D solution into animal approximately $20 \mathrm{~mL}$

94. Inject $12 \mathrm{~mL}$ of histochoice

95. Dissect the muscular branch and gracilis muscle preserve in histochoice

$\underline{\text { Ki-67 Immunohistochemistry Protocol }}$

Materials

Histology Components

96. Microscope slides

97. Staining dishes (4)

98. Incubating chamber

99. Hydrophobic pen

100. Microscope slide rack

101. Hemostats

102. Mounting Medium

103. Cover slips 
Reagents Checklist (See protocol appendix for reagent preparation)

104. Xylene

105. $100 \%$ EtoH

106. $95 \% \mathrm{EtoH}$

107. Distilled Water

108. Phosphate Buffered Saline

109. Promega Proteinase $\mathrm{K}^{*}$

110. PBST*

111. Hydrogen Peroxide $\left(\mathrm{H}_{2} \mathrm{O}_{2}\right)$

112. Blocking Serum*

113. Ki-67 primary antibody*

114. Biotinylated secondary antibody*

115. AB Enzyme*

116. Peroxidase Substrate*

Sample Preparation and Rehydration

117. Section desired number of blocks on a desired number of slides

118. Place slides in a slide rack and put in oven/incubator and turn dial to "7" and remove when wax has melted

119. While was is melting, prepare four staining dishes with the following reagents: xylene, $100 \% \mathrm{EtoH}, 95 \% \mathrm{EtoH}$, and distilled $\mathrm{H}_{2} \mathrm{O}$.

120. When wax is melted, place slide rack in xylene dish for 10 minutes.

121. Place slides in $100 \% \mathrm{EtoH}$ for 2 minutes (x2).

122. Place slides in $95 \%$ EtoH for 2 minutes.

123. Place slides in distilled for 2 minutes.

Staining Procedure

124. Remove slides one by one from distilled water, circle samples with hydrophobic pen, and place in incubator.

125. Incubate samples in Proteinase $\mathrm{K}$ working solution for 10 minutes.

126. Wash with PBS for 5 minutes.

127. Incubate in PBST for 15 minutes.

128. Wash with PBS for 5 minutes.

129. Block non-specific peroxidase binding with $\mathrm{H}_{2} \mathrm{O}_{2}$ for 10 minutes.

130. Wash with distilled $\mathrm{H}_{2} \mathrm{O}$ for 5 minutes.

131. Block samples with blocking serum for 30 minutes.

132. Apply Ki-67 primary antibody to one sample on the slide (leaving only blocking serum on the other sample for a positive control) and incubate over night at $4^{\circ} \mathrm{C}$.

133. Wash with PBS for 5 minutes

134. Incubate in biotinylated secondary antibody for 30 minutes

135. Immediately after applying secondary antibody, prepare AB enzyme. 
136. Wash with PBS for 5 minutes

137. Apply AB enzyme and incubate for 30 minutes

138. Wash with PBS for 5 minutes

139. Apply peroxidase substrate and incubate for 5 minutes

140. Wash slides in distilled $\mathrm{H}_{2} \mathrm{O}$

141. Dip slides in $95 \%$ EtoH for 10 seconds (x2)

142. Dip slides in $100 \%$ EtoH for 10 seconds (x2)

143. Dip slides in xylene for 10 seconds (x3)

144. Mount slides with mounting medium and allow them to dry over night.

\section{Reagent Preparation}

All working solutions can be stored @ $4^{\circ} \mathrm{C}$ for 2-3 weeks unless otherwise specified.

Proteinase K working solution:

Use Promega Proteinase K (Specific Activity: 30u/mg) and dilute 1:500 in PBS.

Phosphate Buffered Saline /w Triton X-100(PBST):

Use $1 \%$ Triton $\mathrm{x}-100$ in PBS (i.e. .05mL of Triton

$\mathrm{X}-100$ in $5 \mathrm{~mL}$ of PBS)

Blocking Serum:

Use the same blocking serum in which your

secondary antibody was raised (i.e. if you're using a

donkey anti-rabbit secondary antibody, use

donkey blocking serum). Add $75 \mu \mathrm{L}$ of blocking

serum stock to $5 \mathrm{~mL}$ of PBST for blocking serum

working solution.

Ki-67 Primary antibody:

Use Abcam Ki-67 rabbit polyclonal primary antibody (ab15580), use a 1:200 dilution in blocking serum working solution (i.e. $10 \mu \mathrm{L}$ of

primary antibody stock in $2 \mathrm{~mL}$ of blocking serum working solution).

Biotinylated Secondary antibody:

Since primary antibody is a rabbit polyclonal, use an "anti-rabbit" secondary antibody (i.e.

donkey anti-rabbit). For working solution add $75 \mu \mathrm{L}$

of blocking serum stock and $25 \mu \mathrm{L}$ of secondary antibody stock to $5 \mathrm{~mL}$ of PBS. 


\begin{abstract}
AB Enzyme:
Use Vector Labs Vectastain Elite ABC reagent. For working solution, add two drops of Reagent A, and two drops of Reagent $\mathrm{B}$ to $5 \mathrm{~mL}$ of PBS, mix immediately and allow $\mathrm{ABC}$ reagent to stand for about 30 minutes before use.

Peroxidase Substrate:

Prepare substrate before use every time, do not store. For working solution add one drop of peroxidase substrate, one drop of DAB chromagen, and 5 drops of $10 \mathrm{x}$ substrate buffer to $1.6 \mathrm{~mL}$ of distilled water.
\end{abstract}

Smooth Muscle Cell Phenotyping Immunofluorescence Protocol

Materials

Histology Components

145. Microscope slides

146. Staining dishes (4)

147. Incubating chamber

148. Hydrophobic pen

149. Microscope slide rack

150. Aluminum Foil

151. Hemostats

152. Cover slips

Reagents Checklist (See Appendix for reagent preparation)

153. Xylene

154. $100 \%$ EtoH

155. $95 \%$ EtoH

156. Distilled Water

157. Phosphate Buffered Saline

158. Promega Proteinase $\mathrm{K}^{*}$

159. PBST*

160. Blocking Serum*

161. Ki-67 primary antibody*

162. Ki-67 fluorescent anti-rabbit secondary antibody*

163. SM $\alpha$-actin fluorescent complex**

164. $10 \%$ Formalin

165. BBI*

166. Fluorescent mounting medium 
Sample Preparation and Rehydration

167. Section desired number of blocks on a desired number of slides

168. Place slides in a slide rack and put in oven/incubator and turn dial to " 7 " and remove when wax has melted

169. While wax is melting, prepare four staining dishes with the following reagents: xylene, $100 \% \mathrm{EtoH}, 95 \% \mathrm{EtoH}$, and distilled $\mathrm{H}_{2} \mathrm{O}$.

170. When wax is melted, place slide rack in xylene dish for 10 minutes.

171. Place slides in $100 \%$ EtoH for 2 minutes ( 2 2).

172. Place slides in $95 \%$ EtoH for 2 minutes.

173. Place slides in distilled for 2 minutes.

Staining Procedure

174. Remove slides one by one from distilled water, circle samples with hydrophobic pen, and place in incubator.

175. Incubate samples in Proteinase $\mathrm{K}$ working solution for 10 minutes.

176. Wash with PBS for 5 minutes.

177. Incubate in PBST for 15 minutes.

178. Wash with PBS for 5 minutes.

179. Block samples with blocking serum for 30 minutes.

180. Incubate in Ki-67 primary antibody over night at $4^{\circ} \mathrm{C}$

181. Wash with PBS for 5 minutes

182. Cover incubator in aluminum foil to protect from the light for rest of procedure

183. Incubate in Ki-67 fluorescent anti-rabbit secondary antibody for 90 minutes

184. Wash with PBST for 5 minutes

185. Incubate in SM $\alpha$-actin fluorescent complex for 45 minutes

186. Wash with PBST for 10 minutes (x3)

187. Wash with PBS for 5 minutes (x2)

188. Fix samples with $10 \%$ formalin for 15 minutes

189. Wash slides with PBS

190. Incubate samples in BBI for 10 minutes

191. Wash slides with PBS

192. Mount slides with fluorescent mounting medium, protect them from light, and allow them to dry over night 


\section{Reagent Preparation}

*All working solutions can be stored @ $4^{\circ} \mathrm{C}$ for 2-3 weeks unless otherwise specified.

**SM $\alpha$-actin fluorescent complex needs to be used within 30 minutes of preparing it.

Proteinase K working solution:

Use Promega Proteinase K (Specific Activity: 30u/mg) and dilute 1:500 in PBS.

Phosphate Buffered Saline /w Triton X-100 (PBST):

Use $0.1 \%$ Triton $\mathrm{x}-100$ in PBS (i.e. .05mL of Triton $\mathrm{X}-100$ in $50 \mathrm{~mL}$ of PBS)

Blocking Serum:

Use the same blocking serum in which your secondary antibody was raised (i.e. if you're using a donkey anti-rabbit secondary antibody, use donkey blocking serum). Add $75 \mu \mathrm{L}$ of blocking serum stock to $5 \mathrm{~mL}$ of PBST for blocking serum working solution.

Ki-67 Primary antibody:

Use Abcam Ki-67 rabbit polyclonal primary antibody (ab15580, Lot \#GR21314-1), use a 1:200 dilution in blocking serum working solution (i.e. $10 \mu \mathrm{L}$ of primary antibody stock in $2 \mathrm{~mL}$ of blocking serum working solution).

Ki-67 fluorescent anti-rabbit secondary antibody: Since primary antibody is a rabbit polyclonal, use an "anti-rabbit" secondary antibody (i.e. donkey anti-rabbit). For working solution dilute anti-rabbit fluorescent secondary antibody 1:1000 in blocking serum working solution (i.e. add $5 \mu \mathrm{L}$ of fluorescent $2^{\circ}$ ab to $5 \mathrm{~mL}$ of donkey serum in PBST).

$\underline{\text { SM } \alpha \text {-actin fluorescent complex: }}$

**Complex must be used with in 30 minutes of preparing it. For 10 slides, add $10 \mu \mathrm{L}$ of sm $\alpha$-actin to $0.5 \mathrm{~mL}$ of PBS. Add $5 \mu \mathrm{L}$ of the desired color of the Zenon labeling component, shake, and incubate for 5 minutes. Add $5 \mu \mathrm{L}$ of Zenon blocking serum, shake and incubate for 5 minutes. Add $.5 \mathrm{~mL}$ of blocking serum working solution. Use within 30 minutes.

BBI fluorescent nuclear stain:

Dilute BBI stock 1:1000 in $18 \mathrm{~m} \Omega \mathrm{H}_{2} \mathrm{O}$ (i.e. $10 \mu \mathrm{L}$ of BBI in $10 \mathrm{~mL}$ of $18 \mathrm{~m} \Omega \mathrm{H}_{2} \mathrm{O}$ ). 
Appendix

Vessel Morphology and Phenotype Raw Data

Day 3

Ligated Left

Gracilis

Block Number

Cross-Sectional

11-222 a

$11-222$ b Area $\left(\mu \mathrm{m}^{2}\right)$

Proliferating

11-230 a

$11-230 \mathrm{~b}$

11-234 a

11-234 b

11-238 a

$11-238 \mathrm{~b}$

11-242

Average

Standard

Deviation

Standard Error

$$
\text { Area }\left(\mu \mathrm{m}^{2}\right)
$$

486.4

441.2

735.3

1928.9

697.1

630.4

867.2

257.9

455.2

722.1777778

Smooth Muscle

Cell Count

$$
\text { Smooth Muscle }
$$

Cell Count

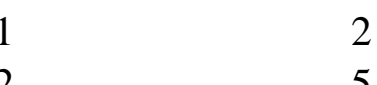

25

$0 \quad 3$

26

$3 \quad 3$

24

23

12

1

1.555555556

3.333333333

488.3396456

0.836660027

0.836660027

162.7798819

0.278886676

0.278886676

$\underline{\text { Ligated Left }}$

Muscular Branch

Block Number

11-223

11-227

11-231

11-235

11-239

11-243

Average

Standard

Deviation

Standard Error

Cross-Sectional Area $\left(\mu \mathrm{m}^{2}\right)$

1735.2

2008.1

1965.8

1750.1

639.4

1764.1

1643.783333

505.8346742

206.506141
Proliferating

Smooth Muscle Smooth Muscle Cell Count

Cell Count 0

$0 \quad 12$

$0 \quad 6$

$0 \quad 10$

$0 \quad 4$

$0 \quad 9$

$0 \quad 8.166666667$

$0 \quad 2.857738033$

$0 \quad 1.166666667$ 
Appendix

Non-Ligated

$\underline{\text { Right Gracilis }}$

Block Number

11-178

11-224

11-228

11-232

11-244

Average

Standard

Deviation

Standard Error

Non-Ligated

Right Muscular

Branch

Block Number

11-225

11-229

11-233

11-237

11-241

11-245

Average

Standard

Deviation

Standard Error

$$
\text { Cross-Sectional }
$$
Area $\left(\mu \mathrm{m}^{2}\right)$ 553.7 259.5 583.8

224.2

407.6

405.76

164.2740789

73.46560147
Proliferating

Smooth Muscle Smooth Muscle Cell Count Cell Count

$\begin{array}{lr}0 & 1 \\ 0 & 2 \\ 0 & 3 \\ 0 & 1 \\ 0 & 2 \\ 0 & 1.8\end{array}$

0

0.836660027

0.374165739
Proliferating

Cross-Sectional Area $\left(\mu \mathrm{m}^{2}\right)$ 4797.7

3113.2

538.8

902.2

2780.3

925.7

2176.316667

1672.308165

682.7169494 Cell Count
Smooth Muscle

Smooth Muscle Cell Count

$\begin{array}{rr}0 & 14 \\ 0 & 8 \\ 0 & 9 \\ 0 & 6 \\ 0 & 11 \\ 0 & 6 \\ 0 & 9 \\ & \\ 0 & 3.098386677 \\ 0 & 1.264911064\end{array}$


Appendix

Day 7

Ligated Left

Gracilis

Block Number
$11-198 \mathrm{a}$
$11-198 \mathrm{~b}$
$11-210 \mathrm{a}$
$11-210 \mathrm{~b}$
$11-218 \mathrm{a}$
$11-218 \mathrm{~b}$
Average
Standard
Deviation
Standard Error

\begin{tabular}{rlrl}
\multicolumn{1}{l}{$\begin{array}{l}\text { Proliferating } \\
\text { Cross-Sectional }\end{array}$} & $\begin{array}{l}\text { Smooth Muscle } \\
\text { Area }\left(\mu \mathrm{m}^{2}\right)\end{array}$ & \multicolumn{2}{l}{$\begin{array}{l}\text { Smooth Muscle Cell } \\
\text { Cell Count }\end{array}$} \\
747.8 & 3 & 3 \\
680.6 & 3 & 6 \\
1207.8 & 3 & 3 \\
980 & 0 & 1 \\
669.5 & 4 & 6 \\
545.7 & 2 & 3 \\
805.2333333 & 2.5 & 1.6666666667 \\
243.8099478 & & & \\
99.5349944 & 0.562731434 &
\end{tabular}

Ligated Left

$\underline{\text { Muscular Branch }}$

Block Number

11-199

11-203

11-207

11-215

Average

Standard

Deviation

Standard Error

$\begin{aligned} & \text { Proliferating } \\ \text { Cross-Sectional } & \text { Smooth Muscle } \\ \text { Area }\left(\mu \mathrm{m}^{2}\right) & \text { Cell Count } \\ 1403.9 & \\ 475 & \\ 763.8 & \\ 4514.6 & \\ 1789.325 & \end{aligned}$

Smooth Muscle Cell
Count

1857.850728

2.708012802

928.9253642

0

1.354006401 
Appendix

Non-Ligated

$\underline{\text { Right Gracilis }}$

Block Number

$\begin{aligned} \text { Cross-Sectional } & \text { Proliferating } \\ \text { Area }\left(\mu \mathrm{m}^{2}\right) & \text { Smooth Muscle } \\ 238.3 & \\ 422.2 & \\ 687.4 & \\ 827.7 & \\ 126.2 & \\ 460.36 & \end{aligned}$

\section{Smooth Muscle Cell}

Count

11-204 a

11-204 b

11-208

11-212

11-220

Average

Standard

Deviation

295.3453792

Standard Error

132.0824689

0

04

$0 \quad 3$

0

$0 \quad 1$

$0 \quad 2.6$

$\begin{array}{ll}0 & 1.516575089 \\ 0 & 0.678232998\end{array}$

Non-Ligated

Right Muscular

Branch

Block Number

11-205

11-209

11-213

11-217

11-221

Average

Standard

Deviation

Standard Error

$\begin{aligned} & \text { Proliferating } \\ \text { Cross-Sectional } & \text { Smooth Muscle } \\ \text { Area }\left(\mu \mathrm{m}^{2}\right) & \text { Cell Count } \\ 1407.2 & \\ 815.7 & \\ 1786.3 & \\ 1217 & \\ 2616 & \\ 1568.44 & \end{aligned}$
Smooth Muscle Cell Count

$0 \quad 5$

$0 \quad 6$

0

0

$0 \quad 10$

$\begin{array}{ll}0 & 7\end{array}$

$\begin{array}{rrr}682.0870274 & 0 & 2 \\ 305.038592 & 0 & 0.894427191\end{array}$


Appendix

Day 14

\section{Ligated Left}

$\underline{\text { Gracilis }}$

Cross-

Sectional Proliferating Smooth Smooth Muscle

Block Number Area $\left(\mu \mathrm{m}^{2}\right) \quad$ Muscle Cell Count Cell Count

$11-246$ 2074.7 890.7

$11-254$

2961.5

$11-258$

2262.2

$11-262$ a

3461.1

2545.9

1464.4

2237.214286

871.3161241

329.3265397

$\begin{array}{ll}0 & 1.397276262 \\ 0 & 0.528120786\end{array}$

Standard Error

Ligated Left

Muscular

Branch

Block Number

Cross-

Sectional

11-195

11-251

11-255

Area $\left(\mu \mathrm{m}^{2}\right)$ 854.4

Proliferating Smooth

Smooth Muscle

11-259

1762.6

Muscle Cell Count

Cell Count

2144.3

4539

0.528120786

$11-263 b$

1751.4

11-265

Average

2382.4

0

Standard

Deviation

2239.016667

0

8

Standard Error

1241.076914

1.505545305

506.6675283

$0 \quad 0.614636297$


Appendix

Non-Ligated

Right Gracilis

\begin{tabular}{|c|c|c|c|}
\hline Block Number & $\begin{array}{l}\text { Cross- } \\
\text { Sectional } \\
\text { Area }\left(\mu \mathrm{m}^{2}\right)\end{array}$ & $\begin{array}{l}\text { Proliferating Smooth } \\
\text { Muscle Cell Count }\end{array}$ & $\begin{array}{l}\text { Smooth Muscle } \\
\text { Cell Count }\end{array}$ \\
\hline $11-248$ & 435 & 0 & 3 \\
\hline $11-252$ & 273.5 & 0 & 2 \\
\hline $11-260$ & 493.2 & 0 & 2 \\
\hline $11-264 b$ a & 447.1 & 0 & 2 \\
\hline $11-264 b$ b & 269.1 & 0 & 2 \\
\hline Average & 383.58 & 0 & 2.2 \\
\hline $\begin{array}{l}\text { Standard } \\
\text { Deviation }\end{array}$ & 104.7838585 & 0 & 0.447213595 \\
\hline $\begin{array}{l}\text { Standard Error } \\
\frac{\text { Non-Ligated }}{\text { Right Muscular }} \\
\text { Branch }\end{array}$ & 46.86076611 & 0 & 0.2 \\
\hline Block Number & $\begin{array}{l}\text { Cross- } \\
\text { Sectional } \\
\text { Area }\left(\mu \mathrm{m}^{2}\right)\end{array}$ & $\begin{array}{l}\text { Proliferating Smooth } \\
\text { Muscle Cell Count }\end{array}$ & $\begin{array}{l}\text { Smooth Muscle } \\
\text { Cell Count }\end{array}$ \\
\hline $11-249$ & 2258.1 & 0 & 12 \\
\hline $11-253$ & 1028.4 & 0 & 7 \\
\hline $11-257$ & 1339.7 & 0 & 8 \\
\hline $11-261$ & 2032 & 0 & 7 \\
\hline Average & 1664.55 & 0 & 8.5 \\
\hline $\begin{array}{l}\text { Standard } \\
\text { Deviation }\end{array}$ & 576.638376 & 0 & 2.380476143 \\
\hline Standard Error & 288.319188 & 0 & 1.190238071 \\
\hline
\end{tabular}


Appendix

$\underline{\text { Statistical Data }}$

Average Vessel Cross

Sectional Area $\left(\mu \mathrm{m}^{2}\right)$

LLG

Day 3 Day 7 Day 14

LLMB

$\begin{array}{lll}772.2 & 805.2 & 2237.2\end{array}$

NLRG

$\begin{array}{lll}1643.8 & 1789.3 & 2239\end{array}$

NLRMB

$405.8 \quad 460.4 \quad 383.6$

$2176.3 \quad 1568.4 \quad 1664.6$

Proliferating Smooth Muscle

Cells

LLG

LLMB

NLRG

NLRMB

\begin{tabular}{|c|c|c|}
\hline Day 3 & Day 7 & Day 14 \\
\hline 1.6 & 2.5 & 0 \\
\hline N/A & N/A & N/A \\
\hline N/A & N/A & N/A \\
\hline N/A & N/A & N/A \\
\hline
\end{tabular}

Smooth Muscle Cells

LLG

Day $3 \quad$ Day $7 \quad$ Day 14

LLMB

$\begin{array}{lll}3.3 & 3.7 & 5.4\end{array}$

NLRG

NLRMB

$\begin{array}{lll}8.2 & 9 & 7.7\end{array}$

$\begin{array}{lll}1.8 & 2.6 & 2.2\end{array}$

$\begin{array}{lll}9 & 7 & 8.5\end{array}$

ANOVA

ischemic Gracilis cross sectional area

$\begin{array}{lr}\text { M1 vs M2 nonsignificant } \\ \text { M1 vs M3 } & \\ \mathrm{P}<.01 & 0.000135 \\ \text { M2 vs M3 } & \\ \mathrm{P}<.01 & \\ \text { nonsignificant } & 0.829399 \\ \text { nonsignificant } & 0.666342 \\ \text { nonsignificant } & 0.666342 \\ & \\ \text { nonsignificant? } & 0.041199 \\ \text { nonsignificant } & 0.49327 \\ \text { nonsignificant } & 0.697779 \\ \text { nonsignificant } & 0.455587 \\ \text { nonsignificant } & 0.088831\end{array}$


Appendix

$\underline{\text { T-Tests }}$

$\mathrm{NI}=$ Nonischemic,

$\mathrm{I}=$ Ischemic p-value

NI vs. I Gracilis Day 3 area $\quad 0.052049$

NI vs. I MB Day 3 area $\quad 0.241757$

NI vs. I Gracilis Day 3 SMCs $\quad 0.012787$

NI vs. I MB Day 3 SMCs $\quad 0.319311$

NI vs. I Gracilis D-7 area $\quad 0.035269$

NI vs. I MB Day 7 area $\quad 0.41617$

NI vs. I Gracilis Day 7 SMCs 0.168312

NI vs. I MB Day 7 SMCs $\quad 0.136281$

NI vs. I Gracilis Day 14 area $\quad 0.000708$

NI vs. I MB Day 14 area $\quad 0.178619$

NI vs. I Gracilis Day 14 SMCs 0.000223

NI vs. I MB Day 14 SMCs $\quad 0.280574$

MB vs Gracilis cross sectional

area

Day 3

0.002464

Day 7

0.184761

Day 14

0.498843

MB vs gracilis vsmes

Day 3

0.003183

Day 7

0.00975

Day 14

0.010033

Proliferating vsmcs

day 3 vs 0

0.000368

day 7 vs 0

0.003374 
Appendix

Vessel Composite Images

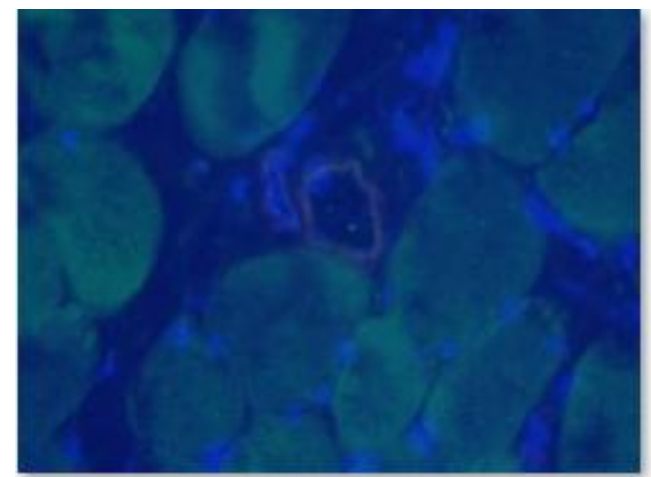

11-178 Composite

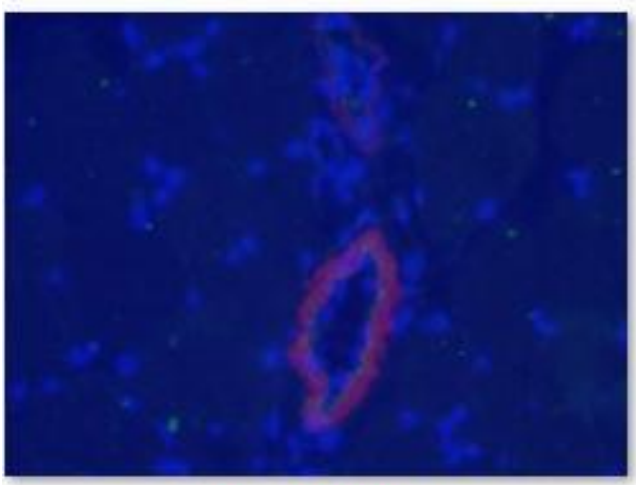

11-198 a Composite

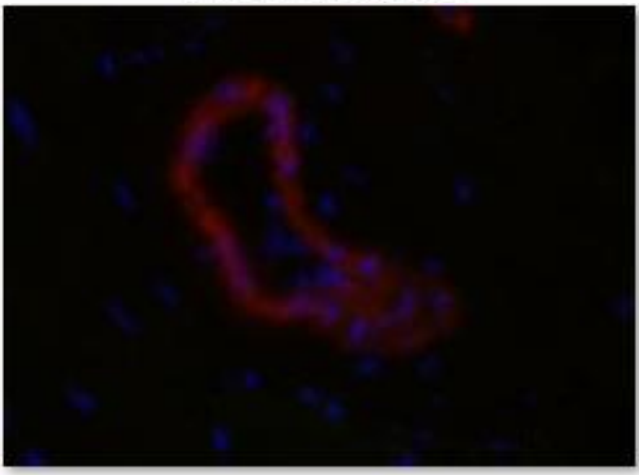

11-199 composite

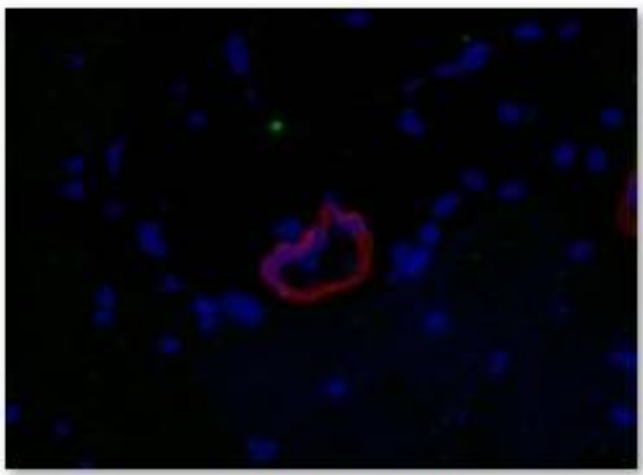

11-204 b composite

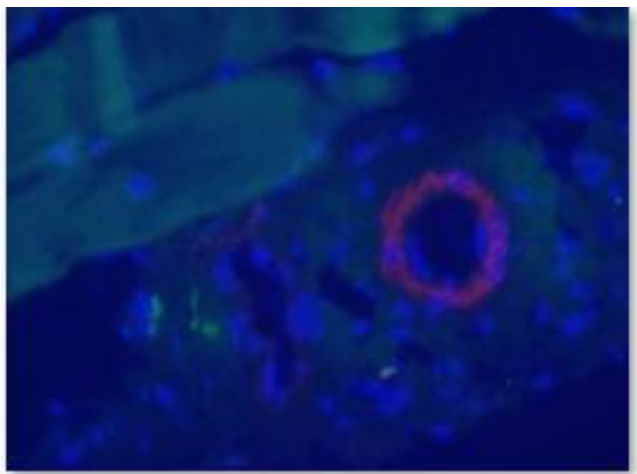

11-195-2 composite

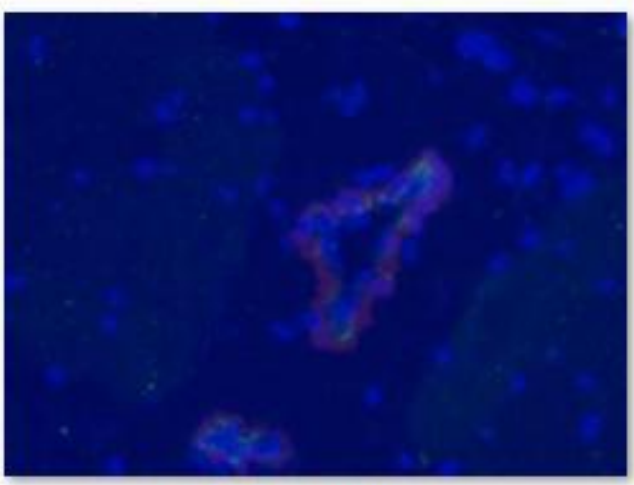

11-198 bComposite

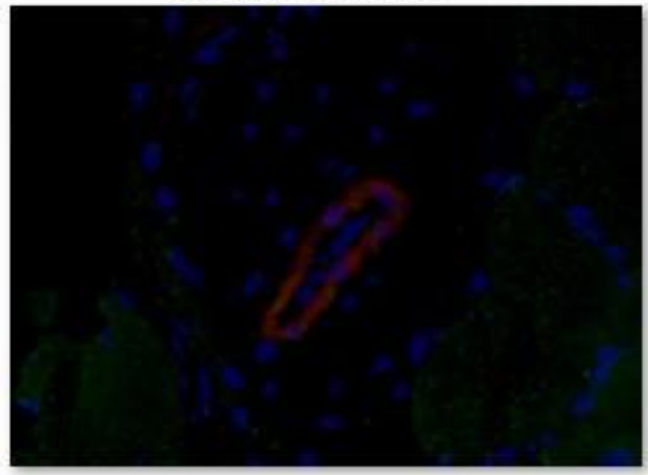

11-203 composite

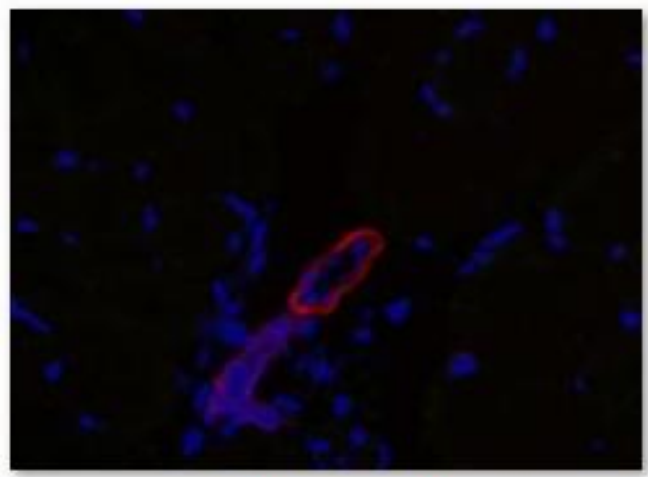

11-204 composite 
Appendix

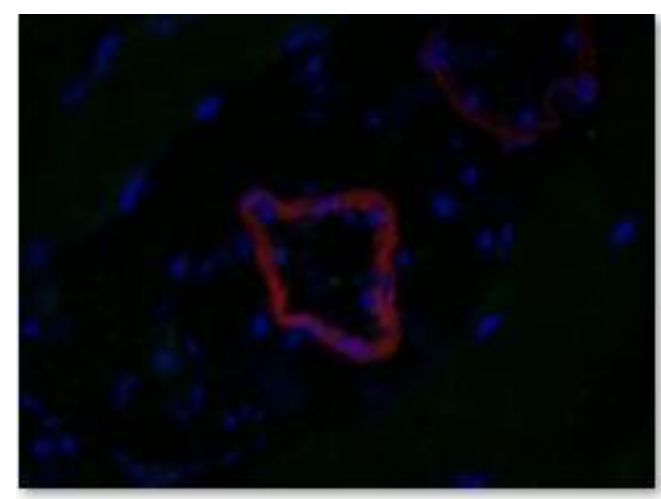

11-205 composite

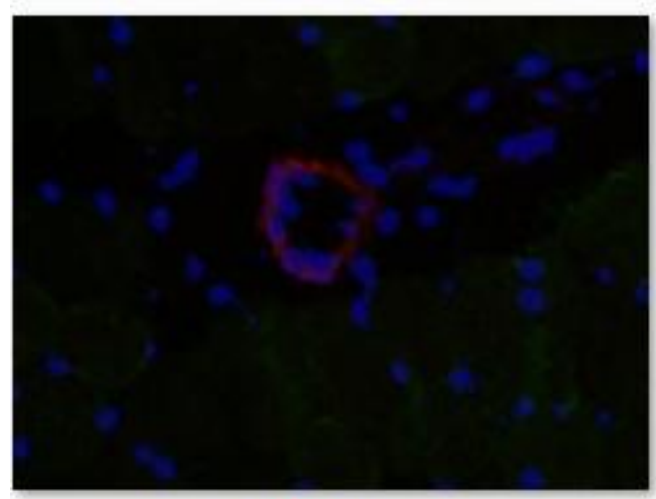

11-208 composite

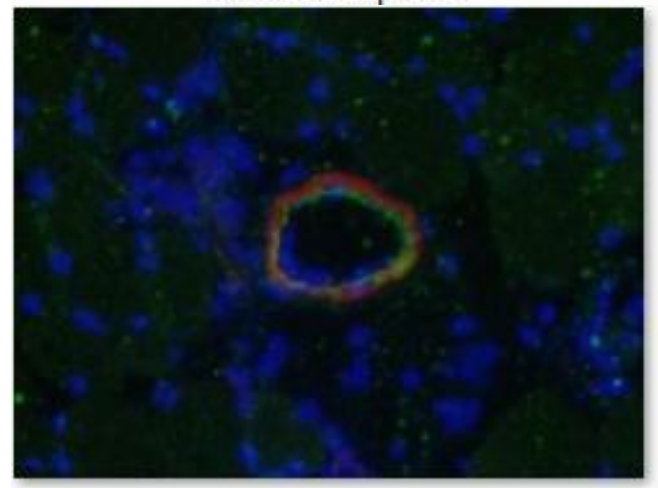

11-210 a composite

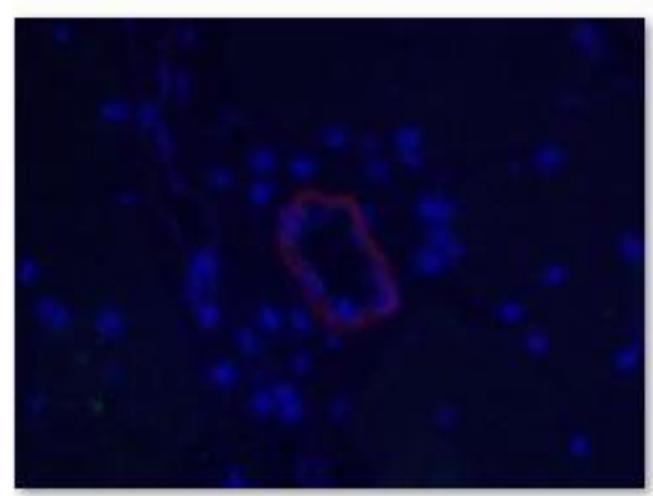

11-212 composite

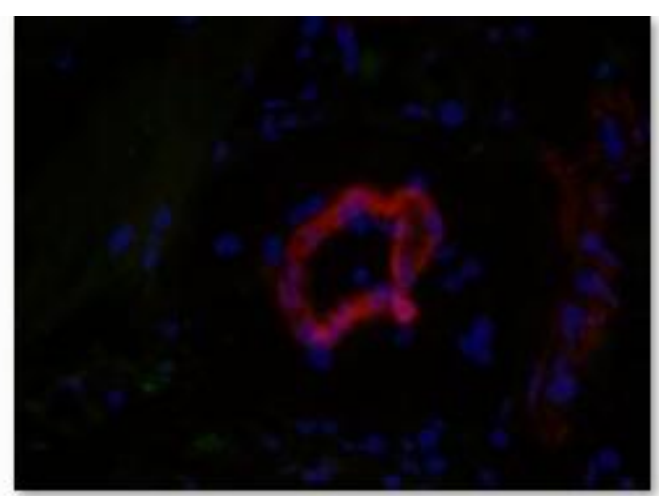

11-207 composite

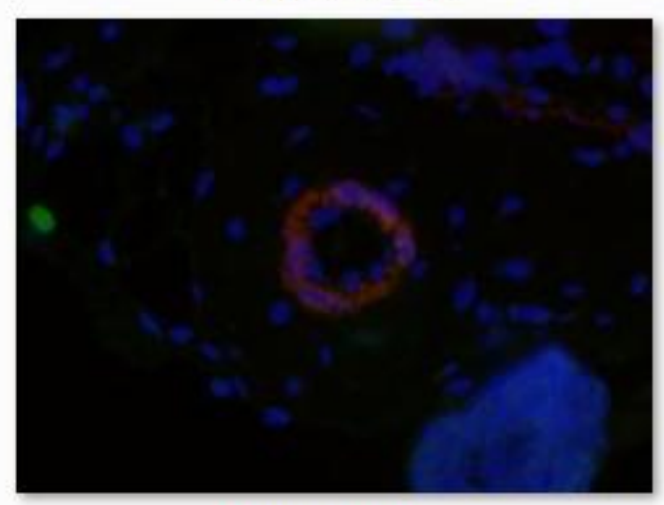

11-209 composite

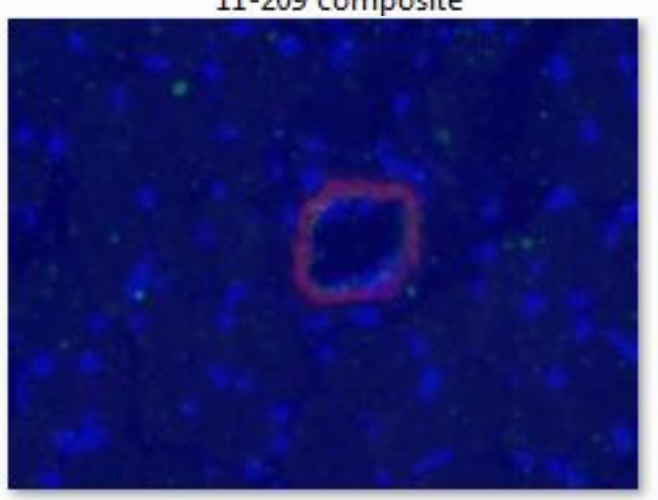

$11-210$ b composite

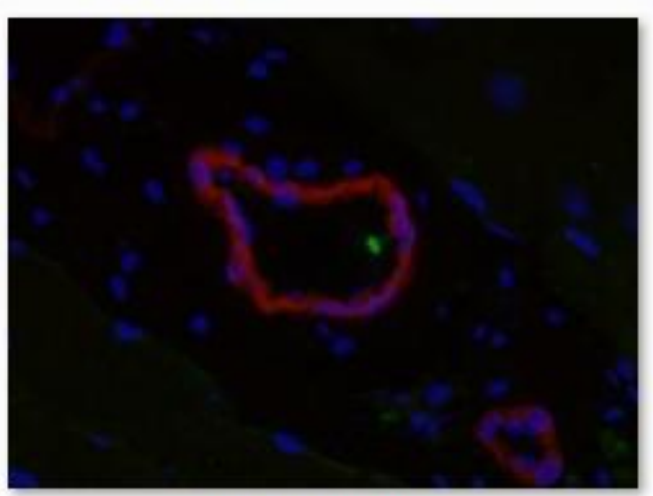

11-213 composite 
Appendix

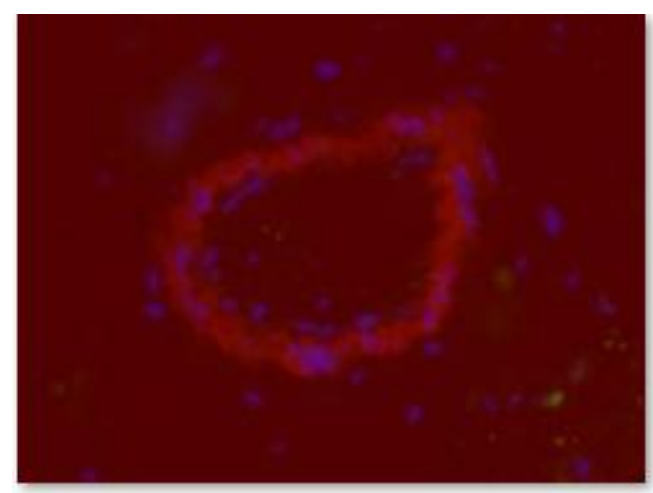

11-215 composite

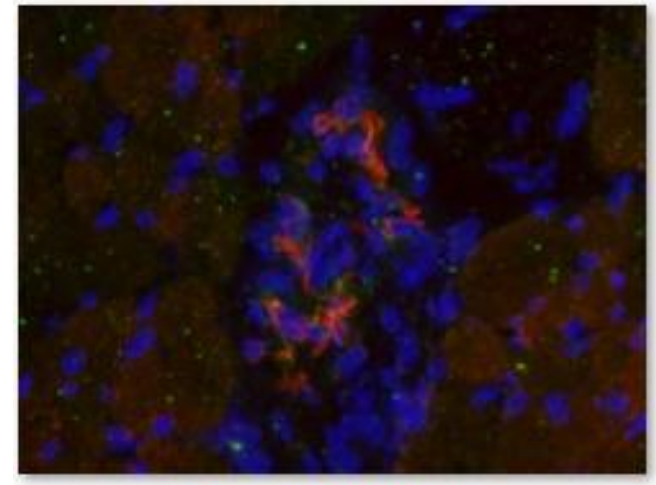

11-218 a composite

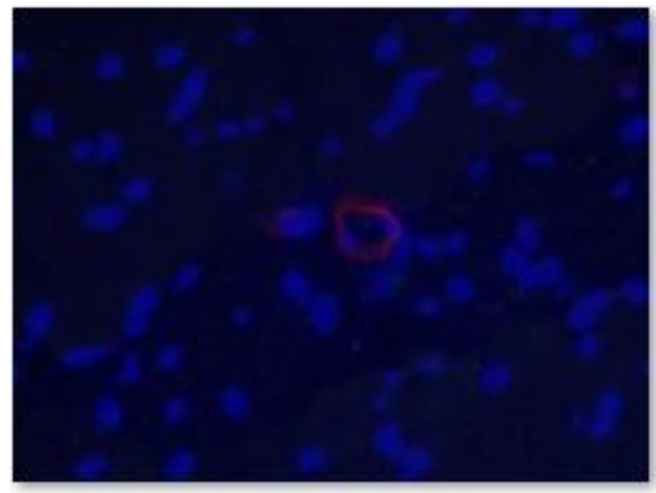

11-220 composite

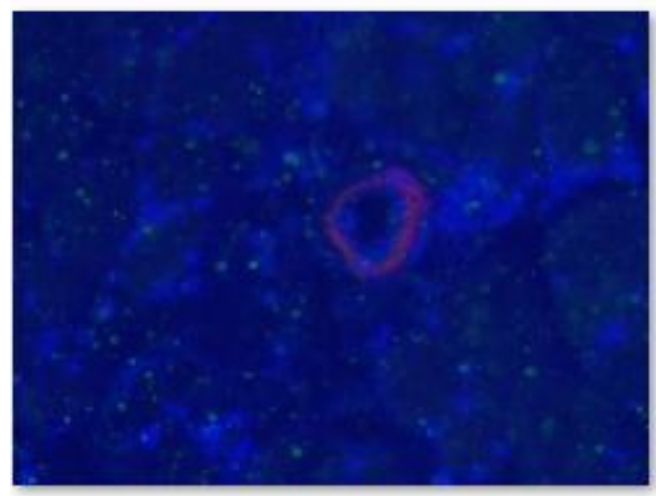

11-222 a composite

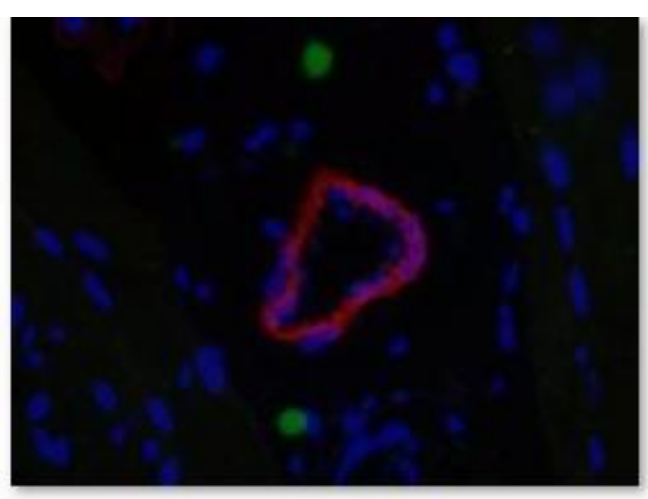

11-217 composite

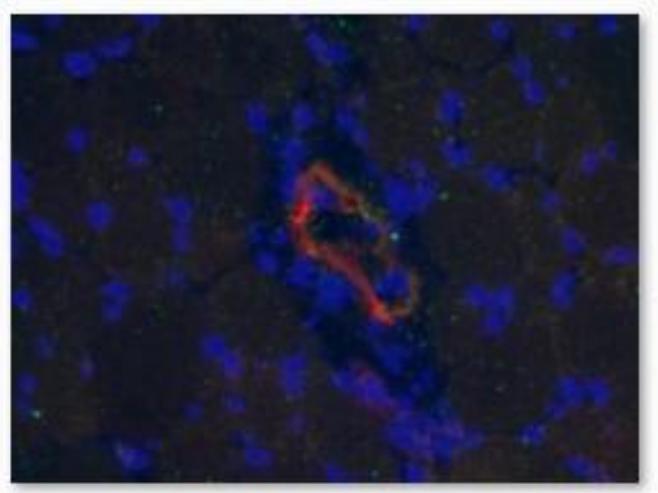

11-218 b composite

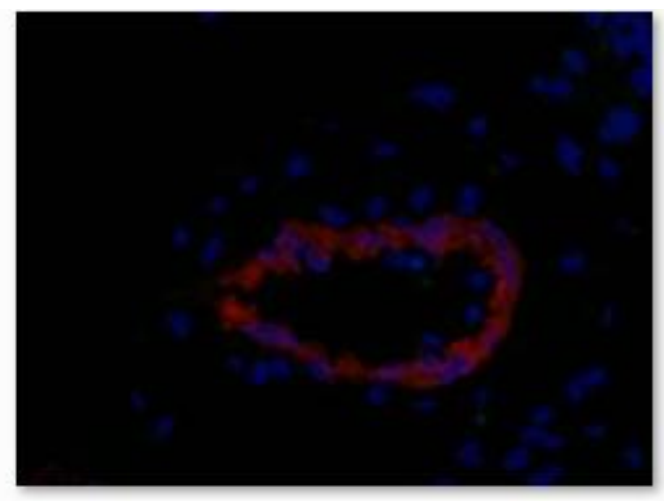

11-221 composite

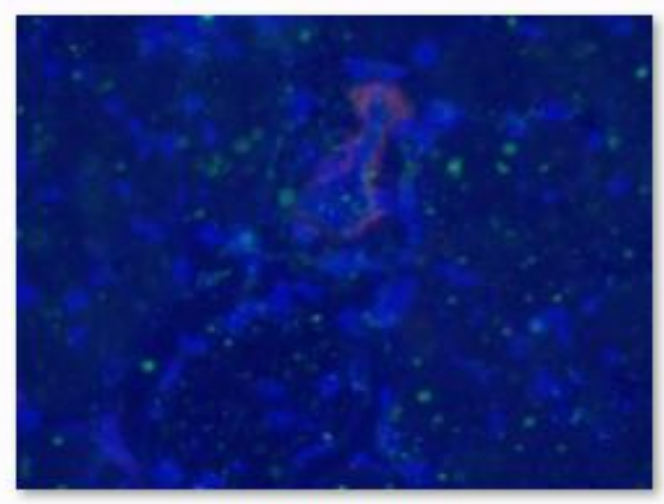

11-222 b composite 
Appendix

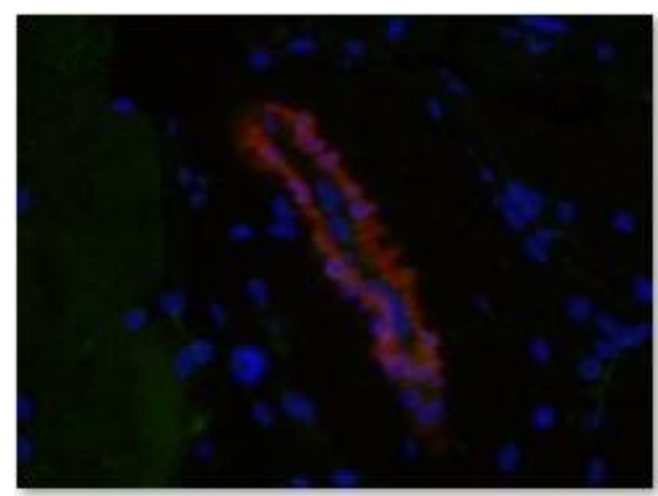

11-223 composite

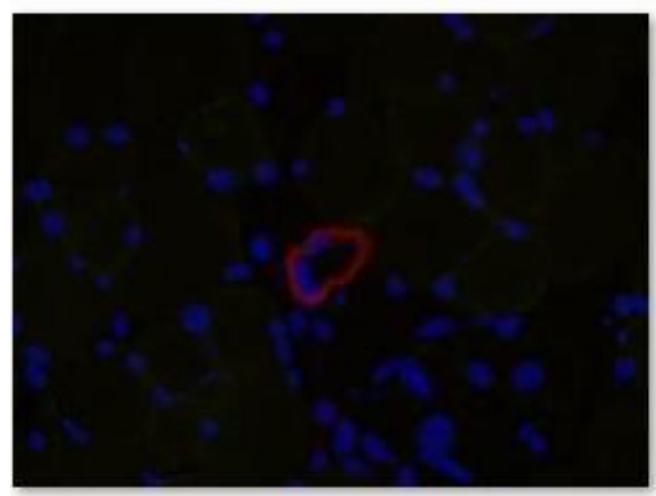

11-224 composite

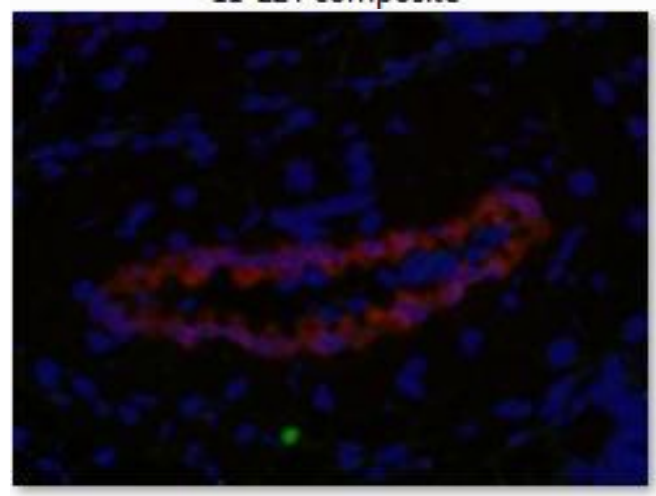

11-227 composite

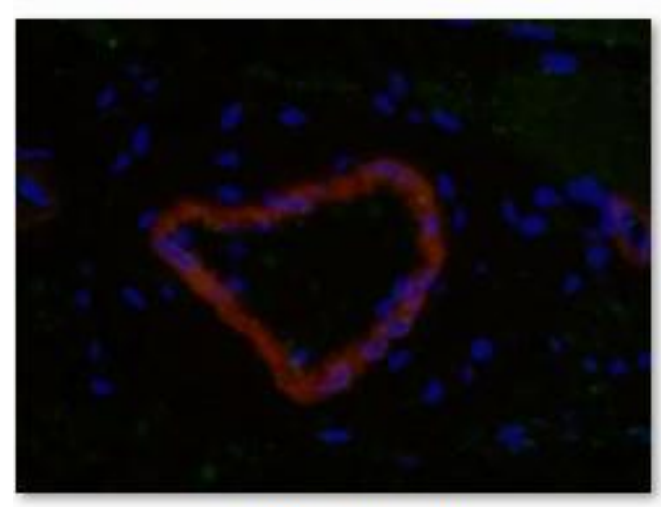

11-229 composite

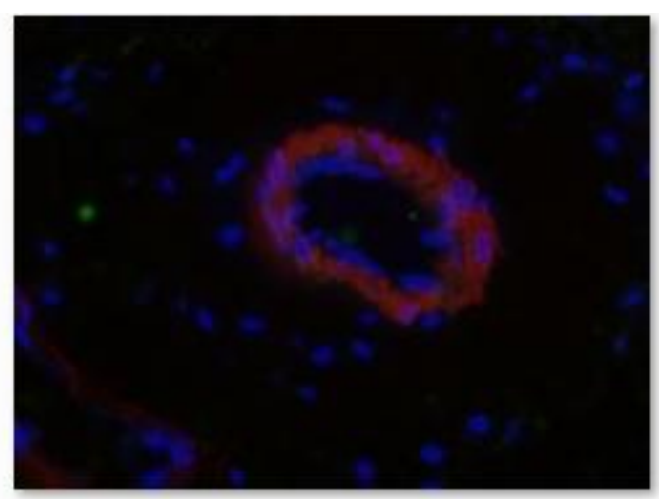

11-223 compositte

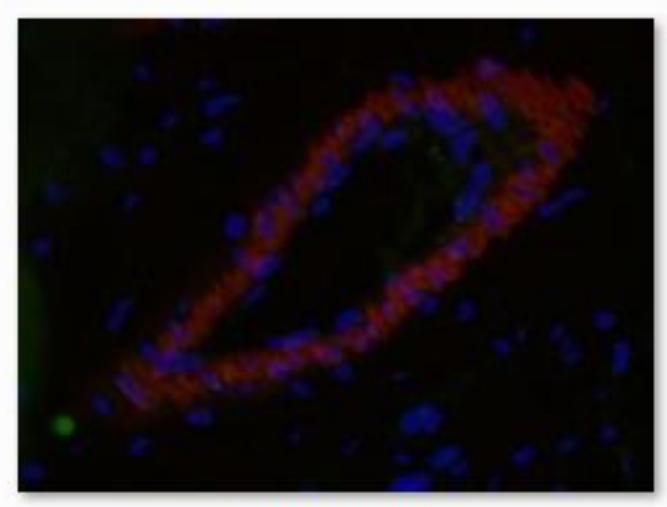

11-225 composite

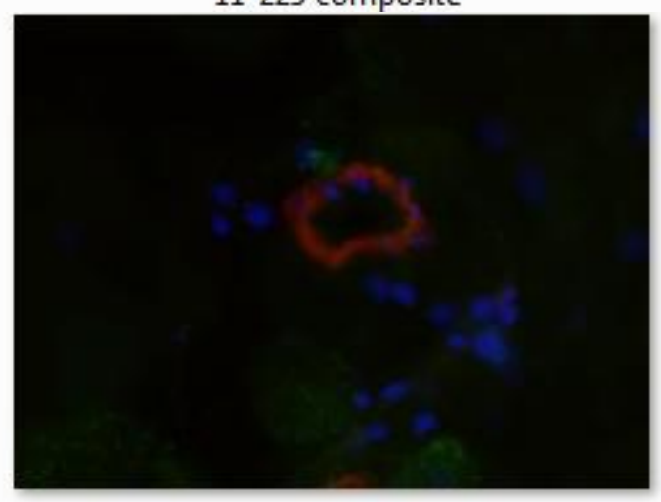

11-228 composite

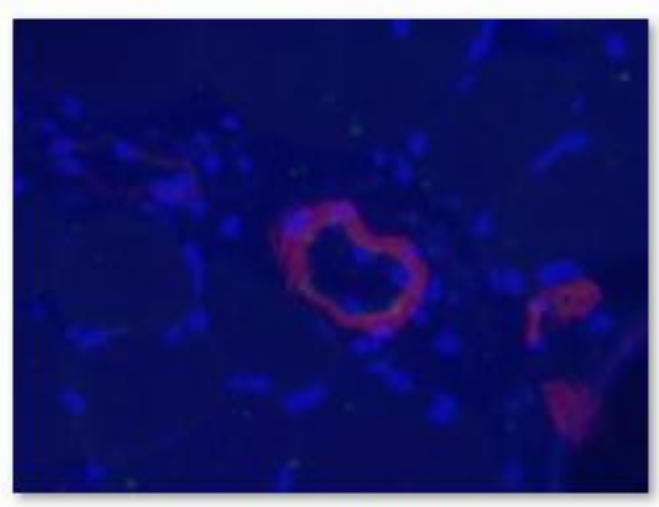

11-230 a composite 
Appendix

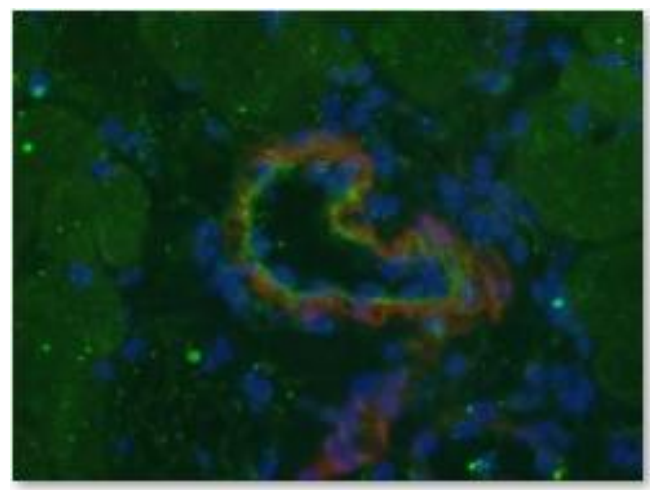

$11-230$ b composite

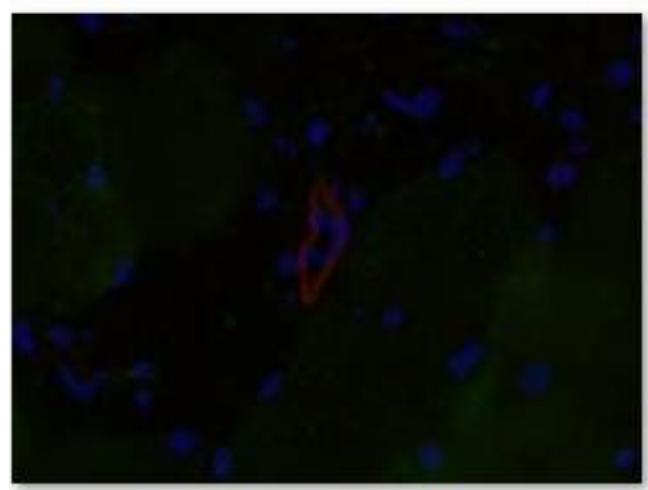

11-232 composite

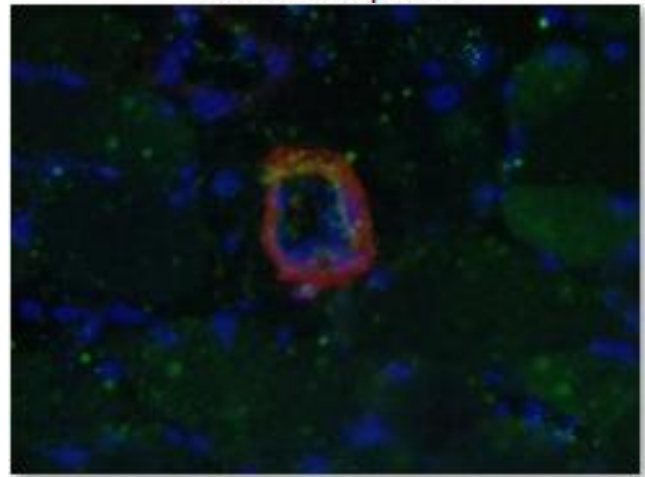

11-234 b composite

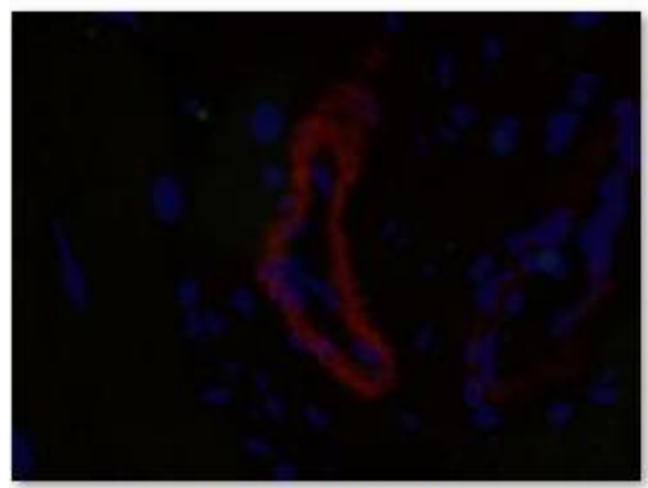

11-237 composite

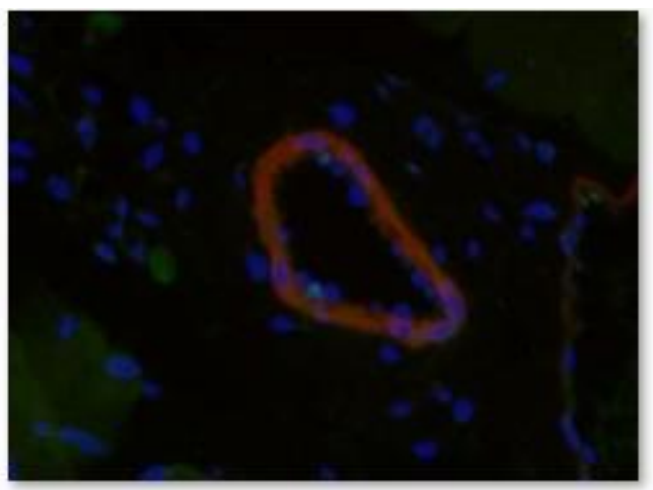

11-231 composite

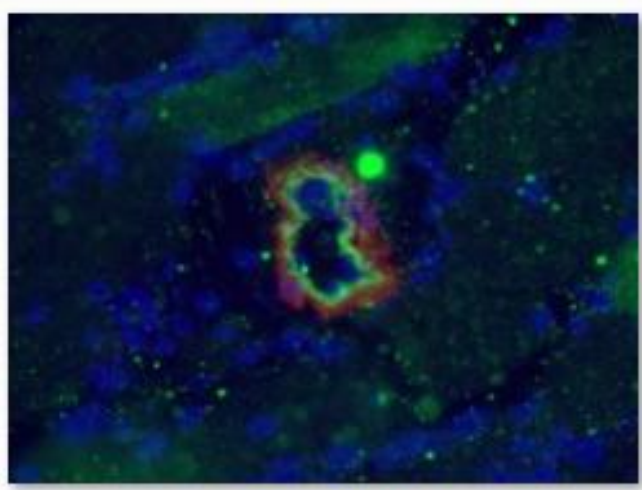

11-234 a composite

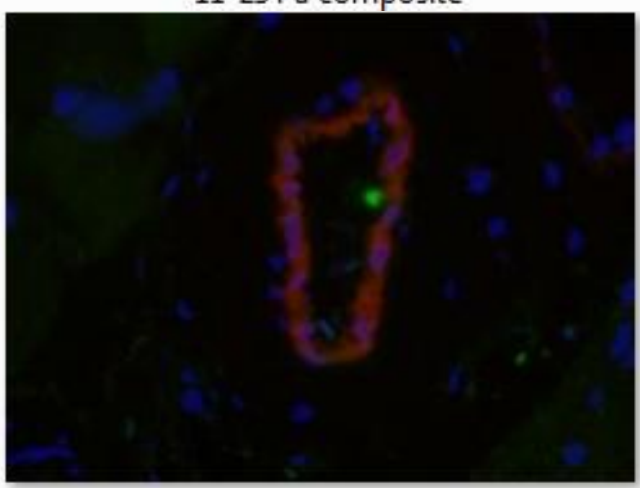

11-235 composite

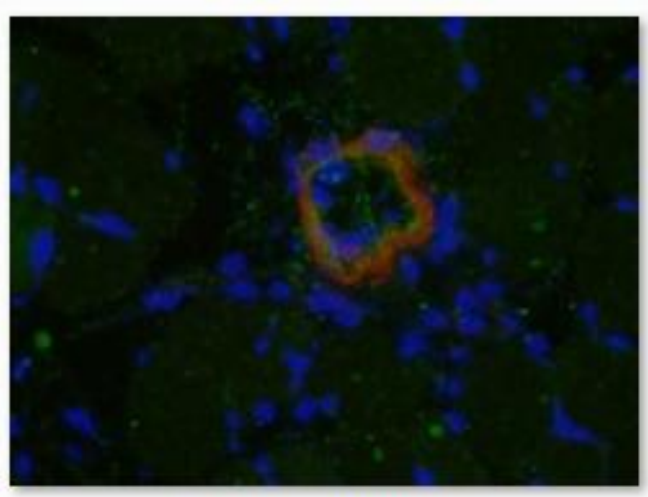

11-238 a composite 
Appendix

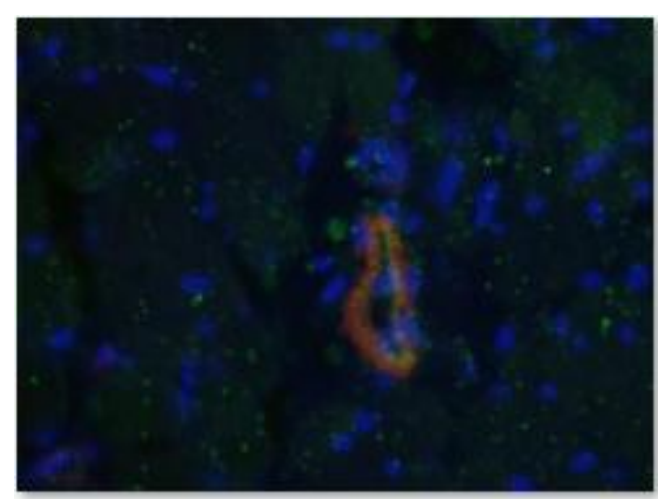

11-238 b composite

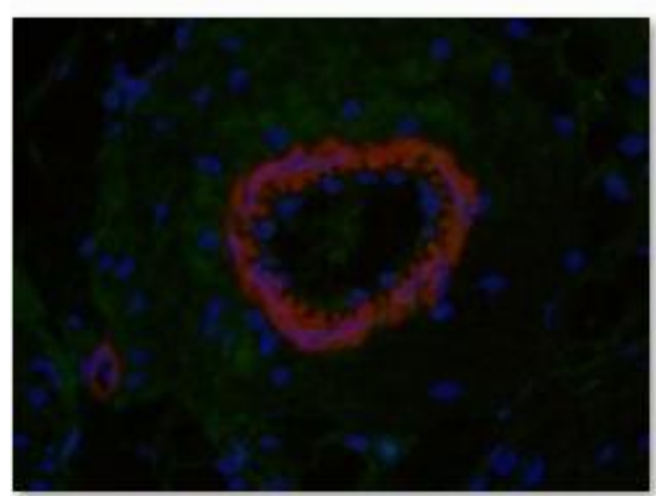

11-241 composite

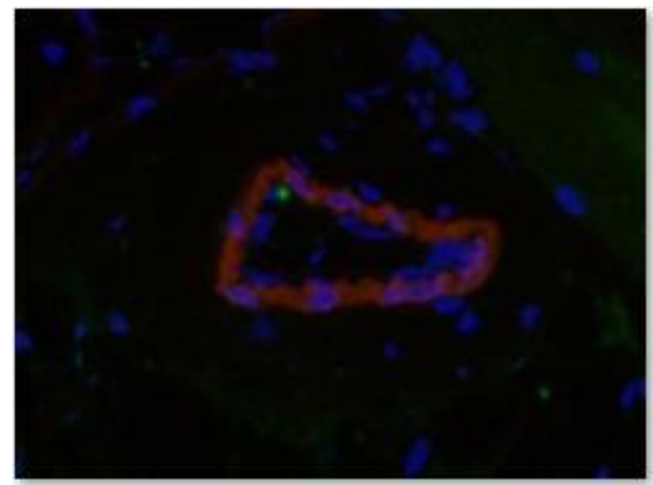

11-243 composite

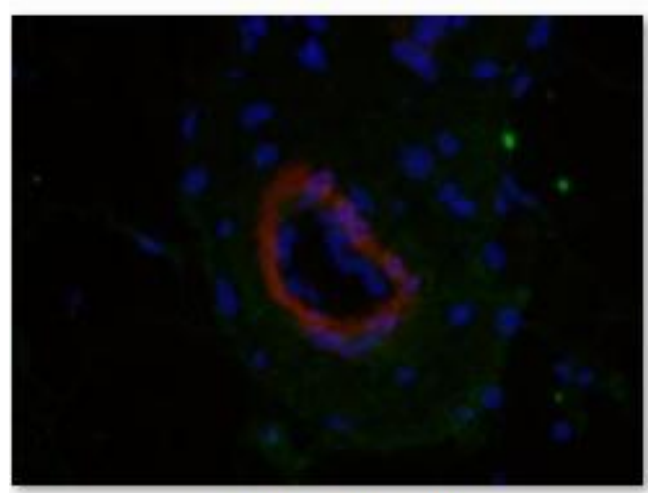

11-245 composite

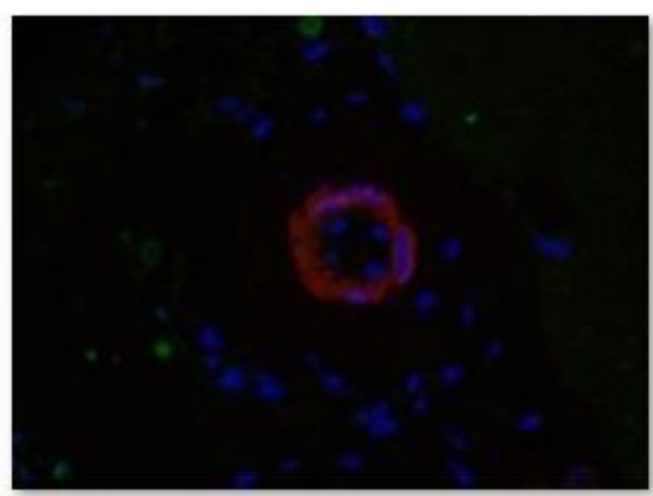

11-239 composite

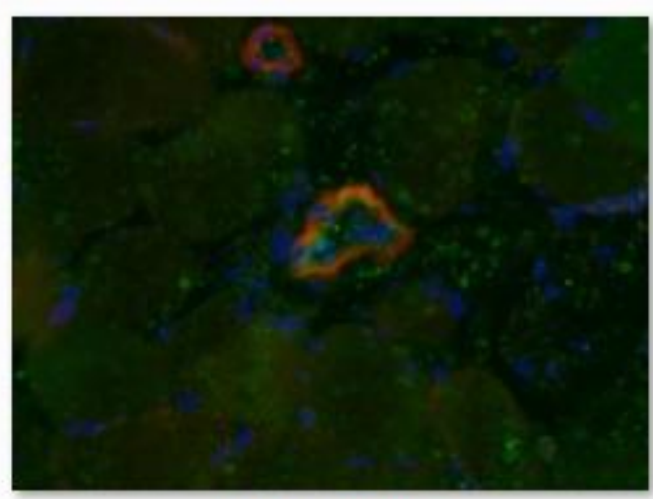

11-242 composite

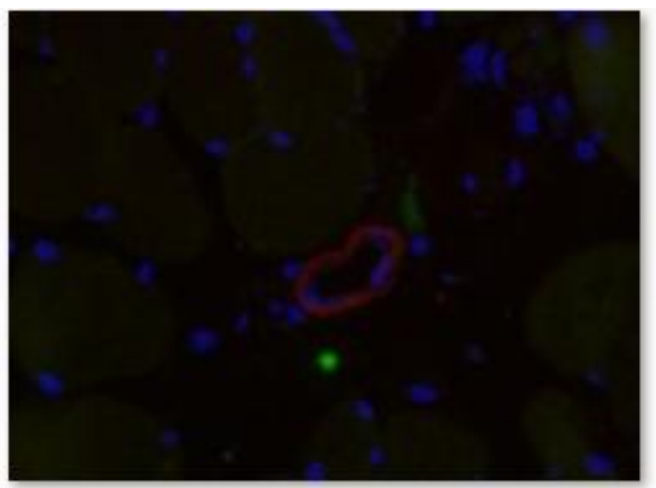

11-244 composite

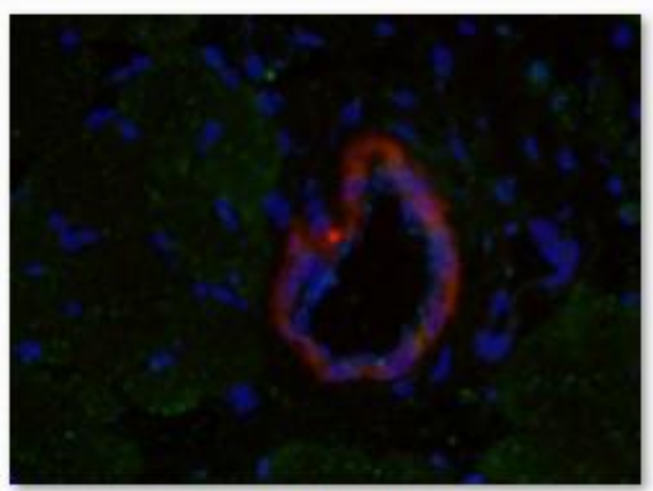

11-246 composite 
Appendix

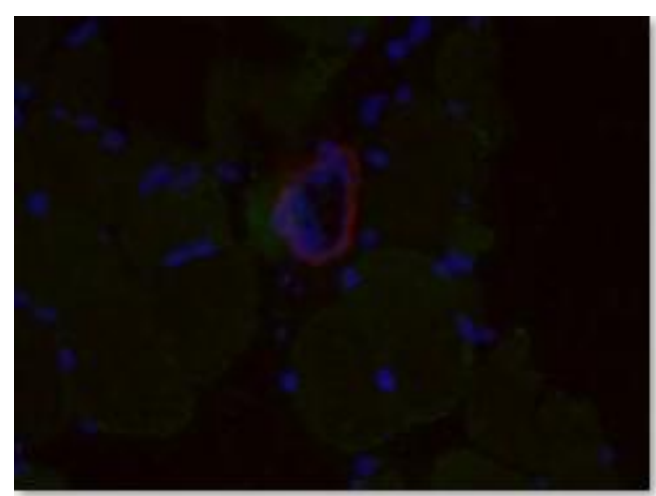

11-248 composite

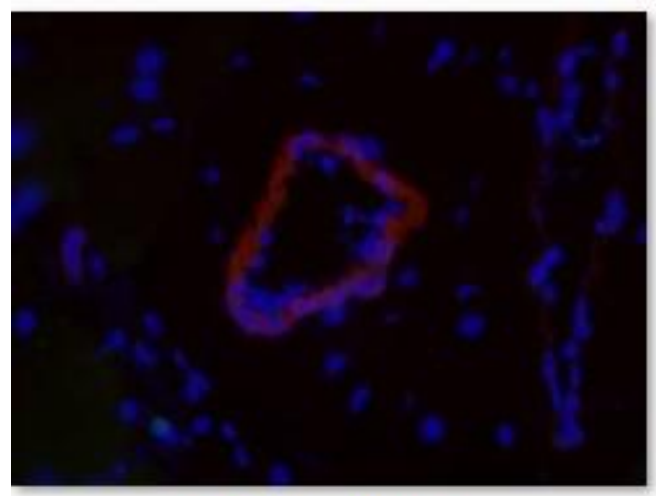

11-251 composite

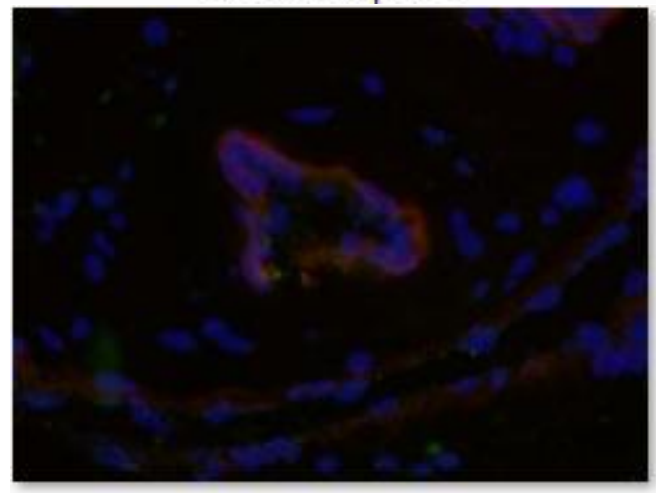

11-253 composite

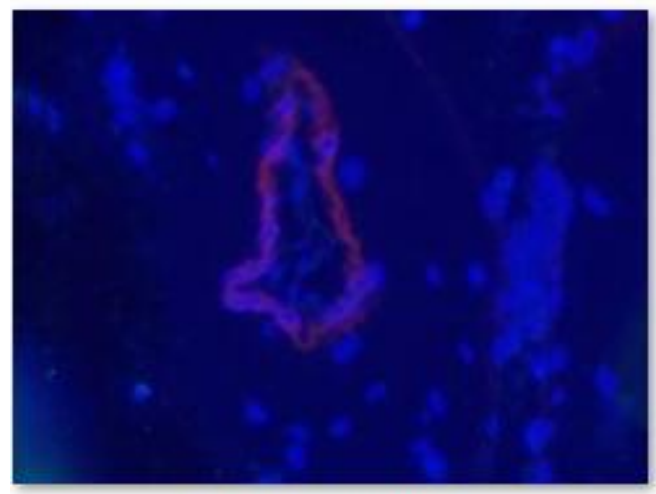

11-257 Composite

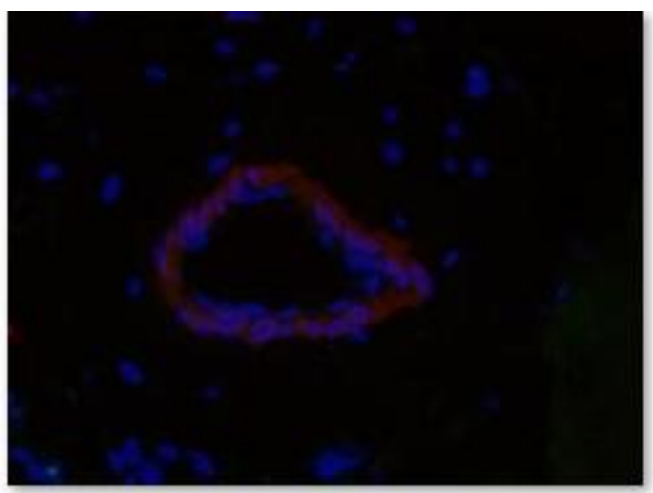

11-249 composite

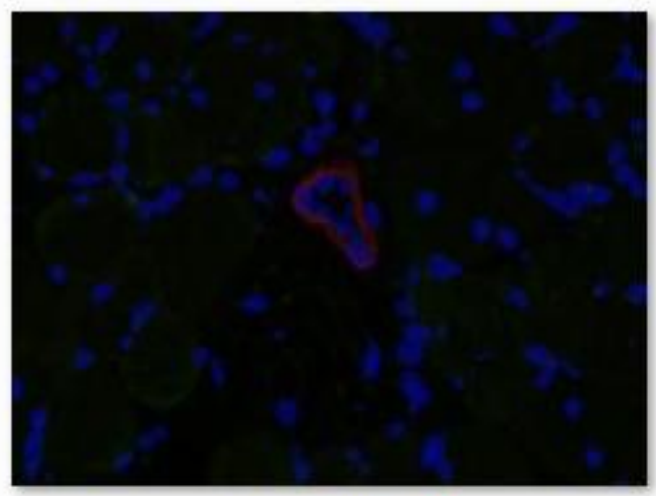

11-252 composite

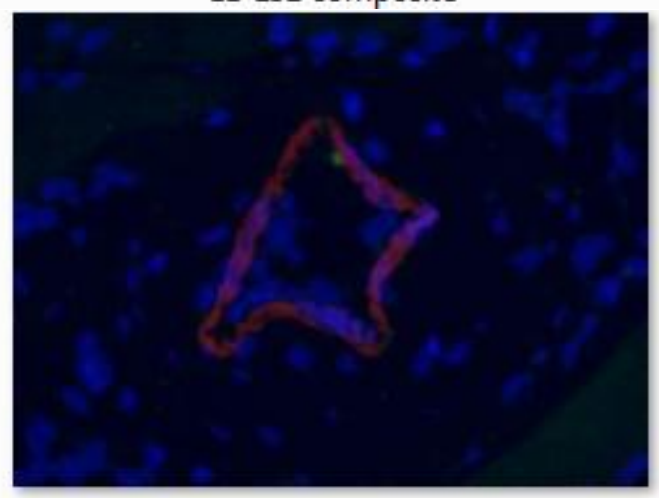

11-255 composite

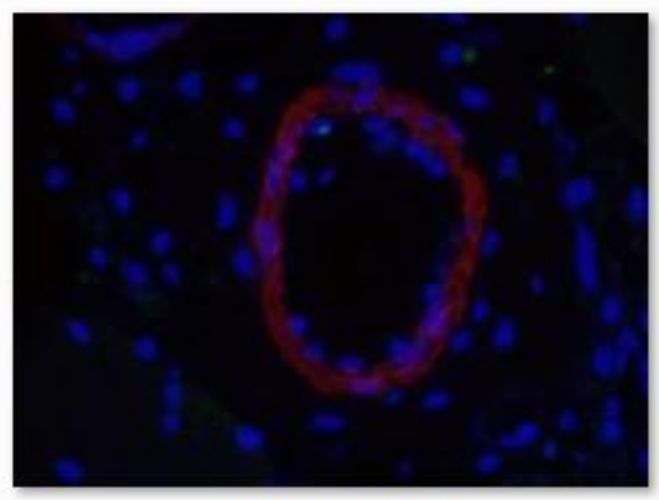

11-259 composite 
Appendix

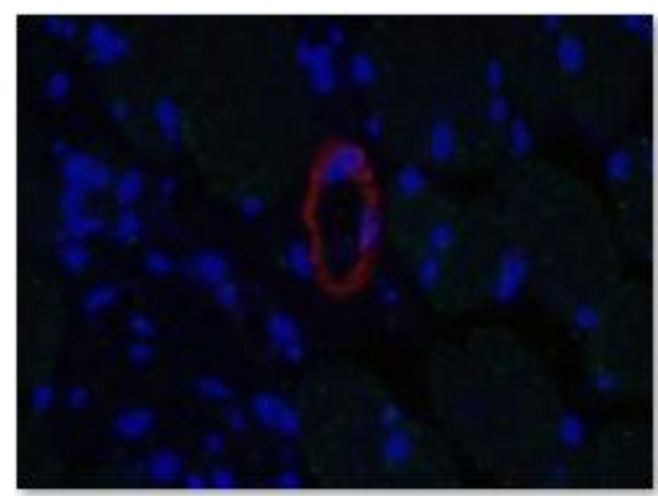

11-260 composite

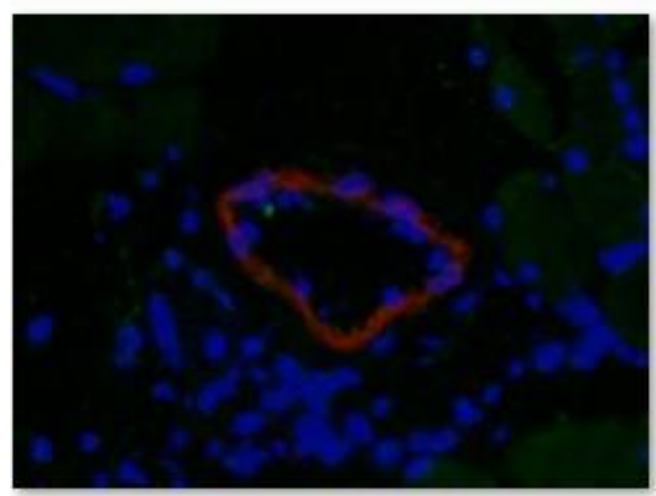

11-262 a composite

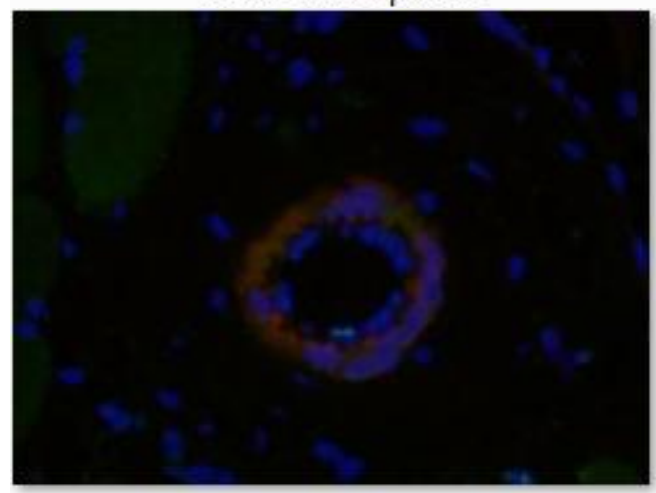

11-263b composite

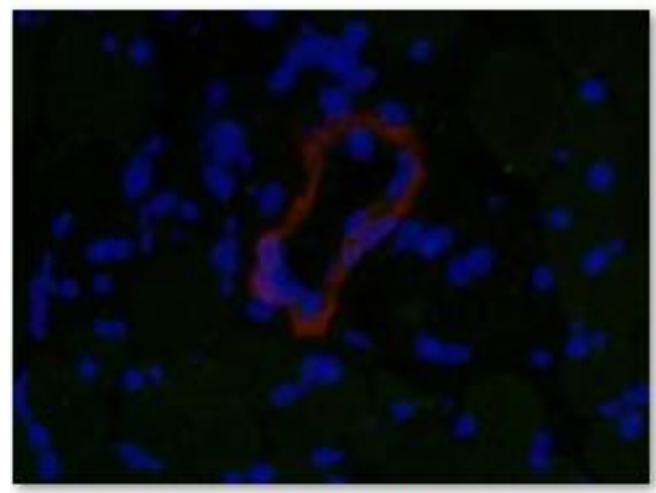

11-264a b composite

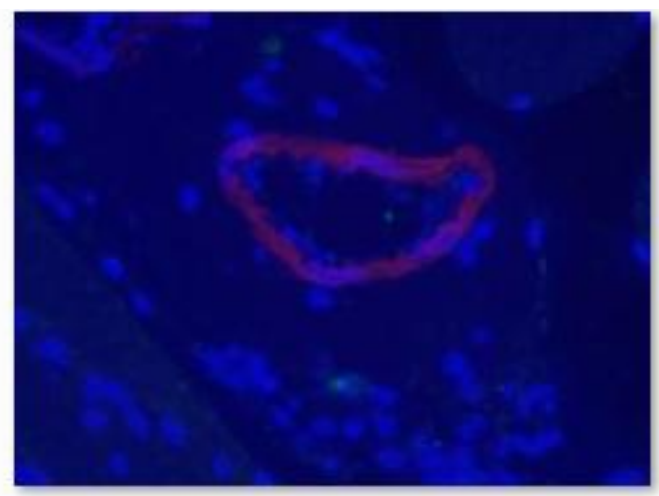

11-261 Composite

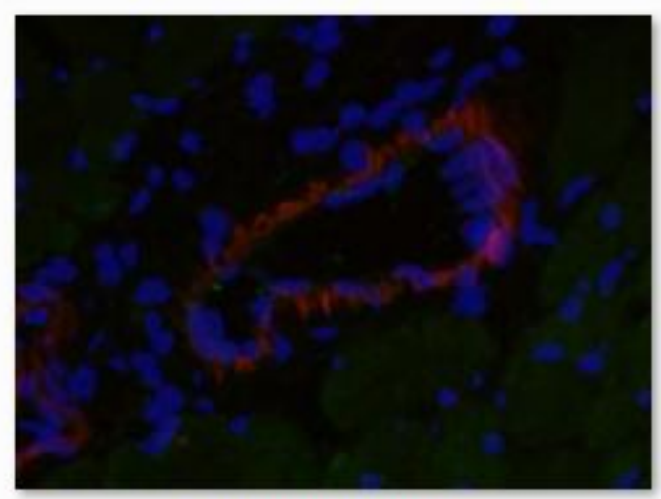

11-262 b composite

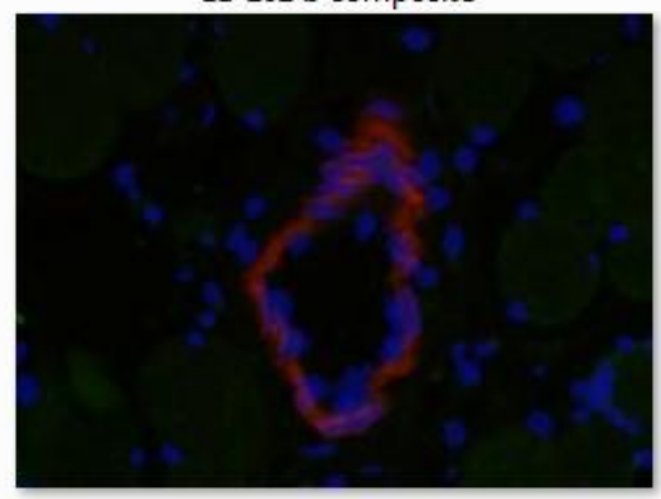

11-264a a composite

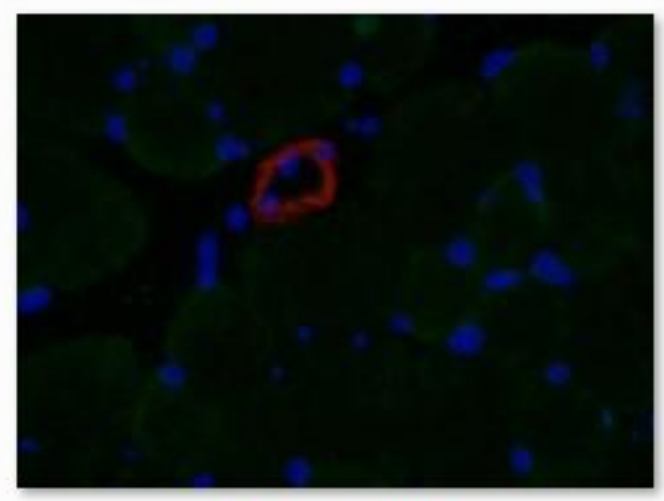

11-264b b composite 
Appendix

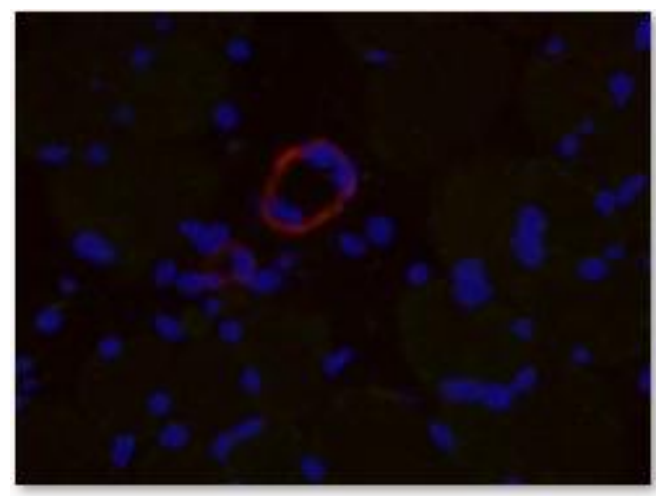

11-264b composite

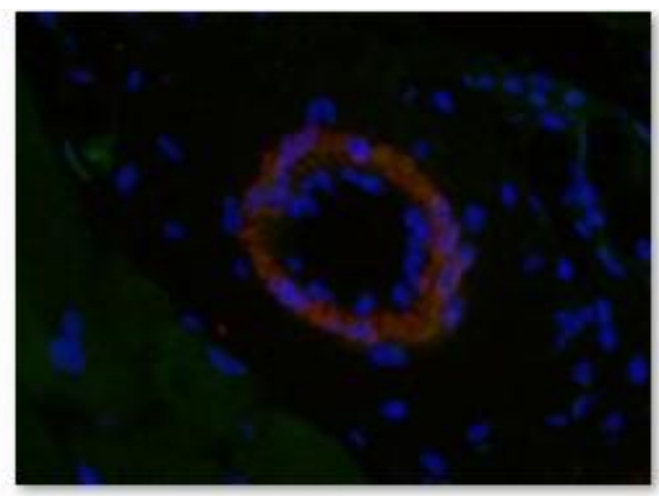

11-265 composite 


\section{Appendix}

\section{Wolters Kluwer}

Health

351 w. Camden Street

Baltimore, MD 21201

4105284000 tel

WWW. LWW. com

$08 / 11 / 11$

\section{INVOICE AND CONDITIONS}

ALEXANDER JEROME BYNUM

6710 TRINIDAD DR

SAN JOSE, CA 95120-3033

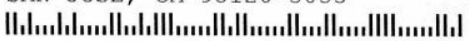

Invoice \# B64330990 Customer \# 000177026046

Re:, ARTER THROMB \& VASC BIO OL

Spec Mat: 2003;23: 1143-1151 for thesis

Permission is granted for your requested use. Please sign and date this form and return with payment (if applicable) in the enclosed envelope.

Please retain a copy for your files. This permission is subject to the following conditions:

1) A credit line will be prominently placed and include: for books - the author(s), title of book, editor, copyright holder, year of publication; for journals - the author(s), title of article, title of journal, volume number, issue number and inclusive pages.

2) The requestor warrants that the material shall not be used in any manner which may be considered derogatory to the title, content, or authors of the material or to LWW.

3) Permission is granted for one time use only as specified in your correspondence. Rights herein do not apply to future reproductions, editions, revisions, or other derivative works.

4) Permission granted is non-exclusive, and is valid throughout the world in the English language only.

5) LWW cannot supply the requestor with the original artwork or a "clean copy."

6) The requestor agrees to secure written permission from the author (for book material only).

7) Permission is valid if the borrowed material is original to a LWW imprint (Lippincott-Raven Publishers, Williams \& Wilkins, Lea \& Febiger, Harwal, Igaku-Shoin, Rapid Science, Little Brown \& Company, Harper \& Row Medical, American Journal of Nursing Co, and Urban \& Schwarzenberg - English Language).

8) Payment can be made via credit card (Amex, VISA, Discover and MC) or by check.

9) If you opt not to use the material requested above, please notify LWW within 90 days of the original invoice date. Please note after 90 days, LWW will not cancel/credit your request which will result into a collections issue.

Card \# Exp Date: 
Appendix

\section{RE: Permission Request from US Elsevier Health Bookshop}

1 message

Gould, Laura (ELS-OXF) <L.Gould@elsevier.com>

Thu, Aug 11, 2011 at 8:27 AM

To: alexanderjbynum@gmail.com

Dear Mr Bynum

We hereby grant you permission to reprint the below mentioned material at no charge in your thesis subject to the following conditions:

1. If any part of the material to be used (for example, figures) has appeared in our publication with credit or acknowledgement to another source, permission must also be sought from that source. If such permission is not obtained then that material may not be included in your publication/copies. 


\section{Appendix}

2. Suitable acknowledgment to the source must be made, either as a footnote or in a reference list at the end of your publication, as follows:

"This article was published in Publication title, Vol number, Author(s), Title of article, Page Nos, Copyright Elsevier (or appropriate Society name) (Year)."

3. Your thesis may be submitted to your institution in either print or electronic form.

4. Reproduction of this material is confined to the purpose for which permission is hereby given.

5. This permission is granted for non-exclusive world English rights only. For other languages please reapply separately for each one required. Permission excludes use in an electronic form other than submission. Should you have a specific electronic project in mind please reapply for permission.

6. This includes permission for UMI to supply single copies, on demand, of the complete thesis. Should your thesis be published commercially, please reapply for permission.

Yours sincerely

\section{Laura Gould}




\section{Appendix}

Rights Associate

Global Rights Department

T: +44 (0)1865 843857

E: L.Gould@elsevier.com

Your future requests will be handled more quickly if you complete the online form at www.elsevier.com/permissions

-----Original Message-----

From: custserv.ehs@elsevier.com [mailto:custserv.ehs@elsevier.com]

Sent: 04 August 2011 22:36

To: Health Permissions (ELS-PHI)

Cc: null@prod.lexis-nexis.com

Subject: Permission Request from US Elsevier Health Bookshop

DaytimePhone: $\underline{4085069134}$

Fax: $\underline{4082686337}$

EmailAddress: alexanderjbynum@gmail.com

TitleRequested: Cardiovascular Physiology

Edition: Eighth Edition

Copyright: 2001

GradeLevel: 


\section{Appendix}

Volume:

Number:

ISBN:

Author: Robert M. Berne, Matthew N. Levy

EHSDivision: Mosby

MaterialDescription: I play to use the schematic diagram of the parallel and series arrangement of the vessels composing the circulatory system (Figure 1-4, Page 4). This figure is located in the first chapter of the text, entitled "The Circuitry"

Whatfor: I will use this diagram in the introduction chapter of my thesis paper in a section entitled "Normal Vascular Anatomy and Function." This diagram will help me illustrate the arrangement of the vessels composing the circulatory system.

RequestersTitle: The Impact of Collateral Enlargement on Smooth Muscle Phenotype

Author: Alexander J. Bynum

Publisher: California Polytechnic State University, San Luis Obispo

useMaterial: In Context

LastName: Bynum

WorkTypeScholarly: Scholarly

WorkTypeOther: Thesis Paper

EstimatedPubDate: November 2011

Market: Academic

MarketOther: Academic Research

Organization: California Polytechnic State University

URL:

Adopted: No

RequestedCopies:

FormatForDeliveryPrint: Website 


\section{Appendix}

FormatForDelivery:

PagesRequested:

Comments:

Password: Yes

address1Ship: 6710 Trinidad Dr.

address2Ship:

cityShip: San Jose

country: US

id=: Alexander

permsend:

stateShip: California

zipShip: 95120 